Identifying Relationships between Systems Engineering Processes and Project Success in NASA Complex Projects and Other Organizations

\author{
by
}

Kathryne Angela Schomburg

\author{
A thesis submitted to the graduate faculty \\ in partial fulfillment of the requirements for the degree of \\ MASTER OF SCIENCE \\ Major: Industrial Engineering \\ Program of Study Committee: \\ Paul J. Componation, Co-Major Professor \\ Caroline Krejci, Co-Major Professor \\ Bob Stephenson
}

Iowa State University

Ames, IA

2015

Copyright (C) Kathryne Angela Schomburg, 2015. All rights reserved. 


\section{DEDICATION}

I would like to dedicate my thesis to my family. I know I have been successful in grad school because of them. To Mom, Dad, Justin, and Kristin, thank you for always motivating me to do my best in school and supporting me always, I feel so lucky to have such a wonderful family. To Eddie, thank you for your love, support, and patience during these past two years of school. To Grandpa Smid, you loved space, and I feel honored to have gotten to write my thesis on NASA. To Uncle Bill, Grandma Velma, and Aunt Jeanie, I miss you all very much, but know you all were proud to see us kids make it through school. 
TABLE OF CONTENTS

LIST OF FIGURES iv

LIST OF TABLES V v

ABSTRACT vii

CHAPTER 1. GENERAL INTRODUCTION 1

Systems Engineering at NASA 1

Thesis Organization 4

References 6

CHAPTER 2. IDENTIFYING RELATIONSHIPS BETWEEN

SYSTEMS ENGINEERING PROCESSES AND PROJECT SUCCESS IN NASA COMPLEX PROJECTS AND OTHER ORGANIZATIONS $\quad 7$

Abstract $\quad 7$

Introduction $\quad 9$

Literature Review $\quad 14$

Methodology 28

Results and Data Analysis $\quad 39$

$\begin{array}{ll}\text { Conclusion } & 83\end{array}$

$\begin{array}{ll}\text { Acknowledgments } & 87\end{array}$

$\begin{array}{ll}\text { References } & 88\end{array}$

CHAPTER 3. GENERAL CONCLUSIONS

$\begin{array}{ll}\text { General Discussion } & 92\end{array}$

Recommendations for Future Research 99

$\begin{array}{ll}\text { Limitations of the Study } & 100\end{array}$

$\begin{array}{ll}\text { References } & 105\end{array}$

APPENDIX A. MODIFIED DATA COLLECTION INSTRUMENT 106

$\begin{array}{lr}\text { APPENDIX B. TERM DEFINITIONS } & 126\end{array}$

APPENDIX C. NASA CENTER DESCRIPTIONS 135

$\begin{array}{ll}\text { ACKNOWLEDGMENTS } & 139\end{array}$ 


\section{LIST OF FIGURES}

Figure 1. The NASA Systems Engineering Engine

Figure 2. Research Plan Flow chart

Figure 3. Systems Engineering "Vee"

Figure 4. Pearson's Correlation to Cost

Figure 5. 2007 NASA MSFC Flight Hardware Study and 2013 Government and Commercial Organizations Study

Figure 6. 2007 NASA MSFC Flight Hardware Study and 2014 NASA Study

Figure 7. 2013 Government and Commercial Organizations Study and 2014 NASA Study

Figure 8. 2013 Government Focused Projects and 2014 NASA Study

Figure 9. 2013 Commercial Focused Projects and 2014 NASA Study

Figure 10. 2014 NASA Study Non-Technical Variables

Figure 11. Project Success Metrics Least Squared Means Plot: Interaction Effect 56

Figure 12. Systems Engineering Processes Least Squared Means Plot: Interaction 60 Effect 


\section{LIST OF TABLES}

Table 1. Modified Data Collection Instrument 28

Table 2. Likert Response Scale Conversion Table 30

Table 3. Survey Participant Responses by NASA Center 33

Table 4. Survey Participant Responses by NASA Center Type 33

Table 5. Focused Data Collection Instrument Sections for Correlation Tables 34

Table 6. Project Description Variables ANOVA Table 48

Table 7. Tukey HSD: Project Description Variables Organization Effect 49

Table 8. Tukey HSD: Project Description Variables Question Effect 51

Table 9. Project Success Metrics ANOVA Table 52

Table 10. Tukey HSD: Project Success Metrics Organization Effect 53

Table 11. Tukey HSD: Project Success Metrics Question Effect 54

Table 12. Systems Engineering Processes ANOVA Table 57

Table 13. Tukey HSD: Systems Engineering Processes Organization Effect 58

Table 14. Tukey HSD: Systems Engineering Processes Question Effect 59

Table 15. ANOVA Summary Testing All 180 Participants 62

Table 16. Government-Focused Projects - Project Description Variables 63 ANOVA Table

Table 17. Commercial-Focused Projects - Project Description Variables 64 ANOVA Table

Table 18. Tukey HSD: Commercial-Focused Projects - Project Description 65 Variables Question Effect

Table 19. NASA Project Description Variables ANOVA Table 
Table 20. Government-Focused Projects - Project Success Metrics 67

Table 21. Tukey HSD: Government-Focused Projects - Project Success 68 Metrics Question Effect

Table 22. Commercial-Focused Projects - Project Success Metrics ANOVA 69

Table

Table 23. Tukey HSD: Commercial-Focused Projects - Project Success Metrics Question Effect

Table 24. NASA Project Success Metrics ANOVA Table 71

Table 25. Tukey HSD: NASA Project Success Metrics Question Effects 72

Table 26. Government-Focused Projects Systems Engineering Processes 73

Table 27. Tukey HSD: Government-Focused Projects Systems Engineering 74

Processes Question Effects

Table 28. Commercial-Focused Projects Systems Engineering Processes 75

Table 29. Tukey HSD: Commercial-Focused Projects - Systems Engineering 76 Processes Question Effects

Table 30. NASA Projects - Systems Engineering Processes ANOVA Table 77

Table 31. NASA Projects - Non-Technical Variables ANOVA Table 79

Table 32. Tukey HSD: NASA Projects - Non-Technical Variables 80

Table 33. Summary of Question Effects Within an Organization 82

Table 34. Number of "N/A" Responses from Participants in Organizations 102

Table 35. Correlations Between Systems Engineering Processes and Project 104 Metrics with High Standard Deviations 


\begin{abstract}
A recognized issue related to the processes in systems engineering is that they vary based on the project and organization. However, understanding how to tailor the systems engineering processes to help ensure project success continues to trouble engineers, and practical tools to help aid engineers in this field are not as readily available as many would like. Moreover, budget and schedule constraints continue to place an additional burden on systems engineering being done well. Many studies on how to help contribute to improving systems engineering exists for different organizations. Yet, most studies are based on case studies from one project, involve a small sample size, or only focus on one organization type. This thesis discusses the results of how systems engineering processes applied to complex projects impact project success based on organization type with a sample size of 180 institutions. The organizations examined are divided into two groups, commercial organizations and government organizations. Within the commercial organization, government-focused projects and commercialfocused projects are examined. Within the government organization, projects from the National Aeronautics and Space Administration (NASA) Agency are examined. NASA is a government organization comprised of 10 Centers located around the country, and for the purpose of this research, is the primary organization discussed and metric in which the other organizations will be quantitatively compared and contrasted against. For this reason, the standard participants used in this research effort were NASA's 17 systems engineering processes. Data was gathered through a modified data collection instrument,
\end{abstract}


and a three-level data analysis was performed. First, meaningful correlations were identified between the systems engineering processes and project success metrics, as well as, non-technical variables and project success metrics for the different organizations. Then, a deeper data analysis was conducted to test for statistically significant differences through project description variables, project success metrics, and systems engineering processes across organization types. Finally, statistically significant differences among the project description variables, project success metrics, systems engineering processes, and non-technical variables were examined within each organization type. The results from the data analysis will be delivered to NASA to help aid in the development of a NASA systems engineering practitioners guide. 


\section{CHAPTER 1. GENERAL INTRODUCTION}

\section{Systems Engineering at NASA}

Systems engineering occurs in all types of organization in an official or unofficial capacity. For example, at NASA systems engineering is a formal process that is applied to projects of all sizes. Whether the project is a cube satellite with a three-year lifecycle or the space launch system (SLS) with a 30-year lifecycle, there are engineers who are assigned to the specific task of overseeing the project's system. However, systems engineering is not only conducted in industry. For example, when a family buys a new car or even the weekly groceries, they apply systems engineering techniques. A grocery list and budget prioritize the family's shopping trip's requirements, and informal trade studies are conducted to determine whether fuel economy or vehicle capacity is most important based on the family's vehicle needs. However, the exact manner in which the systems engineering processes are utilized will vary based on the organization and project. Systems engineering processes for a simple project, like grocery shopping, might consist mostly of mental checks and post-it notes, whereas a complex system like SLS will require rigorous forms and official procedures.

The organizations in any given industry, as well as the types of projects that they work on, will typically vary widely. Therefore, applying a single standardized systems engineering process across an entire industry is inappropriate. In fact, doing so can actually increase project complexity. However, knowing how to optimally tailor these processes based on project type and in differing organizations continues to challenge 
systems engineers. Furthermore, practical tools to aid systems engineers in overcoming these challenges are not always readily available (NASA, 2014).

Addressing these challenges is critical to NASA, which operates on a tight government budget. The 2014 fiscal year budget for NASA was about $\$ 17.7$ billion in discretionary funds, a decrease of about $\$ 50$ million below the 2012 enacted level (The White House, 2014). The requested budget for 2015 is about $\$ 17.4$ billion (NASA, 2014). However, projects at NASA are not becoming less complex, nor are the stakeholders involved any less demanding with regard to complex project success. Therefore, systems engineering across the Agency must be done as effectively and efficiently as possible.

The research described in this thesis addresses these problems by identifying how the systems engineering processes applied to complex projects impact project success based on organization type. A sample size of 180 institutions was divided into two general categories, government organizations and commercial organizations. Projects occurring within commercial organizations were then categorized as being either government-focused or commercial-focused. The National Aeronautics and Space Administration (NASA) Agency, which is a government organization, comprised of 10 Centers located throughout the United States is the primary focus for this research effort. Figure 1 illustrates the NASA Systems Engineering Engine, which displays the 17 systems engineering processes NASA uses when conducting a project. 


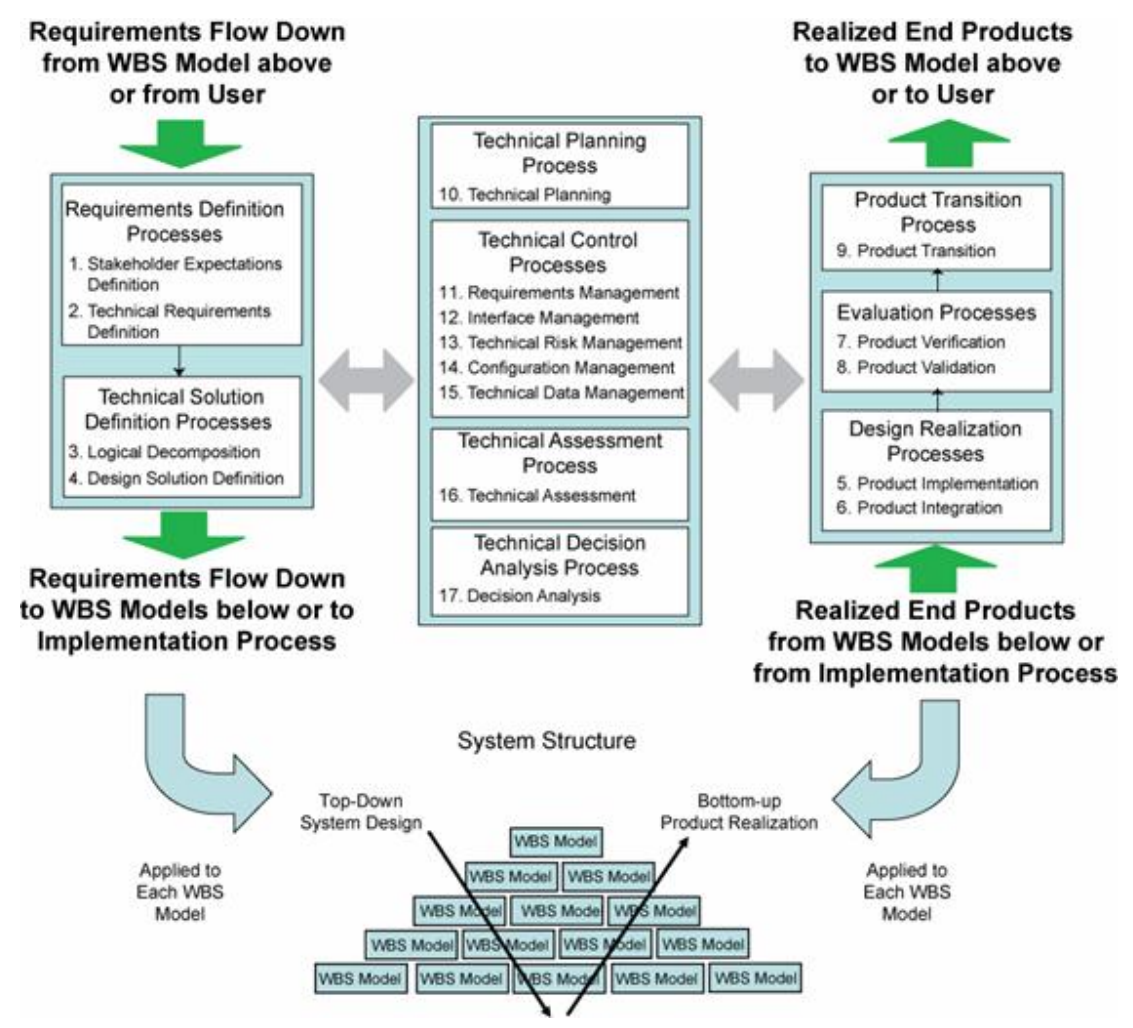

Figure 1. The NASA Systems Engineering Engine (NASA, 2007)

This research synthesizes the results from a three-part study: a 2007 Marshall Space Flight Center (MSFC) Flight Hardware study, a 2013 Government and Commercial Organizations study, and a 2014 NASA Agency study. Data from the three studies was analyzed on three levels. The first analysis assessed the data to identify meaningful correlations between the systems engineering processes and project success metrics. Meaningful correlations between non-technical variables, such as teamwork, and projects success metrics among NASA projects were also identified. From this area of the research, we can see which systems engineering processes more highly correlate with project success, and compare and contrast those findings with meaningful 
correlations on government-focused commercial projects and commercial-focused commercial projects.

Next, a richer data analysis was conducted to test for statistically significant differences among all organizations based upon project description variables, project success metrics, and the systems engineering processes. The final analysis tested for statistically significant differences among the project description variables, project success metrics, systems engineering processes, and non-technical variables within each organization.

The provide insight into whether certain variables used for determining project success across the NASA Agency are similar or different to those being used on government-focused commercial projects and commercial-focused commercial projects. Through this research, we hope to gain a better understanding of how the NASA Centers organize their systems engineering processes and whether these processes are conduced in a manor that ensures project success and efficient resource utilization. Results from the data analysis will contribute to NASA's development of a NASA systems engineering practitioners guide. Additionally, since this study examines government and commercial organizations, the findings will also be transferrable to projects in other industries, such as aerospace and defense.

\section{Thesis Organization}

Figure 2 outlines the research plan this thesis will follow. Chapters 2 and 3 discuss in more detail the research problem, motivation, and contribution that were introduced in Chapter 1. Chapter 2 begins by identifying the research problem and the 
motivation for addressing this problem. A review of the relevant literature review then follows, focusing on the three areas of systems engineering effectiveness that are most important to this research. Next, the methodology of how the 2014 NASA data was collected and integrated into the 2007 MSFC Flight Hardware and 2013 Government and Commercial Organizations is study. Finally, an analysis of the data is presented, followed by a discussion of the results and their implications. Chapter 3 discusses general conclusions drawn from the NASA systems engineering effectiveness phase of the study, limitations of the study, and recommendations for future areas of research in the field based on from the study's findings.

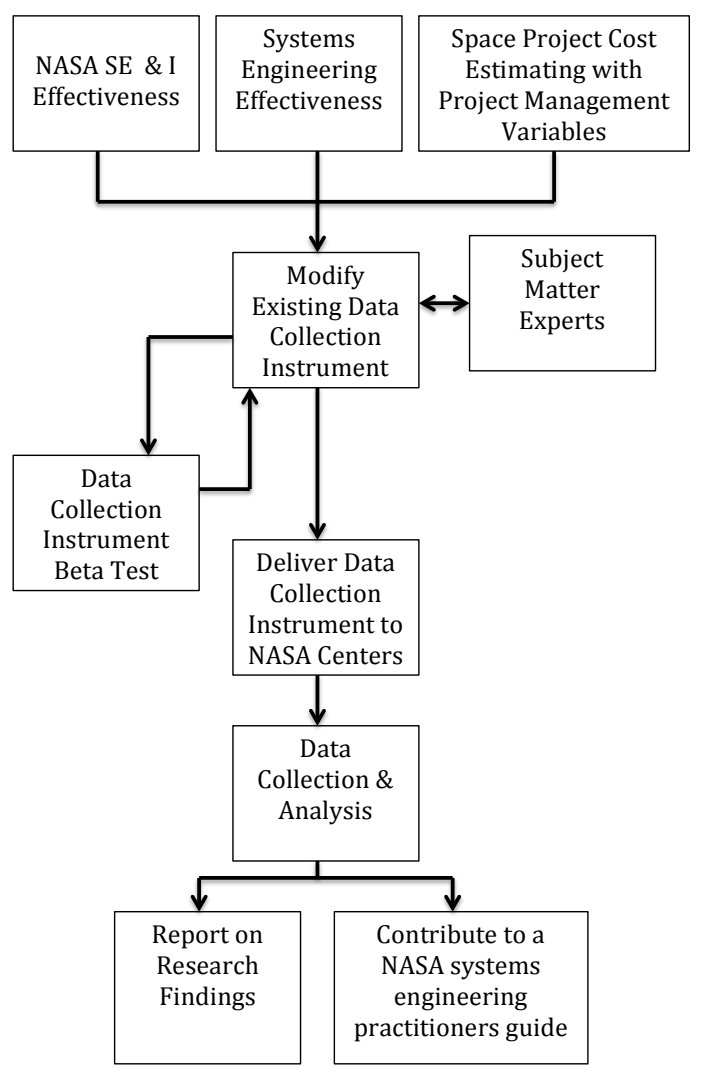

Figure 2. Research Plan Flow Chart 


\section{References}

NASA, S. E. (2014). Systems Engineering at NASA, Past and Present. (K. A. Schomburg, Interviewer)

NASA. (2007). NASA Systems Engineering Handbook. NASA.

NASA. (2014). National Aeronautics and Space Administration. Retrieved November 3, 2014, from FY 2015 President's Budget Request Summary: http://www.nasa.gov/sites/default/files/files/508_2015_Budget_Estimates.pdf

The White House. (2014). Retrieved May 12, 2014, from National Aeronautics and Space Administration:

http://www.whitehouse.gov/sites/default/files/omb/budget/fy2014/assets/nasa.pdf 


\title{
CHAPTER 2. IDENTIFYING RELATIONSHIPS BETWEEN SYSTEMS ENGINEERING PROCESSES AND PROJECT SUCCESS IN NASA COMPLEX PROJECTS AND OTHER ORGANIZATIONS
}

\author{
Kathryne Schomburg ${ }^{1,2}$, Paul Componation ${ }^{3 *}$, Caroline $\mathrm{Krejci}^{2}$, Bob Stephenson ${ }^{4}$
}

A paper to be submitted to The Journal of Systems Engineering

\begin{abstract}
A recognized issue related to the processes in systems engineering is that they vary based on the project and organization. However, understanding how to tailor the systems engineering processes to help ensure project success continues to trouble engineers, and practical tools to help aid engineers in this field are not as readily available as many would like. Moreover, budget and schedule constraints continue to place an additional burden on systems engineering being done well. Many studies on how to help contribute to improving systems engineering exists for different organizations. Yet, most studies are based on case studies from one project, involve a small sample size, or only focus on one organization type. This thesis discusses the results of how systems

\footnotetext{
1 Primary researcher and author

${ }^{2}$ Graduate student and Assistant Professor, respectively, Department of Industrial and Manufacturing Systems Engineering, Iowa State University, Ames, IA 50010

${ }^{3}$ Professor, Department of Industrial, Manufacturing, and Systems Engineering, University of Texas at Arlington, Arlington, TX 76019

${ }^{4}$ Professor, Department of Statistics, Iowa State University, Ames, IA 50010

*To whom all correspondence should be addressed. Email: componation@uta.edu
} 
engineering processes applied to complex projects impact project success based on organization type with a sample size of 180 institutions. The organizations examined are divided into two groups, commercial organizations and government organizations. Within the commercial organization, government-focused projects and commercialfocused projects are examined. Within the government organization, projects from the National Aeronautics and Space Administration (NASA) Agency are examined. NASA is a government organization comprised of 10 Centers located around the country, and for the purpose of this research, is the primary organization discussed and metric in which the other organizations will be quantitatively compared and contrasted against. For this reason, the standard participants used in this research effort were NASA's 17 systems engineering processes. Data was gathered through a modified data collection instrument, and a three-level data analysis was performed. First, meaningful correlations were identified between the systems engineering processes and project success metrics, as well as, non-technical variables and project success metrics for the different organizations. Then, a deeper data analysis was conducted to test for statistically significant differences through project description variables, project success metrics, and systems engineering processes across organization types. Finally, statistically significant differences among the project description variables, project success metrics, systems engineering processes, and non-technical variables were examined within each organization type. The results from the data analysis will be delivered to NASA to help aid in the development of a NASA systems engineering practitioners guide. 


\section{Introduction}

Whether a team at NASA is working on a three-year lifecycle cube satellite project, the 30+-year lifecycle space launch system (SLS), a robotics project, or a research project, there is a team of engineers who are tasked with specifically overseeing that project's system. What this means for NASA is systems engineering is a formal process no matter the project's size.

However, systems engineering is occurring in more organizations than just NASA, especially when considering the official and unofficial procedures any project undergoes. As stated above there are organizations in the government sector, such as NASA, that do have official systems engineering procedures. Outside of NASA and the government sector, systems engineering is also conducted in commercial businesses and even a family's household. Systems engineering processes are utilized in the aerospace industry when new commercial aircrafts are designed, and trade studies are conducted when a family decides whether fuel economy or size is more important when purchasing a new vehicle.

Because systems engineering is utilized in vastly different project types in some capacity or another, it is important to know how and when to tailor the systems engineering processes based on project type and complexity. Unfortunately, tailoring the systems engineering processes is easier said than done, and NASA is a prime example for highlighting the challenges in tailoring these processes based on the project. Practical tools and examples to aid systems engineers in tailoring the systems engineering processes to their particular project continue to not be as readily available as many engineers would like (NASA, 2014). Even more so than at just NASA, different 
organization types exist and project types vary within those organizations. Therefore, having one standardized systems engineering process to apply across a sector can be a factor in increasing project complexity.

Relevant research and tools on how to tailor systems engineering processes to complex projects to ensure project success based on organization type does exist, however, it is still not as present as many would like. The research that has been conducted on how to tailor systems engineering processes to projects mostly consists of a combination of the following: case studies from a single project, small sample sizes, focusing on only one organization type, or results that are only qualitative in their analysis. An example of this is when a group of systems engineering branch chiefs meet to discuss how the systems engineering processes at NASA can be better tailored to a project. The amount of knowledge and experience among the branch chiefs meeting in this type of situation is invaluable, yet more qualitative in nature versus an intentional quantitative analysis. Quantitative research with a strong sample size is necessary to help with the budget and schedule constraints placed on projects carrying high standards of expectation for success.

NASA operates on a tight government budget and due to the reasons stated above, believes this research effort is of interest for the NASA Agency, as well as other organization types. The 2014 fiscal year budget for NASA was about $\$ 17.7$ billion in discretionary funds, a decrease of about $\$ 50$ million below the 2012 enacted level (The White House, 2014). The requested budget for 2015 is about $\$ 17.4$ billion (NASA, 2014). These budgets illustrate how NASA must continue to successfully develop complex projects on an evermore-restrictive budget. 
Therefore, NASA being forced to operate on a reduced budget is the motivation for systems engineering across the Agency to be done as well as possible. With this motivation stated, research is needed to identify which systems engineering processes NASA engineers place greatest emphasis on in determining a project's success, and how these areas of emphasis differ from government-focused projects and commercialfocused projects in commercial organizations.

Findings from this research will contribute to NASA to help aid in the development of a NASA systems engineering practitioners guide. Additionally, since this study examines government-focused projects and commercial-focused projects in commercial organizations, the findings will be transferrable to projects to other industries, for example the aerospace and defense industries.

The primary goal of this thesis is to quantitatively identify how the systems engineering processes applied to complex projects impact project success based on organization type with a sample size of 180 institutions. In the commercial sector, organization type is divided into two general groups, government-focused projects in commercial organizations and commercial-focused projects in commercial organizations. An additional group is also recognized, the National Aeronautics and Space Administration (NASA) Agency. NASA is a government organization comprised of 10 Centers located around the country. In this research effort, NASA will be the primary organization discussed and the metric in which the other government organizations and commercial organizations are being compared and contrasted against. For this reason, figure 1 below is provided to illustrate the NASA Systems Engineering Engine; which displays the 17 systems engineering processes NASA uses when managing a project. 
NASA's 17 systems engineering processes serve as the systems engineering processes used in this study. For additional information regarding the descriptions of each of NASA's 17 systems engineering processes, please see questions $(25-41)$ in Appendix B, “Term Descriptions.

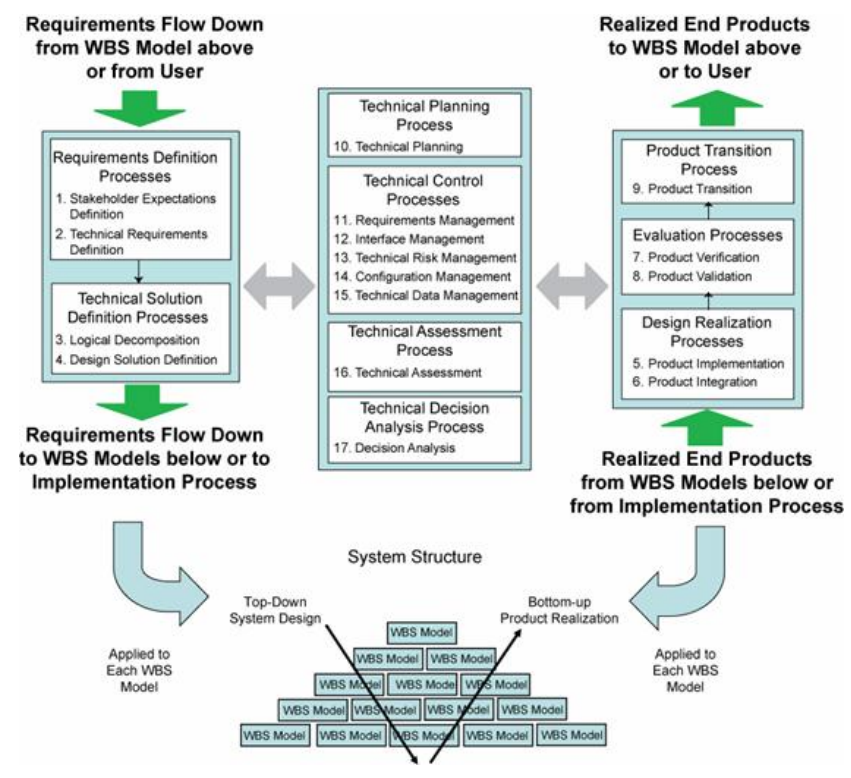

Figure 1. The NASA Systems Engineering Engine (NASA, 2007)

Figure 2 outlines the research plan for the study to be discussed. The research analyzes a three-part study: a 2007 Marshall Space Flight Center (MSFC) Flight Hardware study, a 2013 Government and Commercial Organizations study, and a 2014 NASA Agency study. In order to address the three parts of this study, a literature review focusing on the three areas relating to systems engineering effectiveness is first conducted. Second, a methodology section discusses how the 2014 NASA data was collected and integrated into the data from the 2007 MSFC Flight Hardware and 2013 Government and Commercial Organizations studies. 


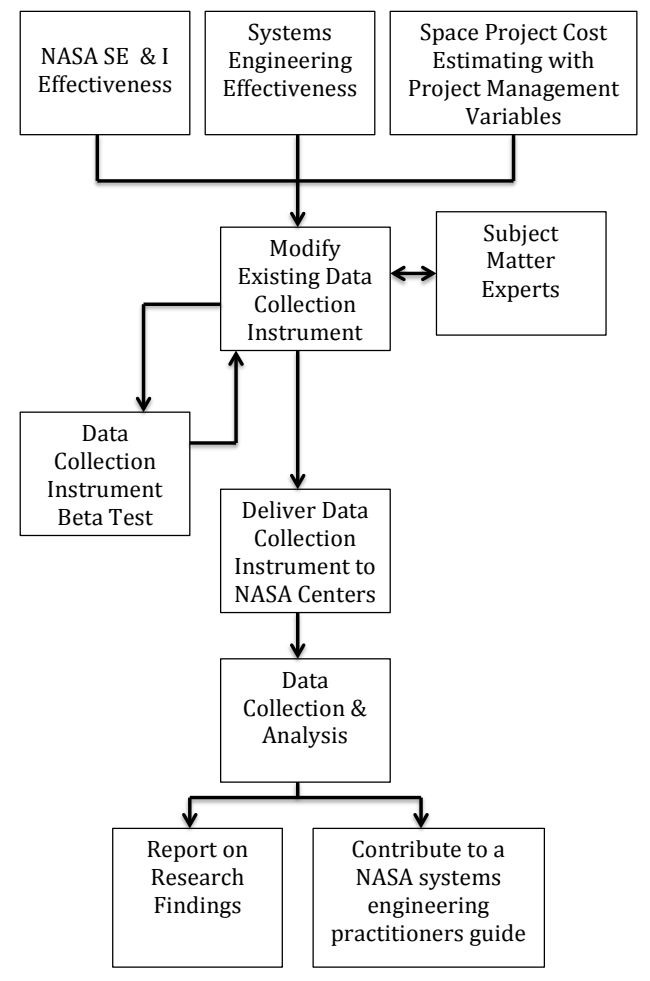

Figure 2. Research Plan Flow Chart

Third, a results and data analysis section summarizes the study's findings through three levels of analysis. In the first level, data from the three studies is quantitatively compared and contrasted to identify meaningful correlations between the systems engineering processes and project success metrics, as well as, the non-technical variables and project success metrics based on organization type. Second, a richer data analysis is conducted to test for statistically significant differences among organizations based upon project description variables, project success, metrics, and the systems engineering processes across organization types. The third level of the data analysis tests for statistically significant variable differences within each organization based upon project 
description variables, project success, metrics, the systems engineering processes, and non-technical variables.

The results look to gather additional insight into whether certain variables used for determining project success across the NASA Agency are similar or different to those being used at other government organizations, as well as commercial organizations. Through this research, we hope to better understand how the NASA Centers organize their systems engineering processes and if these processes are organized in a manor to best ensure project success and resource utilization. Finally, a conclusion summarizes the study and its findings, acknowledges the limitations of the study, and proposes recommendations for future work.

\section{Literature Review}

\section{Overview and project success:}

Research has shown that project success depends on the implementation of systems engineering and project management methodologies. In the context of this research, a project is defined as being successful if it all phases of its lifecycle were successfully completed. In his research on project success, Couillard (1995) collected survey data and then applied a project management method developed by Pinto and Slevin (1988) to gain a better understanding of the connection between project success and project management techniques. Six project success measures and eight variables from this research were used. He found that project success is influenced by multiple factors. For examples, the importance of having the project team know exactly what is expected from them, as well as needing to establish clear and effective communication 
within the project team. Additionally, factors found to meaningfully influence project success were as follows: the degree to which the project team understands the level of authority given to the project manager, how the project team handles problems, and communication among team (Couillard, 1995). Therefore, project success could be influenced by both technical and non-technical variables. A technical variable being a project input where physical measurements could be calculated and obtained. An example of this is payload weight. A non-technical variable is defined as a project input where physical measurements are unable to be calculated or obtained. An example of a non-technical variable is teamwork.

In addition to project success serving as a key indictor for effective systems engineering, a narrowed scope for this research must be defined. The focus of this research effort is to determine which systems engineering processes are of highest value to systems engineers at NASA, and how those processes correlate to project success. Additionally, that information then needs to be compared and contrasted against government-focused projects and commercial-focused projects in commercial organizations, so that NASA as an Agency can clearly identify how systems engineering for them as a government organization differs from commercial organizations. This again is important since a portion of the project work at NASA is contracted out to commercial organizations. Finally, we want to begin introducing the exploration of how non-technical variables might impact project success at NASA.

Therefore, for the purpose of this research the literature review discussed focuses on three main elements: (1) NASA systems engineering and integration effectiveness, (2) systems engineering for government-focused projects and commercial-focused projects in 
commercial organizations, and (3) project cost estimating with non-technical variables at NASA. The first element identifies the work NASA has conducted internally to further develop complex systems engineering effectiveness. The second element summarizes key overall findings of systems engineering effectiveness in government and commercial organizations. The third element discusses existing research that has attempted to identify appropriate non-technical variables to use in parametric cost modeling to help determine success in projects at NASA.

\section{NASA systems engineering and integration effectiveness:}

Through the development of his study, Couillard introduced the idea of examining the relationships between management techniques and project success based on individual complex systems projects. His research pioneered the exploration of different correlations between variation in project management and project success for complex systems projects. His research effort provided a basis for the first phase of the systems engineering effectiveness study discussed in this thesis. This foundational stage was a 2007 MSFC flight hardware systems engineering effectiveness study (Componation, Youngblood, Utley, \& Farrington, 2008).

The 2007 phase developed the foundation for the secondary and current phases of the study, as well as defining the project's long-term goal. The long-term goal is to identify statistical relationships for teams to effectively tailor their systems engineering processes (Componation, Youngblood, Utley, \& Farrington, 2008). The MSFC flight hardware study looked to determine the correlation between the extent of formal systems engineering, the integration process, and organizational implementation with 
programmatic and technical success. The researchers evaluated the systems engineering approach and teaming effectiveness as related to project success. Data for this project was conducted through a series of interviews centered on the International Space Welding Experiment (ISWE) project (Componation, Youngblood, Utley, \& Farrington, 2008). Further discussion of the MSFC flight hardware study can be viewed in figure 6 in the Results and Data Analysis section.

The application of systems engineering to NASA projects has evolved since the agency was created in 1958 (NASA, 2014). In recent years, the evolution of NASA's systems engineering standards has been observed via updates to its unofficial and official manuals. For example, the 1994 Systems Engineering Handbook, “Tools, Techniques, and Lessons Learned" used a product-focused approach, while the 2007 Systems Engineering Handbook focused on processes (Heusner, 2013). Today, systems engineers at NASA continue to use the 1994 product-focused NASA handbook and hope for additional practical, product-focused tools to be developed for use (NASA, 2014). Most NASA centers develop their own internal systems engineering handbooks and tools to use. For example, MSFC developed a practical handbook based on tools, techniques, and lessons learned that was used for the majority of the 1990's and 2000's (Science and Engineering Systems Analysis and Integration Laboratory, Systems Definition Division, 1994).

Another example of differences between organizational systems engineering standards and actual implementation at the Centers involves the structure used to describe the system life cycle. The systems engineering "Vee" chart, displayed in Figure 3, was initially developed by NASA as part of the Software Management and Assurance 
Program and was further developed by Forsberg and Mooz (Forsberg \& Mooz, 1991). In 2007, NASA transitioned to the agency standard which defines the 17 systems engineering processes that was introduced in Figure 1 (NASA, 2007). However, most Centers were and are still using the systems engineering "Vee" chart.

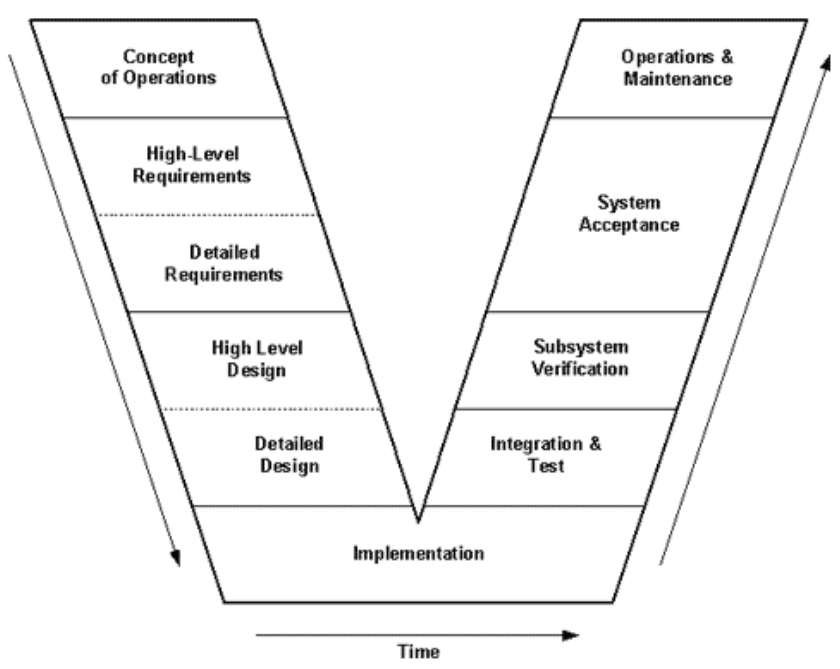

Figure 3. Systems Engineering "Vee"

Internal research at NASA has been conducted with the goal of continuing to improve systems engineering effectiveness within the agency. NASA's motivation is strongly tied to the need for mission success. With increasing complexity due to the integration of hardware and software into projects, the challenge of engineering the systems to meet cost, schedule, and performance requirements within acceptable levels of risk has increased primarily due to the integration of hardware and software into projects (Andary, So, \& Breindel, 2008). Prior to the standardization of official systems engineering processes at NASA, when the systems engineers identified technical risks, the project manager was notified to discuss how to reduce the risk. However, during 
these times, due to cost and schedule, the project manager would generally refuse to approve the recommended technical solution and either accept the risk or implement a portion of the recommended solution. In an attempt to mitigate this issue, Centers have developed tools to aid the Mission Systems Engineers. For example, Goddard Space Flight Center developed the "GOLD Rules" and a System Engineering Requirements Traceability tool (Andary, So, \& Breindel, 2008). The purpose of these tools is to provide a direction for project managers to go in when systems engineers discover an issue. Putting these procedures in place help stop issues from being ignored due to cost and schedule problems.

NASA has also used projects such as the Morpheus project as a challenge to tailor the traditional NASA systems engineering approach to be more appropriate for a lower cost, rapid prototype engineering effort without interfering with the integrity of the systems engineering processes (Devolites \& Hart, 2013). NASA's Morpheus project developed and tested a prototype planetary lander designed to serve as a test-bed for advanced spacecraft technologies. The Morpheus project was suitable for this experiment because the majority of civil servants at the time were either working on the Space Shuttle Program, the International Space Station Program, or the Constellation Program, so Morpheus's small team provided feasibility. Furthermore, the Morpheus project was not required to show compliance with NASA Procedural Requirements 7120.5 , allowing the project's team to operate more freely. The experiment with the Morpheus project was successful. It was robust, efficient compared to alternatives, and unintended consequences were minimized (Devolites \& Hart, 2013). 
From NASA's recent missions, the Johns Hopkins University Applied Physics Laboratory (APL) used the NASA Cost Instrument Cost Model databases to identify trends in project management and systems engineering effort (Shinn, Wolfarth, \& Hahn, 2010). Recent APL projects have shown clear increases in both the estimated and realized costs for systems engineering and project management activities but no definitive rationale to explain the upward trend. However, cost estimating relationships of the most widely-used mission and instrument cost models provide little acknowledgement that project management/systems engineering costs are driven by anything other than hardware and software costs, nor how management and engineering initiatives, policy changes, or risk considerations are driving project management/systems engineering growth (Shinn, Wolfarth, \& Hahn, 2010). Researcher at APL believe the reasons are an absence of data from recent missions subject to the effects of NASA NPR 7120.5D and other policies, earned value and other initiatives, unreliable and inconsistent cost project management/systems engineering data, and perhaps most critically a perceived lack of interest until recently in understanding project management/systems engineering costs (Shinn, Wolfarth, \& Hahn, 2010).

\section{Systems engineering effectiveness:}

Systems engineers at NASA continue to appreciate the 1994 product-focused handbook and hope for additional practical, product-focused tools to be developed in the future (NASA, 2014). However, in addition to the development of practical tools for NASA to use internally, their relationship with commercial organizations is also crucial to their success. The reason, again, is because NASA contracts out many portions of 
their projects to commercial organizations. Therefore, understanding systems engineering effectiveness in commercial organizations for government-focused projects and commercial-focused projects is important. By understanding systems engineering effectiveness in commercial organizations, we will be able to better map NASA's relationship to commercial organizations, and therefore better determine a project's success.

After the 2007 MSFC flight hardware phase of the study, the project transitioned to a 2013 study examining systems engineering effectiveness in government-focused projects and commercial-focused projects in commercial organizations. The study focused on organizations in the Midwest and Southeast regions of the United States (Hansen, 2013). For this phase of the study, a data collection instrument was developed for the participants to use consisting of 50 questions, and used NASA's 17 systems engineering processes as the systems engineering standards to survey against. The data collection instrument will be discussed in more detail in the Methodology section. Participants in this phase of the study totaled to 129: 83 commercial-focused projects' participants and 46 government-focused projects' participants. (Hansen, 2013). In this research, correlation matrices were developed to compare and contrast NASA's 17 systems engineering processes and Couillard's project success metrics from the 2007 phase and 2013 phases of the study. Meaningful correlations will also be further referenced in the Methodology section of this article.

The data from all three phases of this study was gathered through surveying systems engineers. Survey research has the potential to advance the maturity of systems engineering research. Specifically, applying systems engineering to survey research 
enhances the performance of various survey related activities. Based on survey research, recommendations on how systems engineering can improve are through performing an in-depth analysis of the requirements of all the stakeholders in the survey and leveraging the framework for risk and opportunity management offered by systems engineering to address survey data threats to validity (Smartt \& Ferreira, 2013).

Systems engineering is often integrated into a project based on current standards; however, these standards contain inconsistencies (INCOSE, 2014). These inconsistencies are mainly because systems engineers continue to struggle with the basic mathematical relationships that control the development of systems (Honour, 2004). Consequently, practitioners will use heuristics learned during their personal career experiences to guide them in systems engineering. By using heuristics, relationships between project cost and schedule, technical value, technical size, technical complexity, and technical quality are better applied by being more tailored to the specific project's needs, but they have also made the value of systems engineering to projects impossible to quantify (Sheard, 2000). This is because there is no way to quantify the value of systems engineering when each project is being managed based on heuristics of an individual systems engineer's experiences. Each project becomes unique in some manor. Another challenge in valuing systems engineering is the difficulty in quantifying intuitive understanding of the value of reducing risk (Honour, 2004). This is problematic, since the primary purpose of systems engineering concepts and processes is reducing risk early to avoid integration and test problems, thereby reducing cost and shortening schedules.

To address these challenges, a three-year initiative was conducted to transform classical systems engineering measures into leading indicators. Systems engineering 
leading indicators are measures for evaluating the effectiveness of the systems engineering activities on a program in a manner that provides information about impacts that are likely to affect the system or program performance objectives (Rhodes, Valerdi, \& Roedler, 2008).

In an effort to better understand how systems engineering is utilized on a projectby-project basis, the defense sector has been examined in the literature. Defense projects are similar to NASA projects, but both are different from other industrial projects. Defense projects are usually large, complex, and interdisciplinary. They also use stateof-the-art technologies in order to achieve the required operational performance, thus increasing the technological risk involved in their execution (Tishler, Dvir, Shenhar, \& Lipovetsky, 1995). Factors found to be critical to the success of defense projects are: urgency of need, quality of the follow-up team, pre-project preparation, quality of the development team and of its manager, professional growth and continuity, design policy of the developing organization, design considerations in the early phases of the development cycle, systematic use of methods to control schedule, budget, and performance (Tishler, Dvir, Shenhar, \& Lipovetsky, 1995). Additionally, project success has been determined to be positively correlated with the investment in requirements definition and development of technical specifications (Tishler, Dvir, Shenhar, \& Lipovetsky, 1995). All of these factors also have the potential to heavily impact project success within NASA projects. By contrast, findings in defense studies suggest that project success is insensitive to the level of implementation of management processes and procedures, which are readily supported by modern computerized tools and project management training (Tishler, Dvir, Shenhar, \& Lipovetsky, 1995). 
Additionally, the utilization of Bayesian Belief Networks has been used as a method to better understand systems engineering effectiveness within the Department of Defense. Bayesian Belief Networks were used to create causal maps to model relationships present in government acquisitions of complex information systems and create a systems engineering effectiveness index model to identify and analyze systems engineering patterns and predict possible areas of systems engineering performance risk (Doskey, Mazzuchi, \& Sarkani, 2013). The causal map in this approach broke systems engineering effectiveness into three areas: technical, business, and leadership. Results from the study showed successful projects to have a higher correlation across all capabilities with stakeholder management.

Locatelli, Mancini, and Romano examined projects delivered in complex environments that are often late, over-budget and providing fewer benefits that what were originally expected. They determined systems engineering to be the emerging paradigm in complex project environments that transform project governance from "project based" to "system based" and thereby increase the chance of holistic success (Locatelli, Mancini, \& Romano, 2013). This research presents systems engineering tools and techniques focusing, in particular, on the most relevant for project management, project governance and stakeholder management.

Current methods in systems engineering apply decomposition to knowledge, functionality, and product structures. This requires excellent integration and optimization applied in a coordinated way. A more complex system does not necessarily result in a more difficult operational employment. A case can be made that recent systems that are very complex from a development perspective can be easy to employ (Grady, 2009). 
This finding is also supported in more recent studies. Elm and Goldenson found research does indicate that when projects properly apply systems engineering best practices, they tend to perform better than projects that do not (Elm \& Goldenson, 2012). Findings such as these were motivating factors for a continuing phase to the 2007 MSFC flight hardware study.

Due to the complexities project management teams must consider such as novelty and risk management strategy in order to determine the integration of benefits and risks, decision-making tools have been proposed. Such tools hope to help the project manager choose the best way to improve project success rates while controlling the level of risks (Marmier, Gourc, \& Laarz, 2013). However, these tools can sometimes increase project complexity if a foundational phase of the tool's model is to generate all possible project scenarios. Potential project scenarios are generally difficult to foreshadow in unique complex engineering projects, such as the ones conduced by NASA. Moreover, project failures have been known to be caused by: uncertainty in the way projects must be governed, scope ambiguity, technical complexity, and involvement of a large number of

partners with different cultures and different ways of work (Van Marrewijk A. , 2004), (Van Marrewijk, Clegg, Pitsis, \& Veenswijk, 2008).

\section{Project cost estimating with non-technical variables at NASA:}

The final element in this literature review discusses specific research conducted by Hamaker regarding how non-technical variables can influence project success from a systems engineering perspective at NASA. This section summarizes how the non- 
technical variables in our study were identified for use and why they are important to this research effort.

The general problem in space project cost estimating is predicting the cost of projects early in their formulation phase in order to make accurate commitments on what the project is likely to cost. Parametric cost models are typically used because in the early stages of project definition, insufficient detailed information is known to perform other types of estimates, such as detailed engineering estimates that are based on a labor and material buildup of cost. Parametric estimating equations that define the relationship between the independent variables and cost are usually based on historical information. Hamaker's study looked at the influence of non-technical variables in NASA projects and used documentation from 150 projects establishing engineering management variables (Hamaker \& Componation, 2005).

Figure 4 identifies all main variables examined for determining the appropriate parametric cost model. For the purposes of this research, non-technical variables only will be discussed. Figure 4 shows how a correlation analysis using Pearson's product moment correlation was conducted as the analytical approach. The engineering management variables were correlated against cost, with cost acting as the dependent variable. As discussed earlier in Couillard's article, any correlation with 0.4 or greater is considered to be indicative of a significant correlation was used.

For the sake of being thorough, our study used non-technical variables having a correlation almost to 0.4 or greater. These eight variables are highlighted within the boxes below: team experience, requirements volatility, funding constraints, development 
duration, level of testing, number of science organizations, degree of formulation study, and new design factor.

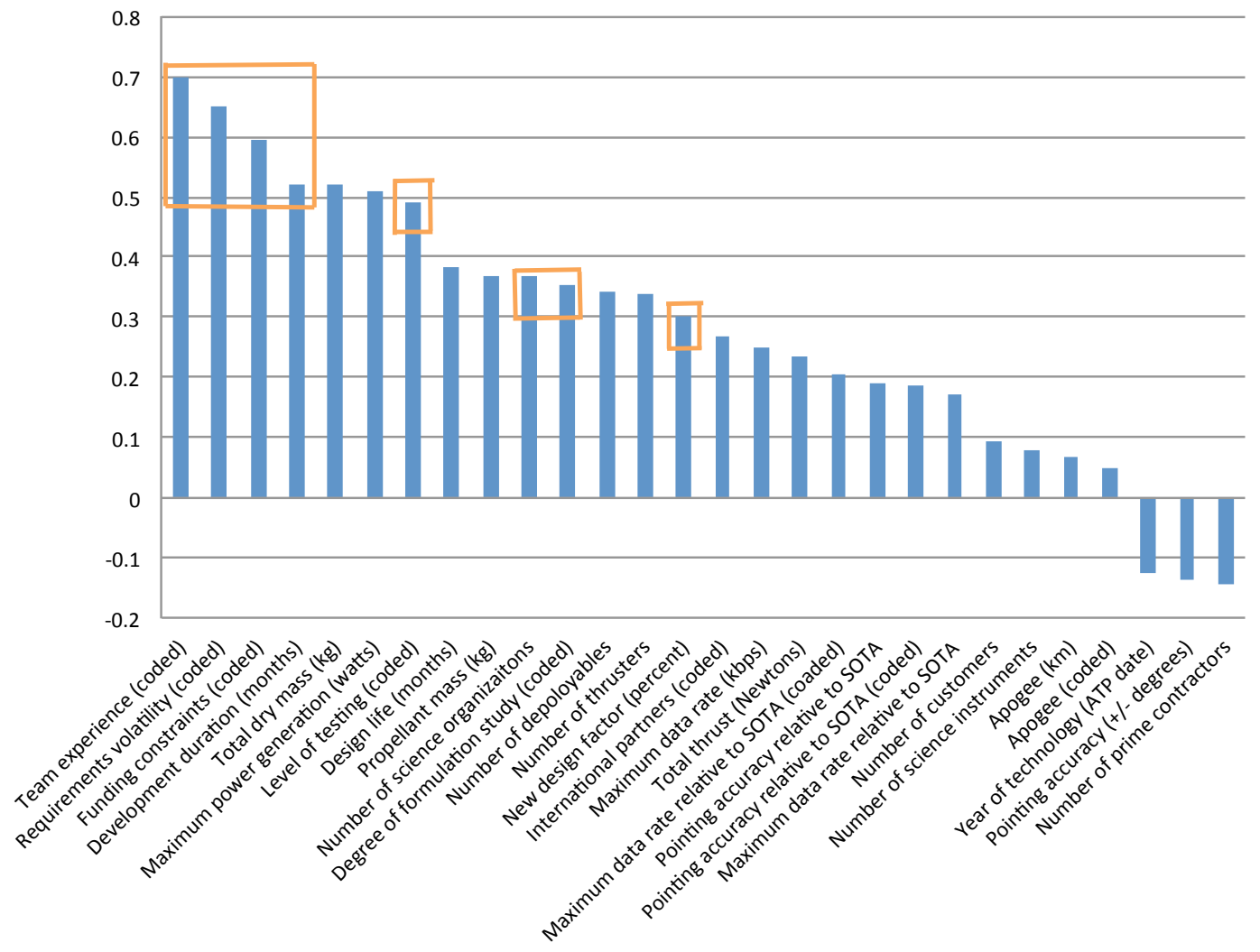

Figure 4. Pearson's Correlation to Cost

This paper further describes how the engineering management variables identified above are used in parametric cost model regression equation to improve predictive capabilities. The general problem in space project cost estimating is predicting the cost of projects early enough in their formulation phase in order to make accurate commitments on what the project is likely to cost. These commitments are made to the project stakeholders (Hamaker \& Componation, 2011). 


\section{Methodology}

Because this research is a continuation of the 2007 MSFC flight hardware study and 2013 government and commercial organizations study, the focus of this section is to describe the process that was used to gather data for the 2014 NASA Agency study. Therefore, this methodology will be specifically discussing the 2014 NASA Agency study. However, the methodologies for the 2007 MSFC flight hardware study and 2013 government and commercial organizations study gathered data in a similar fashion to the 2014 NASA Agency study, using a data collection instrument. To maintain consistency with the previous studies, it was determined that the use of a new data collection instrument for this study was not appropriate. Instead a modified version of the previous data collection instrument was used. This is summarized in table 1.

\section{Table 1. Modified Data Collection Instrument}

\begin{tabular}{|c|l|}
\hline Section & Question Set \\
\hline $\mathbf{1}$ & Basic demographics of the engineer's organization \\
\hline $\mathbf{2}$ & Descriptive information on a specific project the engineer worked on \\
\hline $\mathbf{3}$ & How successful was the project \\
\hline $\mathbf{4}$ & What systems engineering processes were used \\
\hline $\mathbf{5}$ & $\begin{array}{l}\text { Information on how the engineer interacted with his/her distributed team } \\
\text { members }\end{array}$ \\
\hline $\mathbf{6}$ & Influence of non-technical variables in contributing to project success \\
\hline $\mathbf{7}$ & Information on the project's communication and organization level \\
\hline $\mathbf{8}$ & Informal subsystems integration strategies \\
\hline
\end{tabular}

Sections 1 through 5 were included in the original data collection instrument from the 2013 study and are comprised of 50 questions. Sections 6 through 8 increased the number of questions to 79 for the 2014 study. Section 6 measures the influence of nontechnical variables influencing project success, and were formatted through the research 
conducted on space project cost estimating with project management variables, as well as internal research conducted within NASA (Hamaker \& Componation, 2011), (Chapline). A non-technical variable is defined as a project input where physical measurements are unable to be calculated or obtained. An example of a non-technical variable is teamwork. The influence of non-technical variables in systems engineering is of interest to this research because research has shown non-technical variables such as teamwork do impact a project's success. However, quantitatively measuring this impact of non-technical variables in systems engineering is still an undefined area of research. Our 2014 NASA Agency study uses the data from the NASA Agency participants to quantitatively measure the influence of non-technical variables in systems engineering project success. Sections 7 and 8 are collaboration efforts with joint researchers and will not be discussed in this paper. Most questions in sections 1 through 5 were left untouched, except for a few modifications to the jargon to make the questions NASA-specific since the 2013 data collection instrument was written for individuals in government-focused projects and commercial-focused projects in commercial organizations.

The 2013 study used a 4-point Likert response scale to avoid overwhelming participants with too many response options. This addressed the concern that participants would be discouraged from choosing an answer and would instead opt for the "Not Applicable" option (Hansen, 2013). Fortunately, it was determined that this concern was unwarranted. Furthermore, participants in the 2013 study communicated a need for more granularity among response options. Therefore, the 2014 study transitioned to using a 7point Likert response scale (including a "Not Applicable" option) in hopes of gleaning greater insights from the participants' responses. For consistency, the 2014 dataset 
responses were scaled to a 4-point scale, shown in table 2 , based on the assumption that the Likert scale operates on a linear scale.

Table 2. Likert Response Scale Conversion Table

\begin{tabular}{|c|c|c|c|c|}
\hline \multicolumn{2}{|l|}{2013 Study } & New Scale & \multicolumn{2}{|l|}{2014 Study } \\
\hline Strongly Agree & 4 & 4 & Strongly Agree & 7 \\
\hline & & 3.5 & Agree & 6 \\
\hline Agree & 3 & 3 & Somewhat Agree & 5 \\
\hline & & 2.5 & Neither Agree nor Disagree & 4 \\
\hline Disagree & 2 & 2 & Somewhat Disagree & 3 \\
\hline & & 1.5 & Disagree & 2 \\
\hline Strongly Disagree & 1 & 1 & Strongly Disagree & 1 \\
\hline
\end{tabular}

Once the development of the modified data collection instrument was completed, it underwent an alpha test once its preparations were completed. The alpha test was conducted with NASA subject matter experts (SMEs) in early Spring 2014 to ensure the data collection instrument questions were clear and logical for NASA systems engineers to understand (Schomburg, Componation, \& Krejci, 2014). All SMEs either worked directly for NASA or were contracted employees with work supporting NASA projects. The SMEs were supplied the data collection instrument in the same online format as the participants were to receive it in and reviewed each question to approve question appropriateness and section location. The SMEs provided suggestions and comments to improve the quality of the modified data collection instrument, as well as the study overall. The SMEs reviewed each question to approve its appropriateness and section location, and they provided feedback to improve the quality of the modified data collection instrument, as well as the overall study. Since the 2014 phase of the study was a continuation of a larger study, most questions had already been vetted and therefore no 
notable alterations to the modified data collection instrument were deemed necessary. To encourage participant feedback, an additional open-ended question was provided at the end of each question set where participants could provide comments to clarify and/or elaborate on their responses. For further information on the 2014 modified data collection instrument, please see Appendix A, "Modified Data Collection Instrument" where all questions and answer options are listed.

Once the alpha test was completed, a beta test was conducted using only NASA systems engineers. These engineers were all selected from different NASA Centers to provide as much perspective as possible. Only one question, Project Description Question 7, which sought to identify the project's primary focus, needed re-wording in the beta test's phase to confirm the question's appropriateness for NASA systems engineers. Due to the small number of modifications requiring attention in the beta test, the data collection instrument revisions were taken care of relatively quickly.

The data for the 2014 NASA phase of the study was gathered through purposeful sampling and targeted sampling. Purposeful sampling involves selecting informationrich cases for in-depth studies. Information-rich cases are those from which one can learn a great deal about issues of central importance for the purpose of research (Patton, 1990). For the purpose of this research, NASA systems engineers are considered to be a part of a hidden population, difficult to directly access for studies. This is because civil servants are frequently surveyed for government research and the focus of many studies (NASA, 2014). Therefore, we surveyed them through targeted sampling. Targeted sampling provides a cohesive set of research methods that can help researchers study social problems existing among populations that are difficult to reach due to their lack of 
visibility (Watters \& Biernacki, 1989). In order for the data collection instrument to reach systems engineers and systems engineering practitioners at NASA, networks were developed. Relationships with key individuals at NASA Centers were established so contacts at their Centers and others could be obtained for Center deployment. At this point, an initial list of contacts from all ten NASA Centers was compiled for survey deployment. Round 1 of the survey was deployed on July 17, 2014. Multiple rounds of the modified data collection instrument were deployed to allow for engineers to participate in the study who had not had the chance to participate in a previous round.

The modified data collection instrument was deployed two more times to the systems engineers across all the NASA Centers, and was officially closed in September 2014. In total, 51 usable responses were captured from NASA systems engineers from all 10 Centers, including NASA Headquarters. Therefore, the data shown is representative of the whole Agency. The 51 respondents were found by reaching out to all systems engineers at NASA. The engineers were individually contacted to ask about willingness to participate in the study. The 51 responders were essentially the engineers who expressed willingness to participate in the study when asked (Schomburg, Collopy, Componation, \& Krejci, 2015). With the inclusion of the data from the 2013 government and commercial organization study's data, a total of 180 survey responses were available for analysis. Tables 3 and table 4 show the distribution of respondents from the various NASA Centers. 
Table 3. Survey Participant Responses by NASA Center

\begin{tabular}{|l|r|}
\hline \multicolumn{1}{|c|}{ NASA Center } & $\begin{array}{c}\text { Participant } \\
\text { Responses }\end{array}$ \\
\hline Ames Research Center & 3 \\
\hline Glenn Research Center & 2 \\
\hline Goddard Flight Center & 1 \\
\hline Jet Propulsion Laboratory & 7 \\
\hline Johnson Space Center & 2 \\
\hline Kennedy Space Center & 4 \\
\hline Langley Research Center & 9 \\
\hline Marshall Space Flight Center & 20 \\
\hline NASA Headquarters & 1 \\
\hline Stennis Space Center & 1 \\
\hline Armstrong Flight Research Center & 1 \\
\hline
\end{tabular}

Table 4. Survey Participant Responses by NASA Center Type

\begin{tabular}{|l|r|}
\hline \multicolumn{1}{|c|}{ Center Type } & $\begin{array}{c}\text { Participant } \\
\text { Responses }\end{array}$ \\
\hline Research Centers & 11 \\
\hline Flight Centers & 5 \\
\hline Robotics Centers & 8 \\
\hline Manned Centers & 26 \\
\hline Headquarters & 1 \\
\hline
\end{tabular}


By using participant responses from the 2007 and 2013 phases of the study in addition to the 2014 phases, a number of correlation matrices were calculated based on response data to survey sections 3 and 4 , as well as sections 4 and 6 , which are highlighted in table 5.

Table 5. Focused Data Collection Instrument Sections for Correlation Tables

\begin{tabular}{|c|l|c|}
\hline Section & \multicolumn{1}{|c|}{ Section Topic } & Correlation Matrices \\
\hline 1 & Demographics of Engineer's Organization & \\
\hline 2 & Descriptive Project Information & $\mathrm{X}$ \\
\hline 3 & Project Success Metrics & $\mathrm{X}$ \\
\hline 4 & Systems Engineering Processes & $\mathrm{X}$ \\
\hline 5 & Distributed Team Members' Information & \\
\hline 6 & Non-Technical Variables' Interaction & \\
\hline 7 & Organization, Culture, and Communication & \\
\hline 8 & Informal Subsystems Integration Strategies & \\
\hline
\end{tabular}

To ensure consistency and usability from all participant responses in the 2013 and 2014 datasets, whenever a participant answered a question using the Not Applicable option, the response was coded into the data as "missing" and the value was subsequently imputed. Imputed data was generated in R using the Multivariate Imputation by Chained Equations (MICE) package. The following defaults were used: predictive mean matching, logistic regression imputation, polytomous regression imputation for unordered categorical data, and the proportional odds model. The MICE package then generated multiple imputations for incomplete multivariable data using the Gibbs sampling method. The algorithm imputes an incomplete column by generating 'plausible' synthetic values given from other columns in the data (Stef van Buuren [aut, 2014). The Gibbs sampler is a technique for generating random variables from a marginal distribution indirectly without 
having to calculate the density and is also based on the elementary properties of Markov chains (Casella \& George, 1992).

Once the missing values were imputed, a data analysis was conducted. In this study, subjects were the institutions/participants; the predictor variables were: the organization type, question type, and an organization*question interaction; the response were the 180 institutions' responses to each question. Possible sources of bias might be present in each of the three phases of the overall study. The 2007 MSFC flight hardware study collected data through interviews only and from one NASA Center. The 2013 government and commercial organizations study collected its data primarily in the Midwest and Southeast areas of the country. The 2014 NASA Agency study allowed participants to respond based on projects where the lifecycle was not yet completed or the project was canceled, as well as completed projects. Participation from the NASA Centers was also un-proportional. Variability in the study came from two sources: the measurement tool and experimental unit. Each institution participating in the study answered questions based upon their experiences, and therefore might be a source of variability. Finally, how individuals view a Likert scale might differ. Some individuals choose to use extremes such as 'Strongly Agree' or 'Strongly Disagree' where others do not, and therefore might be a source of variability.

Six questions were researched through the use of matrices, and 19 hypotheses were tested through the use of one-way analysis of variance tables. The following questions and hypotheses are listed in the order they will be addressed in the Results and Data Analysis section. 


\section{Matrices' questions:}

Question 1: Do the systems engineering processes for the 2007 MSFC Flight Hardware study meaningfully correlate to the same project success metrics as the 2013 Government and Commercial Organizations study?

Question 2: Do the systems engineering processes for the 2007 MSFC Flight Hardware study meaningfully correlate to the same project success metrics as the 2014 NASA Agency study?

Question 3: Do the systems engineering processes for the 2013 Government and Commercial Organizations study meaningfully correlate to the same project success metrics as the 2014 NASA Agency study?

Question 4: Do the systems engineering processes for the 2013 governmentfocused projects meaningfully correlate to the same project success metrics as the 2014 NASA Agency study?

Question 5: Do the systems engineering processes for the 2013 commercialfocused projects meaningfully correlate to the same project success metrics as the 2014 NASA Agency study?

Question 6: Which non-technical variables meaningfully correlate to project success metrics in the 2014 NASA Agency study? 


\section{Analysis of variance tables' hypotheses:}

Hypothesis 1: At least one organization effect does not equal zero in the Project Description Variables section of the modified data collection instrument.

Hypothesis 2: At least one question effect does not equal zero in the Project Description Variables section of the modified data collection instrument.

Hypothesis 3: At least one organization*question interaction effect does not equal zero in the Project Description Variables section of the modified data collection instrument.

Hypothesis 4: At least one organization effect does not equal zero in the Project Success Metrics section of the modified data collection instrument.

Hypothesis 5: At least one question effect does not equal zero in the Project Success Metrics section of the modified data collection instrument.

Hypothesis 6: At least one organization*question interaction effect does not equal zero in the Project Success Metrics section of the modified data collection instrument.

Hypothesis 7: At least one organization effect does not equal zero in the Systems Engineering Processes section of the modified data collection instrument.

Hypothesis 8: At least one question effect does not equal zero in the Systems Engineering Processes section of the modified data collection instrument.

Hypothesis 9: At least one organization*question interaction effect does not equal zero in the Systems Engineering Processes section of the modified data collection instrument.

Hypothesis 10: At least one question effect does not equal zero in the Project Description Variables section for government-focused projects. 
Hypothesis 11: At least one question effect does not equal zero in the Project Description Variables section for the commercial-focused projects.

Hypothesis 12: At least one question effect does not equal zero in the Project Description Variables section for NASA projects.

Hypothesis 13: At least one question effect does not equal zero in the Project Success Metrics section for the government-focused projects.

Hypothesis 14: At least one question effect does not equal zero in the Project Success Metrics section for the commercial-focused projects.

Hypothesis 15: At least one question effect does not equal zero in the Project Success Metrics section for NASA projects.

Hypothesis 16: At least one question effect does not equal zero in the Systems Engineering Processes section for government-focused projects.

Hypothesis 17: At least one question effect does not equal zero in the Systems Engineering Processes section for commercial-focused projects.

Hypothesis 18: At least one question effect does not equal zero in the Systems Engineering Processes section for NASA projects.

Hypothesis 19: At least one question effect does not equal zero in the NonTechnical Variables section for NASA projects.

In an attempt to gain a qualitative understanding of the survey results, face-to-face interviews were conducted with a random sample of practicing systems engineers at NASA. The goal in doing so was to ensure the findings discovered in the Results and Data Analysis section were in accordance with the quantitative and qualitative information discovered in the modified data collection instruments. The interviews 
hoped to gain insight similar to the April 2008 Systems Engineering Behaviors study; this study learned how systems engineers work on different projects in different programs at different Centers (Derro \& Williams, 2009). Therefore, the face-to-face interviews served as a quality check to the modified data collection instrument.

\section{Results and Data Analysis}

In the Results and Data Analysis section, three levels of data analysis will be discussed. The first level identifies matrices displaying meaningful correlations between NASA's 17 systems engineering processes and Couillard's 9 project success metrics for the 2007 MSFC flight hardware study, 2013 government and commercial organizations study, and 2014 NASA Agency study. Also, a matrix identifying meaningful correlations between the non-technical variables and project success metrics from the 2014 NASA Agency study will also be displayed. In all matrices, a correlation of 0.4 or greater was identified as meaningful. Couillard used 0.4 as a notable value in his work, as did Elm (Couillard, 1995); (Elm \& Goldenson, 2012). The second level uses one-way analysis of variance tables to identify organizational differences among the project description variables, project success metrics, systems engineering processes, and non-technical variables. The third section uses one-way analysis of variance tables to identify variable differences within each organization based on project description variables, project success metrics, systems engineering processes, and non-technical variables. Finally, a discussion section relates the findings back to the initial research question.

Based on the Gibbs sampler technique, it is important to note the correlations calculated in the following matrices are based off one imputation iteration. The 2013 
phase of the study had $3.4 \%$ of the responses missing, and the 2014 phase of the study had $6.7 \%$ of the responses missing. Overall, $4.3 \%$ of the responses in the 180 participant surveys required an imputed value to conduct a proper data analysis. Of the 180 participants, 129 were from the 2013 government and commercial organizations study and 51 were from the 2014 NASA Agency study.

\section{Matrices showing correlations between project success metrics and systems engineering processes}

\begin{tabular}{|c|c|c|c|c|c|c|c|c|c|c|c|c|c|c|c|c|c|}
\hline $\begin{array}{l}\text { ORIGINAL NASA STUDY AND } \\
\text { NEW STUDY: CHECK } \\
\text { Correlation of } 0.4 \text { or greater noted } \\
\text { Project Success and System } \\
\text { Engineering Processes }\end{array}$ & 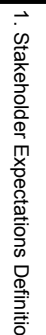 & 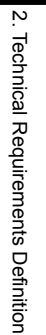 & 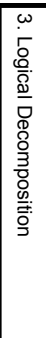 & 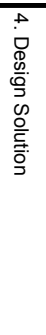 & 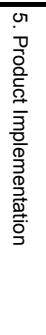 & 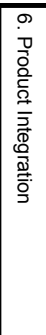 & 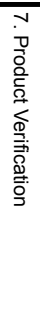 & 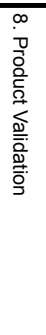 & 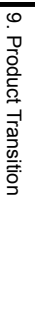 & 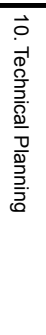 & 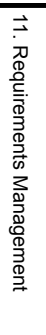 & 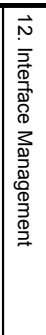 & 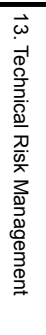 & 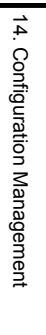 & 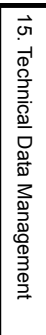 & 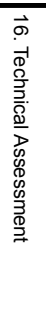 & 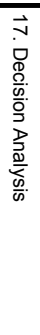 \\
\hline Technical success relative to initial req. & & & .4 & & & & & & .4 & & & & & & & & .4 \\
\hline Technical success relative to similar projects & & & & & & .6 & .5 & & .5 & & & & & & & & \\
\hline On schedule relative to original project plan & & & .4 & & & & & & & .5 & & & & & & & \\
\hline On schedule relative to similar projects & & & & & & & & & & .4 & & & & & & & \\
\hline On budget relative to original project plan & & & & & & & & & & .5 & & .5 & .4 & & & .4 & \\
\hline On budget relative to similar projects & & & & & & & & & & .5 & & & .4 & & & & \\
\hline Satisfaction with project management process & .4 & .5 & & .4 & & & & & & .5 & & & .4 & & & .5 & .4 \\
\hline Overall project success (organization view) & & & & & & .6 & & & .5 & & & & & & & & \\
\hline Overall project success (stakeholder view) & & & & & & & & & & & & & .4 & & & & \\
\hline
\end{tabular}

Figure 5. 2007 MSFC Flight Hardware Study and 2013 Government and Commercial Organizations Study

Figure 5 identifies the correlations between the 17 systems engineering processes and 9 project success metrics from the 2007 and 2013 phases of the study (Hansen, 2013). The shaded cells indicate correlations of at least 0.4 for the 2007 NASA study, and the cells with numerical entries correspond to correlations of at least 0.4 for the 129 participants in the 2013 study examining government-focused projects and commercial- 
focused projects in commercial organizations. Figure 5 serves as the foundational matrix for the overall study. The shaded cells in the 2007 study represent concentrated areas of correlations. More specifically, product implementation, product integration, product verification, technical risk management, and configuration management all show strong positive correlation to technical success and overall project success from the organization view, as well as stakeholder view. The 2013 study produced more sporadic results showing multiple meaningful correlations in technical planning and technical risk management, but not necessarily for the same project success metrics. Overall, outside of the technical planning process little overlap between the two studies is displayed.

\begin{tabular}{|c|c|c|c|c|c|c|c|c|c|c|c|c|c|c|c|c|c|}
\hline $\begin{array}{l}\text { ORIGINAL NASA STUDY AND } \\
2014 \text { STUDY NASA AGENCY } \\
\text { FOCUSED PROJECTS: CHECK } \\
\text { Correlation of } 0.4 \text { or greater noted } \\
\text { Project Success and System } \\
\text { Engineering Processes }\end{array}$ & 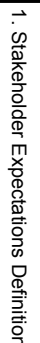 & 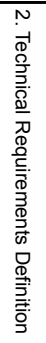 & 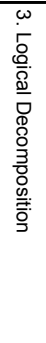 & 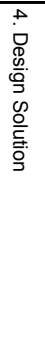 & 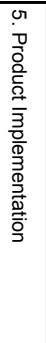 & 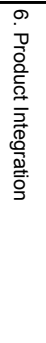 & 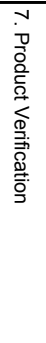 & 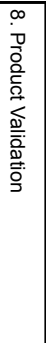 & 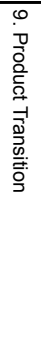 & 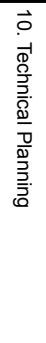 & 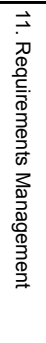 & 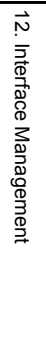 & 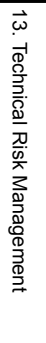 & 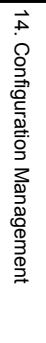 & 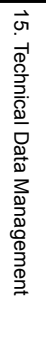 & 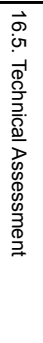 & 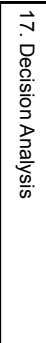 \\
\hline Technical success relative to initial req. & .4 & & & & .6 & .6 & .5 & & .6 & .5 & & .4 & & & & & \\
\hline Technical success relative to similar projects & & & & .5 & .5 & .7 & .6 & & .4 & & & .5 & & & & & \\
\hline On schedule relative to original project plan & .5 & & & & & .4 & .4 & & & .5 & .5 & & & .6 & & & \\
\hline On schedule relative to similar projects & & & & & & .5 & .4 & & & .5 & .4 & & & .6 & & & \\
\hline On budget relative to original project plan & & & & & & & & & & .4 & & & & .5 & & & \\
\hline On budget relative to similar projects & & & & & & .6 & & & & & & & & & & .5 & \\
\hline Satisfaction with project management process & & & & & & .5 & & & & & & & & .5 & & .5 & \\
\hline Overall project success (organization view) & & & & .4 & .5 & .7 & .5 & & .4 & & .4 & .4 & & .5 & .5 & & \\
\hline Overall project success (stakeholder view) & & & & & .5 & .6 & .5 & & .4 & .5 & & .4 & & & .5 & & \\
\hline
\end{tabular}

Figure 6. 2007 MSFC Flight Hardware Study and 2014 NASA Study

Figure 6 identifies meaningful correlations between the 17 systems engineering processes and 9 project success metrics in the 2007 MSFC flight hardware study and the 
2014 NASA phase of the study. The shaded cells again correspond to meaningful correlations in the 2007 study, but the numerical entries now indicate notable correlations among the 51 NASA systems engineering participants in the current phase of the 2014 study. Figure 6 does demonstrate more consistency within the matrix than figure 5 did; the 2014 NASA study produced more concentrated areas of meaningful correlations. The increased consistency in this matrix is most likely due to both studies representing the NASA Agency in some form. Although, intuition might suggest that the response from the two studies would be consistent, this is not the case. For example, process 6, project integration, is more highly correlated with project success on every count except with budget relative to the original project plan in the 2014 NASA Agency study than in the 2007 NASA MSFC flight hardware study. Another notable finding is with process 13, technical risk management. Technical risk management was highly correlated to technical success and overall project success in the 2007 MSFC flight hardware study; however, technical risk management was not significantly acknowledged in the 2014 NASA Agency study at all. A similar finding was discovered in process 14 , configuration management. Both studies found the process to meaningfully correlate to project success, but for different measures. Finally, meaningful correlations dramatically increased in the 2014 study once the systems engineering processes reached the product focused processes, beginning starting at product implementation. 


\begin{tabular}{|c|c|c|c|c|c|c|c|c|c|c|c|c|c|c|c|c|c|}
\hline $\begin{array}{l}2013 \text { Government and } \\
\text { Commercial Organizations Study } \\
\text { And } 2014 \text { NASA Study: CHECK } \\
\text { Correlation of } 0.4 \text { or greater noted } \\
\text { Project Success and System } \\
\text { Engineering Processes }\end{array}$ & 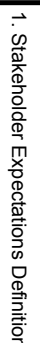 & 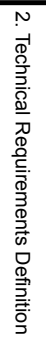 & 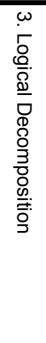 & 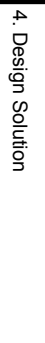 & 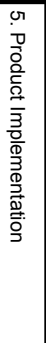 & 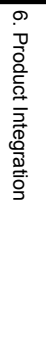 & 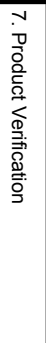 & 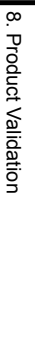 & 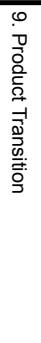 & 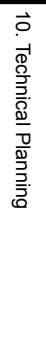 & 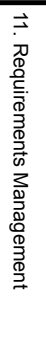 & 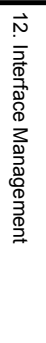 & 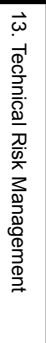 & 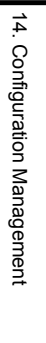 & 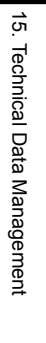 & 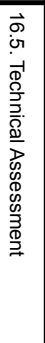 & 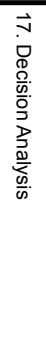 \\
\hline Technical success relative to initial req. & .4 & & & & .6 & .6 & .5 & & .6 & .5 & & .4 & & & & & \\
\hline Technical success relative to similar projects & & & & .5 & .5 & .7 & .6 & & .4 & & & .5 & & & & & \\
\hline On schedule relative to original project plan & .5 & & & & & .4 & .4 & & & .5 & .5 & & & .6 & & & \\
\hline On schedule relative to similar projects & & & & & & .5 & .4 & & & .5 & .4 & & & .6 & & & \\
\hline On budget relative to original project plan & & & & & & & & & & .4 & & & & .5 & & & \\
\hline On budget relative to similar projects & & & & & & .6 & & & & & & & & & & .5 & \\
\hline Satisfaction with project management process & & & & & & .5 & & & & & & & & .5 & & .5 & \\
\hline Overall project success (organization view) & & & & .4 & .5 & .7 & .5 & & .4 & & .4 & .4 & & .5 & .5 & & \\
\hline Overall project success (stakeholder view) & & & & & .5 & .6 & .5 & & .4 & .5 & & .4 & & & .5 & & \\
\hline
\end{tabular}

Figure 7. 2013 Government and Commercial Organizations Study and 2014 NASA Study

Figure 7 represents the similarities and differences among the 2013 government and commercial organization study data and the 2014 NASA systems engineers' responses. The shaded cells indicate correlations of at least 0.4 in the 2013 government and commercial organization study data, while the cells with numerical entries correspond to correlations of at least 0.4 in the 2014 NASA Agency phase of the study. As one might suspect, there is no obvious consistent relationship between the two studies. Systems engineers at NASA produced almost twice as many meaningful correlations between processes and project success than the government and commercial organizations study as a whole. The greater number of correlations in the NASA study could be an indication that NASA systems engineers place a higher value on systems engineering processes impacting project success than the government and commercial 
organizations combined. However, this may also be because the 2013 government and commercial organizations study sought to gain knowledge on the systems engineering processes from a more general level, where the 2014 NASA Agency study gathered knowledge on a specific government organization.

\begin{tabular}{|c|c|c|c|c|c|c|c|c|c|c|c|c|c|c|c|c|c|}
\hline $\begin{array}{l}2013 \text { Study Government Focused } \\
\text { Project And } 2014 \text { NASA Study: } \\
\text { CHECK } \\
\text { Correlation of } 0.4 \text { or greater noted } \\
\text { Project Success and System } \\
\text { Engineering Processes }\end{array}$ & 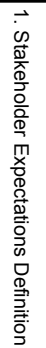 & 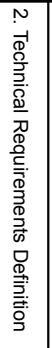 & 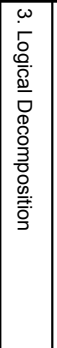 & 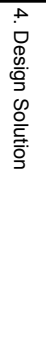 & 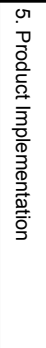 & 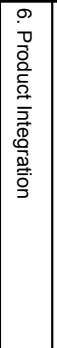 & 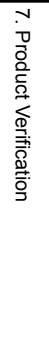 & 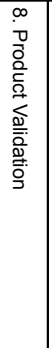 & 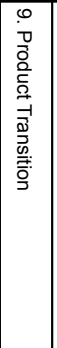 & 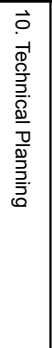 & 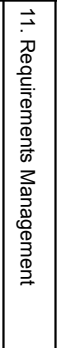 & 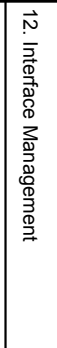 & 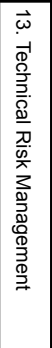 & 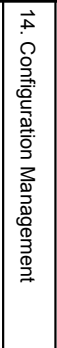 & 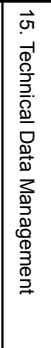 & 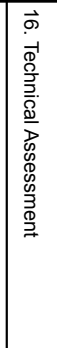 & 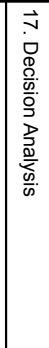 \\
\hline Technical success relative to initial req. & .4 & & & & .6 & .6 & & & .6 & .5 & & .4 & & & & & \\
\hline Technical success relative to similar projects & & & & .5 & .5 & .7 & & & .4 & & & .5 & & & & & \\
\hline On schedule relative to original project plan & .5 & & & & & .4 & & & & .5 & .5 & & & .6 & & & \\
\hline On schedule relative to similar projects & & & & & & .5 & & & & .5 & .4 & & & .6 & & & \\
\hline On budget relative to original project plan & & & & & & & & & & .4 & & & & .5 & & & \\
\hline On budget relative to similar projects & & & & & & .6 & & & & & & & & & & .5 & \\
\hline Satisfaction with project management process & & & & & & .5 & & & & & & & & .5 & & .5 & \\
\hline Overall project success (organization view) & & & & .4 & .5 & .7 & .5 & & .4 & & .4 & .4 & & .5 & .5 & & \\
\hline Overall project success (stakeholder view) & & & & & .5 & .6 & .5 & & .4 & .5 & & .4 & & & .5 & & \\
\hline
\end{tabular}

Figure 8. 2013 Government-Focused Projects and 2014 NASA Study

Figure 8 examines the similarities and differences among the 2013 governmentfocused commercial projects' organization data and the 2014 NASA systems engineers' responses. The shaded cells indicate correlations of at least 0.4 in the 2013 governmentfocused project data, while the cells with numerical entries correspond to correlations of at least 0.4 in the 2014 NASA Agency phase of the study. Both the 2013 governmentfocused projects and 2014 NASA specific projects contain a large number of meaningful correlations. However, the two studies display little overlap among meaningfully 
correlated cells. This might indicate the two studies disagree on how project success is determined relative to the systems engineering processes. Interestingly though, when there is overlap, correlation values are fairly high. An example of this is in product integration. The 2014 NASA study produced a value of 0.7 correlating to overall project success from the organization view. Overall, the processes considered to impact project success for NASA projects are almost completely different from those processes that participants working on government-focused projects in the commercial organization believe impact project success.

\begin{tabular}{|c|c|c|c|c|c|c|c|c|c|c|c|c|c|c|c|c|c|}
\hline $\begin{array}{l}2013 \text { Study Commercial Focused } \\
\text { Project And } 2014 \text { NASA Study: } \\
\text { CHECK } \\
\text { Correlation of } 0.4 \text { or greater noted } \\
\text { Project Success and System } \\
\text { Engineering Processes }\end{array}$ & 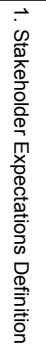 & 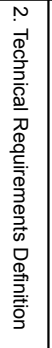 & 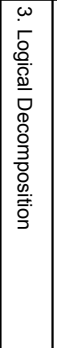 & 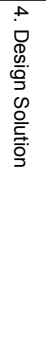 & 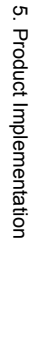 & 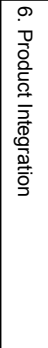 & 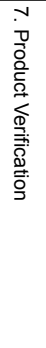 & 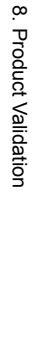 & 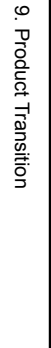 & 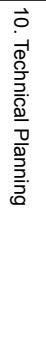 & 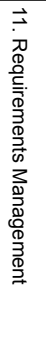 & 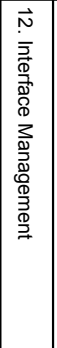 & 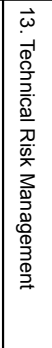 & 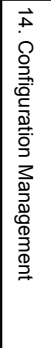 & 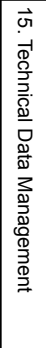 & 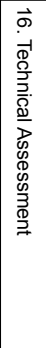 & 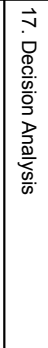 \\
\hline Technical success relative to initial req. & .4 & & & & .6 & .6 & & & .6 & .5 & & .4 & & & & & \\
\hline Technical success relative to similar projects & & & & .5 & .5 & .7 & & & .4 & & & .5 & & & & & \\
\hline On schedule relative to original project plan & .5 & & & & & .4 & & & & .5 & .5 & & & .6 & & & \\
\hline On schedule relative to similar projects & & & & & & .5 & & & & .5 & .4 & & & .6 & & & \\
\hline On budget relative to original project plan & & & & & & & & & & .4 & & & & .5 & & & \\
\hline On budget relative to similar projects & & & & & & .6 & & & & & & & & & & .5 & \\
\hline Satisfaction with project management process & & & & & & .5 & & & & & & & & .5 & & .5 & \\
\hline Overall project success (organization view) & & & & .4 & .5 & .7 & .5 & & .4 & & .4 & .4 & & .5 & .5 & & \\
\hline Overall project success (stakeholder view) & & & & & .5 & .6 & .5 & & .4 & .5 & & .4 & & & .5 & & \\
\hline
\end{tabular}

\section{Figure 9. 2013 Commercial-Focused Projects and 2014 NASA Study}

Figure 9 examines the similarities and differences among the data from the 2013 commercial-focused projects study and the 2014 NASA systems engineers' responses. The shaded cells indicate correlations of at least 0.4 in the 2013 commercial-focused 
project data, while the cells with numerical entries correspond to correlations of at least 0.4 in the 2014 NASA Agency study. Interestingly, both commercial-focused projects and NASA projects consistently value process 6 , product integration, and process 10 , technical planning, as meaningfully correlating to project success. Correlations in figure 8 and figure 9 suggest that NASA systems engineers might approach the systems engineering processes more like commercial-focused projects than government-focused projects.

\begin{tabular}{|c|c|c|c|c|c|c|c|c|c|c|c|}
\hline $\begin{array}{l}\text { Project Success and Non- } \\
\text { Technical Variables } \\
\text { Correlation of } 0.4 \text { or greater to be } \\
\text { noted }\end{array}$ & 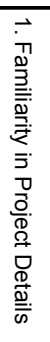 & 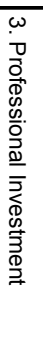 & 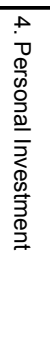 & 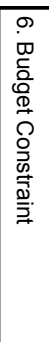 & 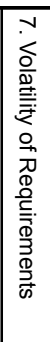 & 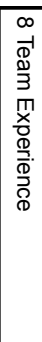 & 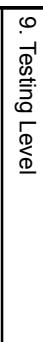 & 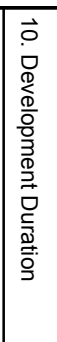 & 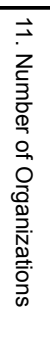 & 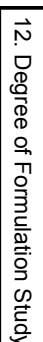 & 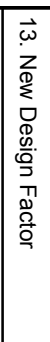 \\
\hline \multicolumn{12}{|l|}{ Technical success relative to initial req. } \\
\hline \multicolumn{12}{|l|}{ Technical success relative to similar projects } \\
\hline On schedule relative to original project plan & .5 & & & & & & & & & & \\
\hline On schedule relative to similar projects & .5 & & & & & & & & & & \\
\hline \multicolumn{12}{|l|}{ On budget relative to original project plan } \\
\hline On budget relative to similar projects & & & & & & .5 & & & & & \\
\hline \multicolumn{12}{|l|}{ Satisfaction with project management process } \\
\hline \multicolumn{12}{|l|}{ Overall project success (organization view) } \\
\hline Overall project success (stakeholder view) & & & & & & & .4 & & & & \\
\hline
\end{tabular}

Figure 10. 2014 NASA Study Non-Technical Variables

In addition to examining how the systems engineering processes correlate to project success, the impact of how non-technical variables correlated to project success was also studied for the 2014 NASA study. Figure 10 illustrates these correlations of at 
least 0.4 . These questions are based on section 6 of the modified data collection instrument. However, not all questions were used because not all were asked on a 7point Likert scale and would not have been able to be coded appropriately. The matrix produced interesting results despite its sparseness. Familiarity in project details correlates relatively highly with schedule relative to the original project plan and relative to similar projects. Team experience also correlates highly with staying on budget. And finally, level of testing has a meaningful correlation with relative overall project success from a stakeholder perspective.

\section{ANOVA tables testing all 180 participants}

Next, three one-way analysis of variance (ANOVA) tables were constructed in JMP using data from all 180 participants from the 2013 government and commercial organizations study, as well as the 2014 NASA Agency study. These three tables were constructed based on results from sections 2,3 , and 4 of the data collection instrument. General information on the design of the data analysis for JMP: the 180 participants were the subjects of the data collection, organization served as the whole plot between subjects factor, the participants were the different types of organizations, and the section's questions were the sub plot within subjects factor. Because each participant answered every question, there was a repeated measurement from the participants. Participants were nested within organizations. Organization refers to: government-focused commercial organization projects (1), commercial-focused commercial organization projects (2), NASA Agency projects (3). Treatment effects were not examined since this was an observational study. The area of highest interest from the ANOVA tables was if there were any differences among the organizations and what the interactions between the 
organizations was, as well as if the groupings of questions were different based on organization.

The first ANOVA table corresponds to section 2 of the data collection instrument, referring to project description variables and is shown in table 6. This table identifies statistically significant differences among the organization effects and questions effects. Regarding organization effects, commercial-focused projects and NASA are found to be significantly different from government-focused projects. In looking at question effects, questions 4 and 2 are found to be significantly different from each other. However, an interaction effect between organization and question was not discovered in the Project Description Variables section when using all 180 participants from the three organization types combined.

Table 6. ANOVA Table: Project Description Variables

\begin{tabular}{|l|r|r|r|r|r|}
\hline Source & DF & $\begin{array}{r}\text { Sum of } \\
\text { Squares }\end{array}$ & Mean Square & F Ratio & Prob. $>$ F \\
\hline Organization & 2 & 10.139 & 5.0956 & 5.8984 & 0.0033 \\
\hline $\begin{array}{l}\text { Question - Project Description } \\
\text { Variables }\end{array}$ & 3 & 2.594 & 0.864667 & 2.6303 & 0.0494 \\
\hline Organization*Question & 6 & 3.717 & 0.6195 & 1.8841 & 0.0816 \\
\hline Participant[Organization]\&Random & 177 & 152.126 & 0.859469 & 2.6142 & $<.0001$ \\
\hline & & & & & \\
\hline Model & 188 & 168.689 & 0.897281 & 2.7292 & $<.0001$ \\
\hline Error & 531 & 174.576 & 0.328769 & & \\
\hline C. Total & 719 & 343.265 & & & \\
\hline
\end{tabular}

The first hypothesis examined if there was a statistically significant organization effect among the Project Description Variables questions. Using an $\alpha=0.05$, we reject the null 
hypothesis and say there are statistically significant organization effects in the Project Description Variables section.

$$
\begin{array}{ll}
\mathrm{H}_{0}: \text { all Organization effects }=0 & \mathrm{~F}=5.8984 \\
\mathrm{H}_{\mathrm{a}}: \text { at least one Organization effect } \neq 0 & \mathrm{P} \text {-value }=0.0033
\end{array}
$$

By rejecting the null hypothesis, a multiple comparison procedure examining the least squared means differences using a Tukey Honestly Significant Difference (HSD) was conducted, and is illustrated in table 7. No differences were identified between the commercial-focused projects' organization and NASA. However the governmentfocused projects' organization is significantly different from both the commercial organization and NASA. This is an interesting result since NASA is a government agency and intuition would lead us to think that NASA and government-focused projects would not be significantly different from each other, but both might be different from commercial-focused projects. One possible explanation for this result might be due to the nature of the projects NASA works on relative to government-focused projects in the commercial organization. For example, NASA often develops projects that are novel in the technical field and will never be reproduced, such as the Space Launch System.

Table 7. Tukey HSD: Project Description Variables Organization Effect

\begin{tabular}{|l|c|r|r|}
\hline \multicolumn{2}{|c|}{$\alpha=0.05$} & \multicolumn{2}{c|}{$Q=2.36365$} \\
\hline Level & \multicolumn{2}{|c|}{ Letter } & Least Sq. Mean \\
\hline Commercial & A & & 3.48 \\
\hline NASA & A & & 3.42 \\
\hline Government & & B & 3.20 \\
\hline
\end{tabular}

Levels not connected by the same letter are significantly different 
The next hypothesis examined tested for statistically significant question effects among the four questions in the Project Description Variables section. Using an $\alpha=$ 0.05 , we reject the null hypothesis and say there are statistically significant question effects among the Project Description Variables. However, this p-value is just barely under $\alpha=0.05$, so extreme differences in this question effect are not anticipated.

$$
\begin{array}{ll}
\mathrm{H}_{0}: \text { all Question effects }=0 & \mathrm{~F}=2.6303 \\
\mathrm{H}_{\mathrm{a}}: \text { at least one Question effect } \neq 0 & \mathrm{P} \text {-value }=0.0494
\end{array}
$$

A multiple comparison procedure looking at the least squared means differences using Tukey HSD is illustrated in table 8 for identifying the differences among questions in the Project Description Variables section. Fewer significant differences were identified here; schedule risk and technical risk differ by less than 0.2 using a Tukey HSD. Therefore at this time, we are only able to identify a significant difference between schedule risk and technical risk. It makes sense that schedule risk and technical risk are significantly different from each other because they are two very different types of risk. However, they are still related. Generally, a higher technical risk equates with more schedule risk since technically risky projects can be time consuming. The reason why participants may have felt their projects had a higher schedule risk than technical risk is because all 180 participants in this study are working on complex projects. Participants are more comfortable working through the technical aspects of a project than having to stay on schedule. What this shows, is there continues to be an opportunity for improvement in project success relative to schedule. Each of these four questions appeared to be answered in the same manner, which is logical since three out of the four questions were asking about the project's risk. 
Table 8. Tukey HSD: Project Description Variables Question Effect

\begin{tabular}{|l|c|c|r|}
\hline \multicolumn{1}{|c|}{$\alpha=0.05$} & \multicolumn{3}{c|}{$\mathrm{Q}=2.57723$} \\
\hline \multicolumn{1}{|c|}{ Level } & \multicolumn{2}{|c|}{ Letter } & Least Sq. Mean \\
\hline 4. Schedule Risk & A & & 3.45 \\
\hline 1. Relevant Scope of Work & A & B & 3.37 \\
\hline 3. Budgetary Risk & A & B & 3.37 \\
\hline 2. Technical Risk & & B & 3.28 \\
\hline
\end{tabular}

Levels not connected by the same letter are significantly different

The final hypothesis examined for the Project Description Variables section tests if there was a statistically significant interaction effect among the organization type and questions. Using an $\alpha=0.05$, we fail reject the null hypothesis and say there is not a statistically significant interaction effect. Due to the lack of statistical significance, we can conclude there is no need to follow up with a multiple comparison procedure.

$$
\begin{array}{ll}
\mathrm{H}_{0}: \text { all Organization*Question effects }=0 & \mathrm{~F}=1.8841 \\
\mathrm{H}_{\mathrm{a}} \text { : at least one Organization*Question effect } \neq 0 & \text { P-value }=0.0816
\end{array}
$$

The Project Description question section produced a low mean square error (0.328769), indicating blocking on "Question" was effective and treatment differences were easier to detect. To summarize this section, statistically significant differences were detected among organization type and questions, but no statistically significant interaction effect between organization type and question was detected.

The second ANOVA table corresponds to section 3 of the data collection instrument, referring to the Project Success Metrics section and is shown in table 9. All three null hypotheses in the Project Success Metrics section are rejected. A statistically significant organization effect, question effect, and interaction effect are detected. A Tukey HSD will show NASA and commercial organizations to be significantly different 
from each other in the organizations effect test. The Tukey HSD for question effects indicated questions $8,2,9,1$ to not be significantly different from each other, questions 6 , 7, and 4 to not be significantly different from each other, and questions 5 and 3 to not be significantly different from each other. When looking at the interaction effect using the Least Squared Means Plot for the Project Success Metrics section, questions 7 - 9 appear to trend more inconsistently relative to the other questions for their respective organization.

Table 9. ANOVA Table: Project Success Metrics

\begin{tabular}{|l|r|r|r|r|r|}
\hline Source & DF & $\begin{array}{r}\text { Sum of } \\
\text { Squares }\end{array}$ & $\begin{array}{r}\text { Mean } \\
\text { Square }\end{array}$ & F Ratio & Prob. $>$ F \\
\hline Organization & 2 & 24.987128 & 12.4936 & 4.2828 & 0.0153 \\
\hline Question - Project Success Metrics & 8 & 81.9556 & 10.2445 & 39.6525 & $<0.0001$ \\
\hline Organization*Question Interaction & 16 & 8.2799 & 0.517494 & 2.0030 & 0.0105 \\
\hline Participant[Organization]\&Random & 177 & 516.3392 & 2.91717 & 11.2913 & $<0.0001$ \\
\hline & & & & & \\
\hline Model & 203 & 644.7175 & 3.17595 & 12.2929 & $<0.0001$ \\
\hline Error & 1416 & 365.8311 & 0.25836 & & \\
\hline C. Total & 1619 & 1010.5486 & & & \\
\hline
\end{tabular}

The first hypothesis examined tested if there were any statistically significant organization effects among the Project Success Metrics questions. Using an $\alpha=0.05$, we reject the null hypothesis and say there are statistically significant organization effects.

$$
\begin{array}{ll}
\mathrm{H}_{0}: \text { all Organization effects }=0 & \mathrm{~F}=4.2828 \\
\mathrm{H}_{\mathrm{a}}: \text { at least one Organization effect } \neq 0 & \text { P-value }=0.0153
\end{array}
$$

By rejecting the null hypothesis, a multiple comparison procedure examining the least squared means differences using a Tukey HSD was conducted, and is illustrated in table 10. No differences were identified between government-focused projects and 
commercial-focused projects in the commercial organization or between NASA and government-focused projects in the commercial organizations. However, NASA was found to be significantly different from commercial-focused projects with regard to participant responses to the Project Success Metrics questions.

Table 10. Tukey HSD: Project Success Metrics Organization Effect

\begin{tabular}{|l|c|c|r|r|}
\hline \multicolumn{2}{|c|}{$\alpha=0.05$} & \multicolumn{2}{c|}{$\mathrm{Q}=2.36365$} \\
\hline Level & \multicolumn{2}{|c|}{ Letter } & Least Sq. Mean \\
\hline NASA & A & & 3.20 \\
\hline Government & A & B & 3.06 \\
\hline Commercial & & B & 2.91 \\
\hline
\end{tabular}

Levels not connected by the same letter are significantly different

The next two hypotheses examined tested for statistically significant question effects among the Project Success Metrics section. A question effect was first tested in the Project Success Metrics section. Using an $\alpha=0.05$, we reject the null hypothesis and say there are statistically significant Question effects in the Project Success Metrics section.

$$
\begin{array}{ll}
\mathrm{H}_{0}: \text { all Question effects }=0 & \mathrm{~F}=39.6535 \\
\mathrm{H}_{\mathrm{a}}: \text { at least one Question effect } \neq 0 & \mathrm{P} \text {-value }=<0.0001
\end{array}
$$

A multiple comparison procedure looking at the least squared means differences using a Tukey HSD is illustrated in table 11. Questions 8, 2, 9, and 1 do not have identifiable differences from each other. It is logical that the participants placed the most value on these metrics since these four questions are looking at the project from a higher level and are validating that the correct project was done correctly. Questions 6, 7, and 4 are not significantly different from each other. Participants appeared to place less value on 
budget and schedule relative to similar projects, as well as satisfaction with the project management process when determining a project's success. Finally, being on budget and schedule relative to the original project plan appeared to hold somewhat little value to participants when examining metrics from what defines a project's success. This is most likely due to the well know assumption that projects often go over budget and past schedule relative to their initial parameters. What is more interesting, is that these results also show little regard for trying to stay on budget and schedule relative to the original project plan by the engineers working on the project. This suggests either budget and schedule need to be more realistically outlined at the beginning of a project's lifecycle or the engineers on these projects need to modify their current strategies to better work to meet original budget and schedule guidelines. A final note on table 11 suggests how the organizations cleanly separated the project success metrics into three categories of what they value at a high, medium, and low level.

Table 11. Tukey HSD: Project Success Metrics Question Effect

\begin{tabular}{|l|l|l|r|r|}
\hline \multicolumn{1}{|c|}{$\alpha=0.05$} & \multicolumn{3}{c|}{$\mathrm{Q}=3.10657$} \\
\hline Level & \multicolumn{2}{|c|}{ Letter } & Least Sq. Mean \\
\hline 8. Overall project success (organization view) & A & & & 3.32 \\
\hline 2. Technical success relative to similar projects & A & & 3.31 \\
\hline 9. Overall project success (stakeholder view) & A & & & 3.30 \\
\hline 1. Technical success relative to initial requirements & A & & & 3.26 \\
\hline 6. On budget relative to similar projects & & B & & 3.02 \\
\hline 7. Satisfaction with project management process & & B & & 2.96 \\
\hline 4. On schedule relative to similar projects & & B & & 2.92 \\
\hline 5. On budget relative to original project plan & & & C & 2.74 \\
\hline 3. On schedule relative to original project plan & & & C & 2.71 \\
\hline
\end{tabular}

Levels not connected by the same letter are significantly different 
The final hypothesis examined for the Project Success Metrics question section tested if there was a statistically significant interaction effect between question and organization. Using an $\alpha=0.05$, we reject the null hypothesis and say there are statistically significant interaction effects.

$$
\begin{array}{ll}
\mathrm{H}_{0}: \text { all Organization*Question effects }=0 & \mathrm{~F}=2.0030 \\
\mathrm{H}_{\mathrm{a}} \text { : at least one Organization*Question effect } \neq 0 & \text { P-value }=0.0105
\end{array}
$$

When examining statistically significant interaction effects, we will not follow up with a Tukey HSD since a Tukey HSD looks at treatment effects and not interaction. We want to see if organizations are responding to the Project Description Questions in a similar fashion. Therefore we want to look at the Least Squared Means Plot illustrated in figure 11 , where government $=1$, commercial $=2$, and NASA $=3$. All three organizations appear to answer questions $1-6$ consistently. Questions $7-9$ appear to lack consistency within question response, especially between organizations 1 and 2, government and commercial respectively. In regard to question 7 , looking at if the project management process used was effective, NASA appeared to agree that on their projects, the project management process used was effective. Government and commercial project organizations appear to slightly disagree. Furthermore, NASA also felt more strongly about their organization and stakeholders viewing their projects as successful versus government-focused projects and commercial-focused projects commercial organizations. 


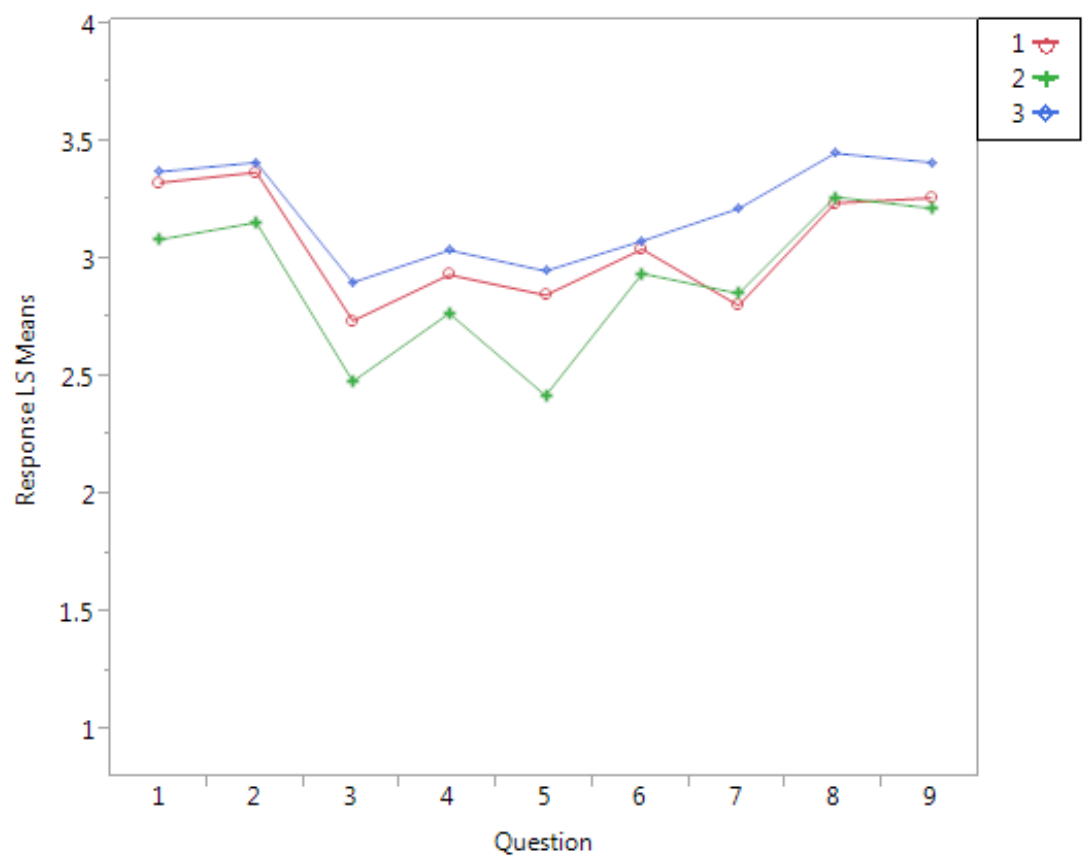

Figure 11. Project Success Metrics Least Squared Means Plot: Interaction Effect

The Project Success Metrics question section produced a low mean square error (0.25836), indicating blocking on "question" was effective and treatment differences were easier to detect. To summarize, in the Project Success Metrics section, an organization effect, question effect, and interaction effect were all discovered when using data from all 180 participants. A Tukey HSD found NASA and commercial-focused projects commercial organization to be significantly different from each other, a second Tukey HSD cleanly separated the Project Success Metrics questions into high, medium, and low-leveled values, and a Least Squared Means Plot found an interesting interaction effect occurring among question $7-9$.

The third ANOVA table corresponds to section 4 of the data collection instrument, referring the 17 Systems Engineering Processes section and is shown in table 12. Here a statistically significant effect is found among organizations, questions, and the 
organization and question interaction. Through the Tukey HSD follow up, NASA is significantly different from commercial-focused projects and government-focused projects in commercial organizations. Several significant differences are discovered among the 17 Systems Engineering Processes by using a Tukey HSD, and interesting discoveries are made looking at the Least Squared Means Plot for detecting interactions.

Table 12. ANOVA Table: Systems Engineering Processes

\begin{tabular}{|l|r|r|r|r|r|}
\hline Source & DF & $\begin{array}{r}\text { Sum of } \\
\text { Squares }\end{array}$ & $\begin{array}{r}\text { Mean } \\
\text { Square }\end{array}$ & F Ratio & Prob. $>$ F \\
\hline Organization & 2 & 49.600137 & 24.8001 & 8.1729 & 0.0004 \\
\hline $\begin{array}{l}\text { Question - Systems Engineering } \\
\text { Processes }\end{array}$ & 16 & 49.172887 & 3.7331 & 10.1124 & $<0.0001$ \\
\hline Organization*Question Interaction & 32 & 19.110890 & 0.597215 & 1.9651 & 0.0010 \\
\hline Participant[Organization]\&Random & 177 & 537.0984 & 3.03445 & 9.9845 & $<0.0001$ \\
\hline & & & & & \\
\hline Model & 227 & 666.8620 & 2.93772 & 9.6662 & $<0.0001$ \\
\hline Error & 2832 & 860.6880 & 0.30392 & & \\
\hline C. Total & 3059 & 1527.5499 & & & \\
\hline
\end{tabular}

The first hypothesis examined if there were any statistically significant organization effects among the Systems Engineering Processes section. Using an $\alpha=0.05$, we reject the null hypothesis and say there are statistically significant organization effects in the Systems Engineering Processes section.

$$
\begin{array}{ll}
\mathrm{H}_{0}: \text { all Organization effects }=0 & \mathrm{~F}=8.1729 \\
\mathrm{H}_{\mathrm{a}} \text { : at least one Organization effect } \neq 0 & \text { P-value }=0.0004
\end{array}
$$

By rejecting the null hypothesis, a multiple comparison procedure examining the least squared means differences using a Tukey HSD was conducted, and is illustrated in table 13. No differences were identified between government and commercial organizations. 
However, NASA was significantly different from both government and commercial organizations. This difference indicates that NASA places a higher value on the systems engineering processes for a project than either commercial-focused projects or government-focused projects in commercial organizations do.

Table 13. Tukey HSD: Systems Engineering Processes Organization Effect

\begin{tabular}{|l|c|l|r|}
\hline \multicolumn{2}{|c|}{$\alpha=0.05$} & \multicolumn{2}{c|}{$\mathrm{Q}=2.36365$} \\
\hline Level & \multicolumn{1}{|c|}{ Letter } & Least Sq. Mean \\
\hline NASA & A & & 3.36 \\
\hline Commercial & & B & 3.08 \\
\hline Government & & B & 3.07 \\
\hline
\end{tabular}

Levels not connected by the same letter are significantly different

The second hypothesis examined tested for statistically significant question effects in the Systems Engineering Processes section. Using an $\alpha=0.05$, we reject the null hypothesis and say there are statistically significant question effects in the Systems Engineering Processes section.

$$
\begin{array}{ll}
\mathrm{H}_{0}: \text { all Question effects }=0 & \mathrm{~F}=10.1124 \\
\mathrm{H}_{\mathrm{a}} \text { : at least one Question effect } \neq 0 & \text { P-value }=<0.0001
\end{array}
$$

Table 14 follows up with a multiple comparison procedure looking at the Least Squared Means Differences using Tukey HSD. Participants most strongly agreed processes: 7, 5, $8,4,9,15,6$, and 14 were completed. These processes were not significantly different from each other. This might mean at NASA, for example, the duties associated with these processes should fall to the same branch chief if the project is small or a set of branch chiefs who are able to closely work together if the project is large. Processes: 7, 
$5,8,4,9,15,6$, and 14 were significantly different from processes: $11,1,13,2,16$, and 10, as well as processes: $13,2,16,10,17$, and 3. Participants appeared to feel processes: $13,2,16,10,17$, and 3 were completed with less emphasis than other processes.

Table 14. Tukey HSD: Systems Engineering Processes Question Effect

\begin{tabular}{|l|c|c|c|c|c|r|}
\hline \multicolumn{1}{|c|}{$\alpha=0.05$} & \multicolumn{5}{c|}{ Q $=3.46162$} \\
\hline \multicolumn{1}{|c|}{ Level } & \multicolumn{3}{|c|}{ Letter } & Least Sq. Mean \\
\hline 7. Product Verification & $\mathrm{A}$ & & & & & 3.41 \\
\hline 5. Product Implementation & $\mathrm{A}$ & $\mathrm{B}$ & & & & 3.29 \\
\hline 8. Production Validation & $\mathrm{A}$ & $\mathrm{B}$ & & & & 3.29 \\
\hline 4. Design Solution & $\mathrm{A}$ & $\mathrm{B}$ & & & & 3.28 \\
\hline 9. Product Transition & $\mathrm{A}$ & $\mathrm{B}$ & $\mathrm{C}$ & & & 3.26 \\
\hline 15. Technical Data Management & $\mathrm{A}$ & $\mathrm{B}$ & $\mathrm{C}$ & & & 3.25 \\
\hline 6. Product Integration & $\mathrm{A}$ & $\mathrm{B}$ & $\mathrm{C}$ & & & 3.24 \\
\hline 14. Configuration Management & $\mathrm{A}$ & $\mathrm{B}$ & $\mathrm{C}$ & & & 3.23 \\
\hline 12. Interface Management & & $\mathrm{B}$ & $\mathrm{C}$ & & & 3.19 \\
\hline 11. Requirements Management & & $\mathrm{B}$ & $\mathrm{C}$ & $\mathrm{D}$ & & 3.16 \\
\hline 1. Stakeholder Expectations Definition & & $\mathrm{B}$ & $\mathrm{C}$ & $\mathrm{D}$ & & 3.16 \\
\hline 13. Technical Risk Management & & $\mathrm{B}$ & $\mathrm{C}$ & $\mathrm{D}$ & $\mathrm{E}$ & 3.10 \\
\hline 2. Technical Requirements Definition & & $\mathrm{B}$ & $\mathrm{C}$ & $\mathrm{D}$ & $\mathrm{E}$ & 3.09 \\
\hline 16. Technical Assessment & & & $\mathrm{C}$ & $\mathrm{D}$ & $\mathrm{E}$ & 3.07 \\
\hline 10. Technical Planning & & & & $\mathrm{D}$ & $\mathrm{E}$ & 2.97 \\
\hline 17. Decision Analysis & & & & & $\mathrm{E}$ & 2.94 \\
\hline 3. Logical Decomposition & & & & & $\mathrm{E}$ & 2.93 \\
\hline
\end{tabular}

Levels not connected by the same letter are significantly different

The final hypothesis examined for the Systems Engineering Processes question section tested for statistically significant interaction effect among questions and organization types. Using an $\alpha=0.05$, we reject the null hypothesis and say there are statistically significant interaction effects. Again, to see if organizations are responding to the Systems Engineering Processes Questions in a similar fashion, we look at the 
Lease Squared Means Plot in figure 13, where government $=1$, commercial $=2$, and $\mathrm{NASA}=3$.
$\mathrm{H}_{0}$ : all Organization*Question effects $=0$
$\mathrm{F}=1.9651$
$\mathrm{H}_{\mathrm{a}}$ : at least one Organization*Question effect $\neq 0$
$\mathrm{P}$-value $=0.0010$

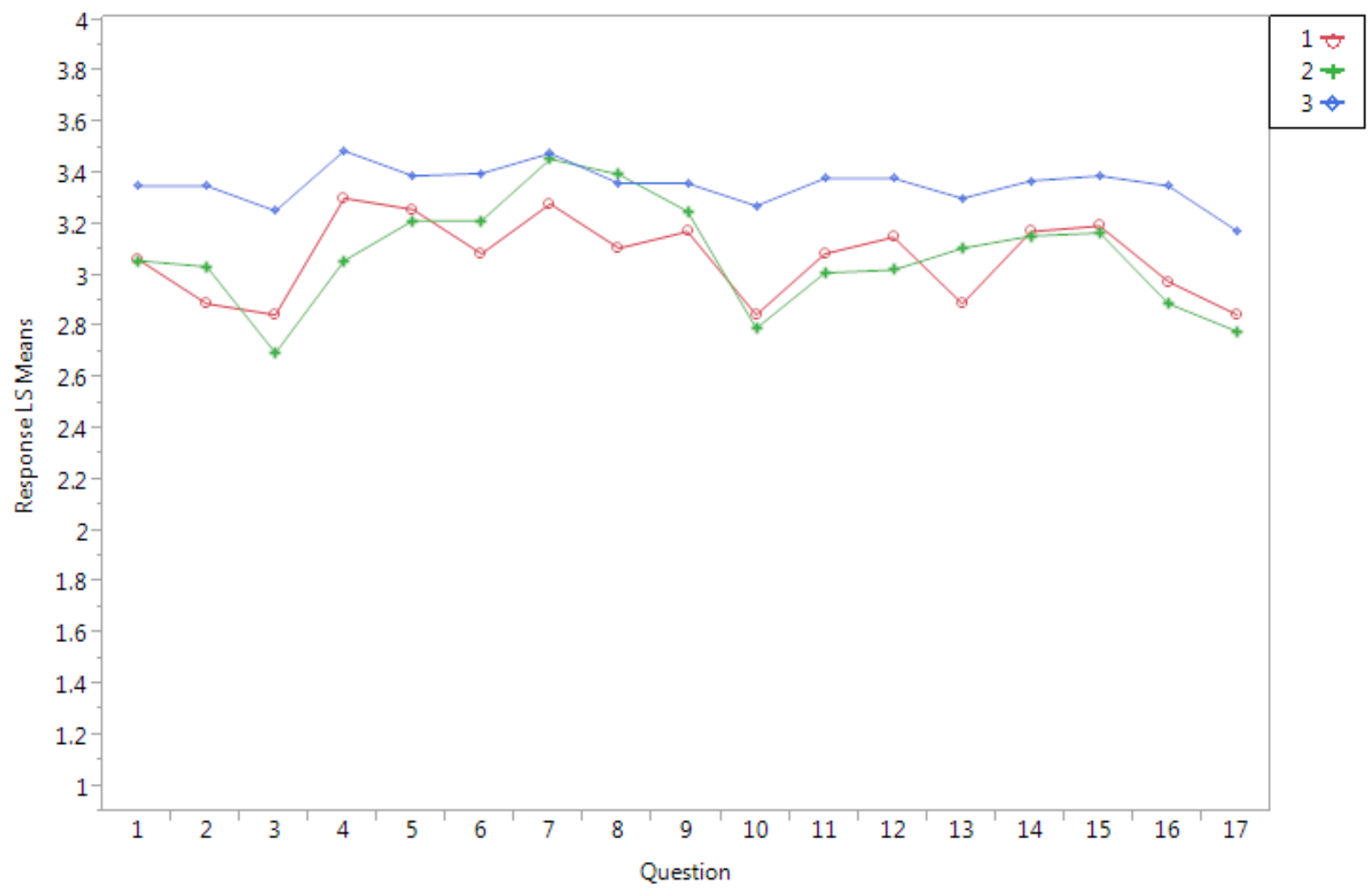

\section{Figure 12. Systems Engineering Processes Least Squared Means Plot: Interaction Effect}

The Systems Engineering Processes question section produced a low mean square error (0.30392), indicating blocking on "question" was effective and treatment differences were easy to detect. In figure 12, NASA engineers rated themselves as generally, more successful at completing the 17 systems engineering processes than commercial-focused projects and government-focused projects in commercial organizations do. However, 
overall trends appeared as well. All three organizations felt least confident in processes 3, 10, and 17, logical decomposition, technical planning, and decision analysis, respectively. Processes 4 and 7, design solution definition and product verification respectively seemed to generally receive the highest ratings from the three organizations. Finally, figure 13 showed NASA to be most consistent in how they approached the 17 systems engineering processes. Government (1) and commercial (2) organizations' projects appeared to have quite a bit of variability in how they approach the systems engineering processes. Organization 2, the commercial organization, showed some notable peaks and valleys in the processes they feel they do well at and do not do well at. This might be due to the variety of commercial-focused projects being done. Government-focused commercial organization projects (1) also had some notable peaks and valleys across the processes as well, but not as many as commercial-focused projects in commercial organizations (2). This is most likely due to projects needing to be more standardized with government projects where commercial-focused projects are more able to choose which processes to place emphasis on when conducting their projects.

To summarize, significant differences were detected among organization effect, question effect, and organization and question interaction effect in the Systems Engineering Processes section when using data from all 180 participants from the three organization types. Regarding the organization effect, a Tukey HSD found NASA to be significantly different from commercial and government organizations. Multiple observations were made using the Tukey HSD for question effect and the Least Squared Means Plot for interaction effect. Table 15 summarizes all hypotheses tested in this section. 
Table 15. ANOVA Summary Testing All 180 Participants

\begin{tabular}{|l|l|l|l|}
\hline \multicolumn{1}{|c|}{ Section } & \multicolumn{1}{|c|}{ Hypothesis } & P-value & F Ratio \\
\hline $\begin{array}{l}\text { Project Description } \\
\text { Variables }\end{array}$ & $\begin{array}{l}\mathrm{H}_{0}: \text { all Organization effects }=0 \\
\mathrm{H}_{\mathrm{a}}: \text { at least one Organization effect } \neq 0\end{array}$ & 0.0033 & 5.8984 \\
\hline $\begin{array}{l}\text { Project Description } \\
\text { Variables }\end{array}$ & $\begin{array}{l}\mathrm{H}_{0}: \text { all Question effects }=0 \\
\mathrm{H}_{\mathrm{a}}: \text { at least one Question effect } \neq 0\end{array}$ & 0.0494 & 2.6303 \\
\hline $\begin{array}{l}\text { Project Description } \\
\text { Variables }\end{array}$ & $\begin{array}{l}\mathrm{H}_{0}: \text { all Organization*Question effects }=0 \\
\mathrm{H}_{\mathrm{a}}: \text { at least one Organization*Question effect } \neq 0\end{array}$ & 0.0816 & 1.8841 \\
\hline $\begin{array}{l}\text { Project Success } \\
\text { Metrics }\end{array}$ & $\begin{array}{l}\mathrm{H}_{0}: \text { all Organization effects }=0 \\
\mathrm{H}_{\mathrm{a}}: \text { at least one Organization effect } \neq 0\end{array}$ & 0.0153 & 4.2828 \\
\hline $\begin{array}{l}\text { Project Success } \\
\text { Metrics }\end{array}$ & $\begin{array}{l}\mathrm{H}_{0}: \text { all Question effects }=0 \\
\mathrm{H}_{\mathrm{a}}: \text { at least one Question effect } \neq 0\end{array}$ & $<0.0001$ & 39.6535 \\
\hline $\begin{array}{l}\text { Project Success } \\
\text { Metrics }\end{array}$ & $\begin{array}{l}\mathrm{H}_{0}: \text { all Organization*Question effects }=0 \\
\mathrm{H}_{\mathrm{a}}: \text { at least one Organization*Question effect } \neq 0\end{array}$ & 0.0105 & 2.0030 \\
\hline $\begin{array}{l}\text { Systems } \\
\text { Engineering } \\
\text { Processes }\end{array}$ & $\begin{array}{l}\mathrm{H}_{0}: \text { all Organization effects }=0 \\
\mathrm{H}_{\mathrm{a}}: \text { at least one Organization effect } \neq 0\end{array}$ & 0.0004 & 8.1729 \\
\hline $\begin{array}{l}\text { Systems } \\
\text { Engineering } \\
\text { Processes }\end{array}$ & $\begin{array}{l}\mathrm{H}_{0}: \text { all Question effects }=0 \\
\mathrm{H}_{\mathrm{a}}: \text { at least one Question effect } \neq 0\end{array}$ & $<0.0001$ & 10.1124 \\
\hline $\begin{array}{l}\text { Systems } \\
\text { Engineering } \\
\text { Processes }\end{array}$ & $\begin{array}{l}\mathrm{H}_{0}: \text { all Organization*Question effects }=0 \\
\mathrm{H}_{\mathrm{a}}: \text { at least one Organization*Question effect } \neq 0\end{array}$ & 0.0010 & 1.9651 \\
\hline
\end{tabular}

\section{ANOVA tables testing government, commercial, and NASA separately}

The third section of the data analysis uses one-way ANOVA tables to identify questions differences at an individual organization level. The three organizations are government-contracted projects, commercial-contracted projects, and NASA projects. The ANOVA tables used sections 2, 3, 4, and 6, Project Description Variables, Project Success Metrics, Systems Engineering Processes, and Non-Technical Variables, respectively from the data collection instrument. Each ANOVA table only contains the participants from each respective organization being tested. The government-focused 
projects' organization contains 46 participants, the commercial-focused projects' organization contains 83 participants, and NASA contains 51 participants.

The first set of ANOVA tables corresponds to section 2 of the data collection instrument, referring to Project Description Variables. In this set of ANOVA tables, we will see statistically significant differences were not detected within government-focused projects or NASA projects, but statistically significant differences were detected in commercial-focused projects.

The first hypothesis tests for government-contracted projects' question effects in the Project Description Variables section and refers to table 16.

\section{Table 16. ANOVA Table: Government-Focused Projects - Project Description Variables}

\begin{tabular}{|l|r|r|r|r|r|}
\hline Source & DF & $\begin{array}{r}\text { Sum of } \\
\text { Squares }\end{array}$ & $\begin{array}{r}\text { Mean } \\
\text { Square }\end{array}$ & F Ratio & Prob. $>$ F \\
\hline $\begin{array}{l}\text { Question - Project Description } \\
\text { Variables }\end{array}$ & 3 & 3.21739 & 1.07246 & 2.6190 & 0.0535 \\
\hline Participants - Government & 45 & 40.4565 & 0.89903 & 2.1954 & 0.0003 \\
\hline & & & & & \\
\hline Model & 48 & 43.673913 & 0.909873 & 2.2219 & 0.0002 \\
\hline Error & 135 & 55.282609 & 0.409501 & & \\
\hline C. Total & 183 & 98.956522 & & & \\
\hline
\end{tabular}

The hypothesis tests whether there are any statistically significant question effects among the four questions in the Project Description Variables section. Using an $\alpha=0.05$, we fail to reject the null hypothesis and say there are not any statistically significant question effects among the questions in the Project Description Variables section for governmentcontracted projects. 


$$
\begin{array}{ll}
\mathrm{H}_{0}: \text { all Question effects }=0 & \mathrm{~F}=2.6190 \\
\mathrm{H}_{\mathrm{a}}: \text { at least one Question effect } \neq 0 & \text { P-value }=0.0535
\end{array}
$$

Due to the lack of support for any significant differences, a Tukey HSD is not necessary for seeking additional information on question effects for this test. The Project Description Variables question section produced a low mean square error (0.409501), indicating blocking on "question" was effective and treatment differences were easy to detect for the government-focused projects in commercial organizations.

The second hypothesis tests for statistically significant question effects among the Project Description Variables section for the commercial-focused projects' organization. The ANOVA table shown in table 17 is used to test the question effects hypothesis.

Table 17. ANOVA Table: Commercial-Focused Projects Project Description Variables

\begin{tabular}{|l|r|r|r|r|r|}
\hline Source & DF & $\begin{array}{r}\text { Sum of } \\
\text { Squares }\end{array}$ & $\begin{array}{r}\text { Mean } \\
\text { Square }\end{array}$ & F Ratio & Prob. $>$ F \\
\hline $\begin{array}{l}\text { Question - Project Description } \\
\text { Variables }\end{array}$ & 3 & 2.80422 & 0.93474 & 2.8944 & 0.0359 \\
\hline Participants - Commercial & 82 & 62.6747 & 0.76433 & 2.3667 & $<0.0001$ \\
\hline & & & & & \\
\hline Model & 85 & 65.47892 & 0.770340 & 2.853 & $<0.0001$ \\
\hline Error & 246 & 79.44578 & 0.322950 & & \\
\hline C. Total & 331 & 144.92470 & & & \\
\hline
\end{tabular}

By using an $\alpha=0.05$, we reject the null hypothesis and say there are statistically significant differences among the four Project Description Variables questions for the commercial-contracted questions. 


$$
\begin{array}{ll}
\mathrm{H}_{0}: \text { all Question effects }=0 & \mathrm{~F}=2.8944 \\
\mathrm{H}_{\mathrm{a}}: \text { at least one Question effect } \neq 0 & \mathrm{P} \text {-value }=0.0359
\end{array}
$$

A multiple comparisons procedure looking at the least squared means differences is then conducted using a Tukey HSD and shown in table 18.

\section{Table 18. Tukey HSD: Commercial-Focused Projects - Project Description Variables Question Effect}

\begin{tabular}{|l|c|c|r|}
\hline \multicolumn{1}{|c|}{$\propto=0.50$} & \multicolumn{3}{c|}{$\mathrm{Q}=2.5867$} \\
\hline Level & \multicolumn{2}{|c|}{ Letter } & Least Sq. Mean \\
\hline 4. Schedule Risk & A & & 3.59 \\
\hline 3. Budgetary Risk & A & B & 3.55 \\
\hline 2. Technical Risk & A & B & 3.43 \\
\hline 1. Relevant Scope of Work & & B & 3.36 \\
\hline
\end{tabular}

Levels not connected by the same letter are significantly different

Questions 4 and 1 are the only questions that can be identified as significantly different from each other. However, these results differ from the results in table 8, looking at Project Description Variables question effects among all 180 institutions. In table 8, questions 4 and 2 were significantly different from each other, with question 2 receiving the lowest value. However, at the organizational level, for commercial-focused projects, relevant scope of work is least important. The Project Description Variables question section produced a low mean square error (0.322950) indicating blocking on "Question" was effective and treatment differences were easy to detect for the commercial-focused projects in commercial organizations. 
The final hypothesis examined for the Project Description Variables section tests whether there are any statistically significant question effects among NASA projects in the Project Description Variables section. Table 19 illustrates the results from the NASA projects for the Project Description Variables section.

Table 19. ANOVA Table: NASA Project Description Variables

\begin{tabular}{|l|r|r|r|r|r|}
\hline Source & DF & $\begin{array}{r}\text { Sum of } \\
\text { Squares }\end{array}$ & $\begin{array}{r}\text { Mean } \\
\text { Square }\end{array}$ & F Ratio & Prob. $>$ F \\
\hline $\begin{array}{l}\text { Question - Project Description } \\
\text { Variables }\end{array}$ & 3 & 0.40196 & 0.13399 & 0.5044 & 0.6798 \\
\hline Participants - NASA & 50 & 48.9951 & 0.9799 & 3.6886 & $<0.0001$ \\
\hline & & & & & \\
\hline Model & 53 & 49.397059 & 0.932020 & 3.5084 & $<0.0001$ \\
\hline Error & 150 & 39.848039 & 0.265654 & & \\
\hline C. Total & 203 & 89.245098 & & & \\
\hline
\end{tabular}

Using an $\alpha=0.05$, we fail to reject the null hypothesis and say there are no statistically significant differences among the four Project Description Variables question for NASA projects.

$$
\begin{array}{ll}
\mathrm{H}_{0}: \text { all Question effects }=0 & \mathrm{~F}=0.5044 \\
\mathrm{H}_{\mathrm{a}} \text { : at least one Question effect } \neq 0 & \mathrm{P} \text {-value }=0.6798
\end{array}
$$

This indicates that the NASA engineers who participated in the study answered all four questions in the Project Description Variables questions in a similar manner. Therefore, due to the lack of support for any significant differences, a Tukey HSD is not necessary for seeking additional information on question effects for this test. The Project Description Variables question section produced a low mean square error $(0.265654)$ 
indicating blocking on "question" was effective and treatment differences were easy to detect for the NASA Agency organization.

To summarize the findings from the Project Description Variables section testing for statistically significant differences among organization question effects, statistically significant differences were detected among the questions in the commercial-focused projects but not the government-focused projects or NASA projects. A Tukey HSD was used to identify the least squared means differences among the questions for the commercial-focused projects, and questions 4 and 1 were identified as significantly different.

The second set of tables are used to test for statistically significant question effects for the Project Success Metrics section at an organization level. In this set of ANOVA tables, we will see statistically significant differences were detected within government-focused projects, commercial-focused projects, and NASA projects.

The first ANOVA table testing for statistically significant question effects in the Project Success Metrics section looks at government-focused projects and is seen in table 20.

Table 20. ANOVA Table: Government-Focused Projects - Project Success Metrics

\begin{tabular}{|l|r|r|r|r|r|}
\hline Source & DF & $\begin{array}{r}\text { Sum of } \\
\text { Squares }\end{array}$ & $\begin{array}{r}\text { Mean } \\
\text { Square }\end{array}$ & F Ratio & Prob. $>$ F \\
\hline $\begin{array}{l}\text { Question - Project Success } \\
\text { Metrics }\end{array}$ & 8 & 21.5411 & 2.69263 & 10.1428 & $<0.0001$ \\
\hline Participants - Government & 45 & 105.256 & 2.33902 & 8.8108 & $<0.0001$ \\
\hline & & & & & \\
\hline Model & 53 & 126.79710 & 2.39240 & 9.0119 & $<0.0001$ \\
\hline Error & 360 & 95.57005 & 0.36547 & & \\
\hline C. Total & 413 & 222.36715 & & & \\
\hline
\end{tabular}


Using an $\alpha=0.05$, we reject the null hypothesis and say there are statistically significant differences among the nine questions in the Project Success Metrics section for government-focused projects.

$$
\begin{array}{ll}
\mathrm{H}_{0}: \text { all Question effects }=0 & \mathrm{~F}=10.1428 \\
\mathrm{H}_{\mathrm{a}}: \text { at least one Question effect } \neq 0 & \text { P-value }=<0.0001
\end{array}
$$

A multiple comparison procedure looking at the least squared means differences using a Tukey HSD is illustrated in table 21.

Table 21. Tukey HSD: Government-Focused Projects Project Success Metrics Question Effect

\begin{tabular}{|l|l|l|l|r|}
\hline \multicolumn{1}{|c|}{$\propto=0.50$} & \multicolumn{5}{c|}{$\mathrm{Q}=3.12078$} \\
\hline \multicolumn{1}{|c|}{ Level } & \multicolumn{2}{c|}{ Letter } & Least Sq. Mean \\
\hline 2. Technical success relative to similar projects & A & & & 3.33 \\
\hline 1. Technical success relative to initial requirements & A & & & 3.26 \\
\hline 9. Overall project success (stakeholder view) & A & B & & 3.24 \\
\hline 8. Overall project success (organization view) & A & B & & 3.24 \\
\hline 6. On budget relative to similar projects & A & B & C & 3.04 \\
\hline 4. On schedule relative to similar projects & & B & C & 2.94 \\
\hline 5. On budget relative to original project plan & & & C & 2.85 \\
\hline 7. Satisfaction with project management process & & & C & 2.80 \\
\hline 3. On schedule relative to original project plan & & & C & 2.74 \\
\hline
\end{tabular}

Levels not connected by the same letter are significantly different

Immediately, we see that table 21 does not identify significant differences as definitively as table 11 did when all 180 organizations were tested. In table 21, questions 2, 1, 9, and 8 are significantly different from questions $4,5,7$, and 3. The significant differences among questions are still quite similar to the significant differences identified for all 180 institutions in table 11. However, the results in table 21 are not as conclusive. The most notable takeaway is the similarity between table 11 and table 21. At an overall level, 
table 11 showed us how little value participants place on budget and schedule relative to the original project plan regardless of the organization type. What is most important is overall project success and overall technical success. Engineers working on governmentfocused projects see value in the project being completed correctly relative to the technical requirements, and these values translate across other organization types. The Project Success Metrics question section produced a low mean square error $(0.36547)$ indicating blocking on "question" was effective and treatment differences were easy to detect for the government-focused projects in commercial organizations.

The second ANOVA table in tests whether there is any statistically significant differences among the nine questions in the Project Success Metrics section for commercial-contracted projects. Table 22 illustrates these results.

Table 22. ANOVA Table: Commercial-Focused Projects - Project Success Metrics

\begin{tabular}{|l|r|r|r|r|r|}
\hline Source & DF & $\begin{array}{r}\text { Sum of } \\
\text { Squares }\end{array}$ & $\begin{array}{r}\text { Mean } \\
\text { Square }\end{array}$ & F Ratio & Prob. $>$ F \\
\hline $\begin{array}{l}\text { Question - Project Success } \\
\text { Metrics }\end{array}$ & 8 & 62.7738 & 7.84672 & 26.3966 & $<0.0001$ \\
\hline Participants - Commercial & 82 & 257.213 & 3.13674 & 10.5521 & $<0.0001$ \\
\hline & & & & & \\
\hline Model & 90 & 319.98661 & 3.55541 & 11.9605 & $<0.0001$ \\
\hline Error & 656 & 195.00402 & 0.29726 & & \\
\hline C. Total & 746 & 514.99063 & & & \\
\hline
\end{tabular}


Using an $\alpha=0.05$, we reject the null hypothesis and say there are statistically significant differences among question effects for the commercial-focused projects in the Project Success Metrics section.

$$
\begin{array}{ll}
\mathrm{H}_{0}: \text { all Question effects }=0 & \mathrm{~F}=26.3966 \\
\mathrm{H}_{\mathrm{a}}: \text { at least one Question effect } \neq 0 & \text { P-value }=<0.0001
\end{array}
$$

To identify which questions are significantly different from each other, a multiple comparisons procedure looking at the least squared means differences using Tukey HSD was conducted and is shown in table 23.

\section{Table 23. Tukey HSD: Commercial-Focused Projects Project Success Metrics

\begin{tabular}{|c|c|c|c|c|c|c|}
\hline \multicolumn{3}{|l|}{$\propto=0.50$} & \multicolumn{4}{|c|}{$\mathrm{Q}=3.11217$} \\
\hline Level & \multicolumn{5}{|c|}{ Letter } & Least Sq. Mean \\
\hline 8. Overall project success (organization view) & A & & & & & 3.27 \\
\hline 9. Overall project success (stakeholder view) & A & & & & & 3.22 \\
\hline 2. Technical success relative to similar projects & A & $\mathrm{B}$ & & & & 3.16 \\
\hline 1. Technical success relative to initial requirements & A & B & $\mathrm{C}$ & & & 3.08 \\
\hline 6. On budget relative to similar projects & & $\mathrm{B}$ & $\mathrm{C}$ & $\mathrm{D}$ & & 2.94 \\
\hline 7. Satisfaction with project management process & & & $\mathrm{C}$ & $\mathrm{D}$ & & 2.86 \\
\hline 4. On schedule relative to similar projects & & & & $\mathrm{D}$ & & 2.77 \\
\hline 3. On schedule relative to original project plan & & & & & $\mathrm{E}$ & 2.48 \\
\hline 5. On budget relative to original project plan & & & & & $\mathrm{E}$ & 2.42 \\
\hline
\end{tabular} Question Effect}

Levels not connected by the same letter are significantly different

Table 23 provides a great deal of information, however we will discuss the more notable differences. Questions 8, 9, 2, and 1 were ranked highest, as were they in table 11 when looking at question effects from all 180 participants. Also in table 23 and table 11 , questions $8,9,2$, and 1 were significantly different from questions 3 and 5 . These results are again consistent with the discoveries found in table 11 looking at the Project Success 
Metrics Question Effect among all organizations and table 21, which looked at the Project Success Metrics Question Effect in government-focused projects. One particularly interesting finding in table 23 that was not as clear in table 21 is that commercial-focused projects tend to rank project success metrics in high, medium, and low levels, just like what was seen in table 11 and in generally the same order. This indicates that commercial-focused projects are most interested in completing the project rather than following a strict process of rules. The Project Success Metrics question section produced a low mean square error (0.29726) indicating blocking on "question" was effective and treatment differences were easy to detect for the commercial-focused projects in commercial organizations.

The final ANOVA table tests for question effects in the Project Success Metrics section is for NASA projects and is illustrated in table 24.

Table 24. ANOVA Table: NASA Project Success Metrics

\begin{tabular}{|l|r|r|r|r|r|}
\hline Source & DF & $\begin{array}{r}\text { Sum of } \\
\text { Squares }\end{array}$ & $\begin{array}{r}\text { Mean } \\
\text { Square }\end{array}$ & F Ratio & Prob. $>$ F \\
\hline $\begin{array}{l}\text { Question - Project Success } \\
\text { Metrics }\end{array}$ & 8 & 19.0763 & 2.38453 & 12.6741 & $<0.0001$ \\
\hline Participants - NASA & 50 & 153.87 & 3.07741 & 16.3568 & $<0.0001$ \\
\hline & & & & & \\
\hline Model & 58 & 172.94662 & 2.98184 & 15.8488 & $<0.0001$ \\
\hline Error & 400 & 75.25708 & 0.18814 & & \\
\hline C. Total & 458 & 248.20370 & & & \\
\hline
\end{tabular}

Using an $\alpha=0.05$, we reject the null hypothesis and say there are significant differences among the nine questions in the Project Success Metrics section for NASA projects.

$$
\begin{array}{ll}
\mathrm{H}_{0}: \text { all Question effects }=0 & \mathrm{~F}=12.6741 \\
\mathrm{H}_{\mathrm{a}} \text { : at least one Question effect } \neq 0 & \text { P-value }=<0.0001
\end{array}
$$


Table 25 follows up with a Tukey HSD multiple comparison procedure to look at the least squared means differences.

Table 25. Tukey HSD: NASA Project Success Metrics Question Effects

\begin{tabular}{|l|c|c|c|r|}
\hline \multicolumn{2}{|c|}{$\propto=0.50$} & \multicolumn{3}{c|}{$\mathrm{Q}=3.11887$} \\
\hline \multicolumn{1}{|c|}{ Level } & \multicolumn{2}{c|}{ Letter } & Least Sq. Mean \\
\hline 8. Overall project success (organization view) & A & & & 3.45 \\
\hline 2. Technical success relative to similar projects & A & & \\
\hline 9. Overall project success (stakeholder view) & A & & & 3.41 \\
\hline 1. Technical success relative to initial requirements & A & & & 3.41 \\
\hline 7. Satisfaction with project management process & A & B & & 3.37 \\
\hline 6. On budget relative to similar projects & & B & C & 3.22 \\
\hline 4. On schedule relative to similar projects & & B & C & 3.08 \\
\hline 5. On budget relative to original project plan & & B & C & 3.04 \\
\hline 3. On schedule relative to original project plan & & & C & 2.95 \\
\hline
\end{tabular}

Levels not connected by the same letter are significantly different

Questions 8, 2, 9, 1, and 7 are significantly different from questions 6, 4, 5, and 3. These results are consistent with the discoveries made in the commercial-focused projects Tukey HSD table, government-focused projects Tukey HSD table, and overall Tukey HSD in table 11. This shows that to NASA, as well as in other organizations, ensuring a project's completion is much more important than maintaining the project's original budget or schedule. We might have expected NASA to value the Project Success Metrics differently than government-focused and commercial-focused commercial organizations, but this was not the case. Despite NASA being a government agency working on unique projects, their motives for project success align almost exactly with commercial organization. The Project Success Metrics question section produced a low mean square error (0.18814) indicating blocking on "question" was effective and treatment differences were easy to detect for the NASA Agency Organization. 
Overall, the Project Success Metrics section provided fairly consistent results among organization types. Statistically significant question effects were discovered among government-focused commercial projects, commercial-focused commercial projects, and NASA projects. Furthermore, when following up with a Tukey HSD, overall project success and technical success were most important to all organizations while budget and schedule relative to the original project plan were least important. We are also able to conclude that table 11's results were representative of not only the study overall, but also representative of the organizations at an individual level.

The third set of ANOVA tables test whether statistically significant question effects exist in the Systems Engineering Processes section for government-focused projects, commercial-focused projects, and NASA projects. What we will find out in this section is there are statistically significant question effects among government-focused projects, commercial-focused project but not NASA projects.

Table 26 is the first ANOVA table in the Systems Engineering Processes section to test for statistically significant question effects among government-focused projects.

Table 26. ANOVA Table: Government-Focused Projects Systems Engineering Processes

\begin{tabular}{|l|r|r|r|r|r|}
\hline Source & DF & $\begin{array}{r}\text { Sum of } \\
\text { Squares }\end{array}$ & $\begin{array}{r}\text { Mean } \\
\text { Square }\end{array}$ & F Ratio & Prob. $>$ F \\
\hline $\begin{array}{l}\text { Question - Systems Engineering } \\
\text { Processes }\end{array}$ & 16 & 18.5448 & 1.15905 & 3.5384 & $<0.0001$ \\
\hline Participants - Government & 45 & 194.073 & 4.31273 & 13.1289 & $<0.0001$ \\
\hline & & & & & \\
\hline Model & 61 & 212.61765 & 3.48554 & 10.6107 & $<0.0001$ \\
\hline Error & 720 & 236.51407 & 0.32849 & & \\
\hline C. Total & 781 & 449.13171 & & & \\
\hline
\end{tabular}


Using an $\alpha=0.05$, we reject the null hypothesis and say there are significant differences among the 17 Systems Engineering Processes for government-contracted projects.

$$
\begin{array}{ll}
\mathrm{H}_{0}: \text { all Question effects }=0 & \mathrm{~F}=3.5384 \\
\mathrm{H}_{\mathrm{a}}: \text { at least one Question effect } \neq 0 & \text { P-value }=<0.0001
\end{array}
$$

Using a Tukey HSD, table 27 follows up with a multiple comparisons procedure looking at the Least Squared Means Differences.

Table 27. Tukey HSD: Government-Focused Projects Systems Engineering Processes Question Effects

\begin{tabular}{|l|c|c|r|}
\hline \multicolumn{1}{|c|}{$\propto=0.50$} & \multicolumn{2}{|c|}{$\mathrm{Q}=3.47101$} \\
\hline \multicolumn{1}{|c|}{ Level } & Letter & Least Sq. Mean \\
\hline 4. Design Solution & $\mathrm{A}$ & & 3.30 \\
\hline 7. Product Verification & $\mathrm{A}$ & & 3.28 \\
\hline 5. Product Implementation & $\mathrm{A}$ & $\mathrm{B}$ & 3.26 \\
\hline 15. Technical Data Management & $\mathrm{A}$ & $\mathrm{B}$ & 3.20 \\
\hline 9. Product Transition & $\mathrm{A}$ & $\mathrm{B}$ & 3.17 \\
\hline 14. Configuration Management & $\mathrm{A}$ & $\mathrm{B}$ & 3.17 \\
\hline 12. Interface Management & $\mathrm{A}$ & $\mathrm{B}$ & 3.15 \\
\hline 8. Product Validation & $\mathrm{A}$ & $\mathrm{B}$ & 3.10 \\
\hline 6. Product Integration & $\mathrm{A}$ & $\mathrm{B}$ & 3.09 \\
\hline 11. Requirements Management & $\mathrm{A}$ & $\mathrm{B}$ & 3.09 \\
\hline 1. Stakeholder Expectations Definition & $\mathrm{A}$ & $\mathrm{B}$ & 3.07 \\
\hline 16. Technical Assessment & $\mathrm{A}$ & $\mathrm{B}$ & 2.98 \\
\hline 2. Technical Requirements Definition & $\mathrm{A}$ & $\mathrm{B}$ & 2.89 \\
\hline 13. Technical Risk Management & & $\mathrm{B}$ & 2.89 \\
\hline 3. Logical Decomposition & & $\mathrm{B}$ & 2.85 \\
\hline 10. Technical Planning & & $\mathrm{B}$ & 2.85 \\
\hline 17. Decision Analysis & & 2.85 \\
\hline
\end{tabular}

Levels not connected by the same letter are significantly different

Table 27 shows processes 4,7 , and 5 to be significantly different from processes 3,10 , and 17. This means in government-focused projects, engineers feel design solution, 
product verification, and product implementation are more important than logical decomposition, technical planning, and decision analysis. These results are interesting, but it is unclear as to why processes 4,7 , and 5 are significantly more important in government-focused commercial projects than processes 3, 10, and 17. However, table 14 showed these same significant differences when testing all 180 participants from the three organizations types in this study. The Systems Engineering Processes question section produced a low mean square error (0.32849) indicating blocking on "question" was effective and treatment differences were easy to detect for the government-focused projects in the commercial organization.

Table 28 is the second ANOVA table in this set to test for statistically significant differences among question effects in the Systems Engineering Processes section for commercial-focused projects.

Table 28. ANOVA Table: Commercial-Focused Projects Systems Engineering Processes

\begin{tabular}{|l|r|r|r|r|r|}
\hline Source & DF & $\begin{array}{r}\text { Sum of } \\
\text { Squares }\end{array}$ & $\begin{array}{r}\text { Mean } \\
\text { Square }\end{array}$ & F Ratio & Prob. $>$ F \\
\hline $\begin{array}{l}\text { Question - Systems Engineering } \\
\text { Processes }\end{array}$ & 16 & 56.9426 & 3.55891 & 10.2689 & $<0.0001$ \\
\hline Participants - Commercial & 82 & 260.621 & 3.1783 & 9.1706 & $<0.0001$ \\
\hline & & & & & \\
\hline Model & 98 & 317.56343 & 3.24044 & 9.3499 & $<0.0001$ \\
\hline Error & 1312 & 454.70446 & 0.34657 & & \\
\hline C. Total & 1410 & 772.26790 & & & \\
\hline
\end{tabular}

Using an $\alpha=0.05$, we reject the null hypothesis and say there are statistically significant differences among the 17 Systems Engineering Processes for government-focused projects. 


$$
\begin{array}{ll}
\mathrm{H}_{0}: \text { all Question effects }=0 & \mathrm{~F}=10.2689 \\
\mathrm{H}_{\mathrm{a}}: \text { at least one Question effect } \neq 0 & \text { P-value }=<0.0001
\end{array}
$$

To identify where those significant differences are located, a multiple comparison procedure looking at the Least Squared Means Differences using a Tukey HSD was conducted and provided in table 29.

Table 29. Tukey HSD: Commercial-Focused Projects - Systems Engineering

\begin{tabular}{|c|c|c|c|c|c|c|c|c|}
\hline \multicolumn{4}{|l|}{$\propto=0.50$} & \multicolumn{5}{|c|}{$Q=3.46533$} \\
\hline Level & & & & ette & & & & Least Sq. Mean \\
\hline 7. Product Verification & A & & & & & & & 3.46 \\
\hline 8. Product Validation & $\mathrm{A}$ & $\mathrm{B}$ & & & & & & 3.40 \\
\hline 9. Product Transition & $\mathrm{A}$ & $\mathrm{B}$ & $\mathrm{C}$ & & & & & 3.25 \\
\hline 5. Product Implementation & A & $\mathrm{B}$ & $\mathrm{C}$ & & & & & 3.22 \\
\hline 6. Product Integration & A & B & $\mathrm{C}$ & & & & & 3.22 \\
\hline 15. Technical Data Management & A & $\mathrm{B}$ & $\mathrm{C}$ & $\mathrm{D}$ & & & & 3.17 \\
\hline 14. Configuration Management & A & $\mathrm{B}$ & $\mathrm{C}$ & $\mathrm{D}$ & & & & 3.17 \\
\hline 13. Technical Risk Management & & $\mathrm{B}$ & $\mathrm{C}$ & $\mathrm{D}$ & $\mathrm{E}$ & & & 3.11 \\
\hline 1. Stakeholder Expectations Definition & & & $\mathrm{C}$ & $\mathrm{D}$ & $\mathrm{E}$ & $\mathrm{F}$ & & 3.06 \\
\hline 4. Design Solution & & & $\mathrm{C}$ & $\mathrm{D}$ & $\mathrm{E}$ & $\mathrm{F}$ & & 3.06 \\
\hline 2. Technical Requirements Definition & & & $\mathrm{C}$ & $\mathrm{D}$ & $\mathrm{E}$ & $\mathrm{F}$ & & 3.04 \\
\hline 12. Interface Management & & & $\mathrm{C}$ & $\mathrm{D}$ & $\mathrm{E}$ & $\mathrm{F}$ & & 3.02 \\
\hline 11. Requirements Management & & & $\mathrm{C}$ & $\mathrm{D}$ & $\mathrm{E}$ & $\mathrm{F}$ & $\mathrm{G}$ & 3.01 \\
\hline 16. Technical Assessment & & & & $\mathrm{D}$ & $\mathrm{E}$ & $\mathrm{F}$ & $\mathrm{G}$ & 2.89 \\
\hline 10. Technical Planning & & & & & $\mathrm{E}$ & $\mathrm{F}$ & $\mathrm{G}$ & 2.80 \\
\hline 17. Decision Analysis & & & & & & $\mathrm{F}$ & $\mathrm{G}$ & 2.78 \\
\hline 3. Logical Decomposition & & & & & & & $\mathrm{G}$ & 2.70 \\
\hline
\end{tabular}
Processes Question Effects

Levels not connected by the same letter are significantly different

The more notable observations from the table show processes $7,8,9,5,6,15$, and 14 are significantly different from processes $1,4,2,12,11,16,10$ and 17. Processes 7, 8, 9, 5, 6,15 , and 14 are also significantly different from processes $11,16,10,17$, and 3 . These 
results are unique from the results found in table 11 and table 27, which looked at the question effect from all three-organization types and government-focused commercial organizations, respectively. In table 29 , we see commercial-focused projects appear to focus on the product driven processes rather than the overall project driven processes. This is interesting; since table 23 showed commercial-focused projects tend to focus on overall project success when evaluating their project success metrics. But, when engineers are looking at the actual processes, product processes are significantly more important than the other processes. The Systems Engineering Processes question section produced a low mean square error (0.34657) indicating blocking on "question" was effective and treatment differences were easy to detect for the commercial-focused projects in the commercial organization.

Table 30 is the final ANOVA table in this set and tests for statistically significant question effects in the Systems Engineering Processes section for NASA projects.

Table 30. ANOVA Table: NASA Projects - Systems Engineering Processes

\begin{tabular}{|l|r|r|r|r|r|}
\hline Source & DF & $\begin{array}{r}\text { Sum of } \\
\text { Squares }\end{array}$ & $\begin{array}{r}\text { Mean } \\
\text { Square }\end{array}$ & F Ratio & Prob. $>$ F \\
\hline $\begin{array}{l}\text { Question - Systems Engineering } \\
\text { Processes }\end{array}$ & 16 & 4.67762 & 0.29235 & 1.3801 & 0.1441 \\
\hline Participants - NASA & 50 & 82.4031 & 1.64806 & 7.7799 & $<0.0001$ \\
\hline & & & & & \\
\hline Model & 66 & 87.08074 & 1.31941 & 6.2284 & $<0.0001$ \\
\hline Error & 800 & 169.46943 & 0.21184 & & \\
\hline C. Total & 866 & 256.55017 & & & \\
\hline
\end{tabular}


Using an $\alpha=0.05$, we fail to reject the null hypothesis and say there are no significant differences among the 17 Systems Engineering Processes for NASA projects.

$$
\begin{array}{ll}
\mathrm{H}_{0} \text { : all Question effects }=0 & \mathrm{~F}=1.3801 \\
\mathrm{H}_{\mathrm{a}} \text { : at least one Question effect } \neq 0 & \text { P-value }=0.1441
\end{array}
$$

Due to the lack of significant differences, we will not follow up with a Tukey HSD. However, failing to reject the null hypothesis tested is telling. What this test showed is NASA systems engineers find all 17 systems engineering processes to be very important and incremental in a project's lifecycle. This test indicates that in the case of NASA, the 17 Systems Engineering Processes cannot be ranked based on importance or level of emphasis. All processes must be completed with excellence. The Systems Engineering Processes question section produced a low mean square error (0.21184) indicating blocking on "question" was effective and treatment differences were easy to detect for the NASA Agency organization.

Overall, statistically significant question effects were discovered in the Systems Engineering Processes section for government-focused commercial projects and commercial-focused commercial projects, but not for NASA projects. A Tukey HSD discovered the government-focused projects to rank the significantly different systems engineering processes in a similar manner to the overall systems engineering processes question effect Tukey HSD when testing all 180 participants, but this was not the case with commercial-focused projects. 
The final ANOVA table in this paper was calculated from the modified data collection instrument. Table 31 tests for significant differences in the Non-Technical Variables section for NASA projects.

Table 31. ANOVA Table: NASA Projects' Non-Technical Variables

\begin{tabular}{|l|r|r|r|r|r|}
\hline Source & DF & $\begin{array}{r}\text { Sum of } \\
\text { Squares }\end{array}$ & $\begin{array}{r}\text { Mean } \\
\text { Square }\end{array}$ & F Ratio & Prob. $>$ F \\
\hline $\begin{array}{l}\text { Question - Non-Technical } \\
\text { Variables }\end{array}$ & 10 & 127.97979 & 12.798 & 29.1983 & $<0.0001$ \\
\hline Participants - NASA & 50 & 63.84263 & 1.37685 & 2.9131 & $<0.0001$ \\
\hline & & & & & \\
\hline Model & 60 & 191.81490 & 3.19692 & 7.2937 & $<0.0001$ \\
\hline Error & 500 & 219.15658 & 0.43831 & & \\
\hline C. Total & 560 & 410.97148 & & & \\
\hline
\end{tabular}

Using an $\alpha=0.05$, we reject the null hypothesis and say there are statistically significant differences among the 11 questions tested in the Non-Technical Variables section of the modified data collection instrument for NASA projects.

$$
\begin{array}{ll}
\mathrm{H}_{0}: \text { all Question effects }=0 & \mathrm{~F}=29.1983 \\
\mathrm{H}_{\mathrm{a}}: \text { at least one Question effect } \neq 0 & \text { P-value }=<0.0001
\end{array}
$$

A Tukey HSD was used as our multiple comparison procedure for looking at Least Squared Means Differences and is illustrated in table 32. 
Table 32. Tukey HSD: NASA Projects' Non-Technical Variables

\begin{tabular}{|c|c|c|c|c|c|c|}
\hline \multicolumn{3}{|l|}{$\propto=0.50$} & \multicolumn{4}{|c|}{$\mathrm{Q}=3.23371$} \\
\hline Level & \multicolumn{5}{|c|}{ Letter } & Least Sq. Mean \\
\hline 3. Professional Investment & $\mathrm{A}$ & & & & & 3.63 \\
\hline 4. Personal Investment & $\mathrm{A}$ & & & & & 3.50 \\
\hline 8. Team Experience & $\mathrm{A}$ & & & & & 3.45 \\
\hline 1. Familiarity in Project Details & A & & & & & 3.44 \\
\hline 9. Level of Testing & A & $\mathrm{B}$ & & & & 3.26 \\
\hline 12. Degree of Formulation Study & & $\mathrm{B}$ & $\mathrm{C}$ & & & 2.99 \\
\hline 13. New Design Factor & & B & $\mathrm{C}$ & & & 2.97 \\
\hline 10. Development Duration & & $\mathrm{B}$ & $\mathrm{C}$ & & & 2.94 \\
\hline 11. Number of Organizations & & & $\mathrm{C}$ & $\mathrm{D}$ & & 2.64 \\
\hline 6. Budget Constraint & & & & $\mathrm{D}$ & $\mathrm{E}$ & 2.31 \\
\hline 7. Volatility of Requirements & & & & & $\mathrm{E}$ & 2.11 \\
\hline
\end{tabular}

Levels not connected by the same letter are significantly different

Regarding the notable observations, questions 3, 4, 8, 1, and 9 were significantly different from questions $12,13,10$, and 11 , as well as questions $3,4,8,1$, and 9 were significantly different from questions 6 and 7. Table 32 indicates which non-technical variables or engineering management skills might be important in a project and be recognized when forming a project's core set of engineers. Budget constraints and volatility of requirements are virtually unimportant in comparison to an engineer's professional and personal investment in the project, the team's experience, familiarity in the project's details, and the level of testing the project undergoes. Furthermore, the results suggest degree of formulation study, new design factor, development duration, and number of organizations should be secondary considerations as well.

When comparing table 32 to table 14, which uses a Tukey HSD to identify significant differences among NASA's 17 systems engineering processes for all 180 participants, notable observations were also identified. For example personal investment, 
professional investment, team experience, and familiarity in project details at NASA all had higher least squared mean values than any of the systems engineering processes' least squared mean values when all 180 participants were analyzed together. This result could be indicating that the current design of NASA's 17 systems engineering processes might not be correctly capturing the inputs that most impact project success. At NASA, leading indicators for project success might actually stem from personal investment, professional investment, team experience, and familiarity in project details. Due to these results, further analysis of how non-technical variables impact government-focused projects in commercial organizations and commercial-focused projects in commercial organizations could benefit project success. If similar results to what was discovered in tables 31 and 32 are discovered for the commercial sector, then further analysis to how systems engineering is conducted within government agencies and commercial agencies, as well as across government and commercial agencies should be examined.

In addition to the findings discussed above, the interviews also indicated that systems engineers at NASA value practical tools that show them how to directly apply systems engineering requirements and procedures (NASA, 2014). However, currently there are only general tools that exist to help systems engineers and practitioners at NASA navigate through the 2007 handbook (Jansma, 2008). It has also been recognized that NASA has been faced with a unique challenge in technology, organization, and culture for finding an Agency-specific project management framework that can distinguish itself among different types of projects (Shenhar, et al., 2005). One proposed tool has been to adapt the "Novelty, Complexity, Technology, Pace 'Diamond' Model" to NASA. In an attempt to help develop NASA's systems engineers, programs like the 
Systems Engineering Leadership Development Program (SELDP) have been created

(Williams \& Reyes, 2012). The goal is to identify, train, and develop the entire learning systems and not just the program participants so that a greater contribution can be made to the organization. Despite the practical tools that do currently exist at NASA to help systems engineers and engineering practitioners, more are wanted. Table 33 summarizes the hypotheses tested in this section.

Table 33. Summary of Question Effects Within an Organization

\begin{tabular}{|c|c|c|c|c|}
\hline Section & Organization & Hypothesis & P-value & F Ratio \\
\hline $\begin{array}{l}\text { Project } \\
\text { Description } \\
\text { Variables }\end{array}$ & $\begin{array}{l}\text { Government- } \\
\text { Focused Projects }\end{array}$ & $\begin{array}{l}\mathrm{H}_{0}: \text { all Question effects }=0 \\
\mathrm{H}_{\mathrm{a}}: \text { at least one Question effect } \neq 0\end{array}$ & 0.0535 & 2.6190 \\
\hline $\begin{array}{l}\text { Project } \\
\text { Description } \\
\text { Variables }\end{array}$ & $\begin{array}{l}\text { Commercial- } \\
\text { Focused Projects }\end{array}$ & $\begin{array}{l}\mathrm{H}_{0}: \text { all Question effects }=0 \\
\mathrm{H}_{\mathrm{a}}: \text { at least one Question effect } \neq 0\end{array}$ & 0.0359 & 2.8944 \\
\hline $\begin{array}{l}\text { Project } \\
\text { Description } \\
\text { Variables }\end{array}$ & NASA & $\begin{array}{l}\mathrm{H}_{0}: \text { all Question effects }=0 \\
\mathrm{H}_{\mathrm{a}}: \text { at least one Question effect } \neq 0\end{array}$ & 0.6798 & 0.5044 \\
\hline $\begin{array}{l}\text { Project Success } \\
\text { Metrics }\end{array}$ & $\begin{array}{l}\text { Government- } \\
\text { Focused Projects }\end{array}$ & $\begin{array}{l}\mathrm{H}_{0}: \text { all Question effects }=0 \\
\mathrm{H}_{\mathrm{a}}: \text { at least one Question effect } \neq 0\end{array}$ & $<0.0001$ & 10.1428 \\
\hline $\begin{array}{l}\text { Project Success } \\
\text { Metrics }\end{array}$ & $\begin{array}{l}\text { Commercial- } \\
\text { Focused Projects }\end{array}$ & $\begin{array}{l}\mathrm{H}_{0}: \text { all Question effects }=0 \\
\mathrm{H}_{\mathrm{a}}: \text { at least one Question effect } \neq 0\end{array}$ & $<0.0001$ & 26.3966 \\
\hline $\begin{array}{l}\text { Project Success } \\
\text { Metrics }\end{array}$ & NASA & $\begin{array}{l}\mathrm{H}_{0}: \text { all Question effects }=0 \\
\mathrm{H}_{\mathrm{a}}: \text { at least one Question effect } \neq 0\end{array}$ & $<0.0001$ & 12.6741 \\
\hline $\begin{array}{l}\text { Systems } \\
\text { Engineering } \\
\text { Processes }\end{array}$ & $\begin{array}{l}\text { Government- } \\
\text { Focused Projects }\end{array}$ & $\begin{array}{l}\mathrm{H}_{0}: \text { all Question effects }=0 \\
\mathrm{H}_{\mathrm{a}}: \text { at least one Question effect } \neq 0\end{array}$ & $<0.0001$ & 3.5384 \\
\hline $\begin{array}{l}\text { Systems } \\
\text { Engineering } \\
\text { Processes }\end{array}$ & $\begin{array}{l}\text { Commercial- } \\
\text { Focused Projects }\end{array}$ & $\begin{array}{l}\mathrm{H}_{0}: \text { all Question effects }=0 \\
\mathrm{H}_{\mathrm{a}}: \text { at least one Question effect } \neq 0\end{array}$ & $<0.0001$ & 10.2689 \\
\hline $\begin{array}{l}\text { Systems } \\
\text { Engineering } \\
\text { Processes }\end{array}$ & NASA & $\begin{array}{l}\mathrm{H}_{0}: \text { all Question effects }=0 \\
\mathrm{H}_{\mathrm{a}}: \text { at least one Question effect } \neq 0\end{array}$ & 0.1441 & 1.3801 \\
\hline $\begin{array}{l}\text { Non-Technical } \\
\text { Variables }\end{array}$ & NASA & $\begin{array}{l}\mathrm{H}_{0}: \text { all Question effects }=0 \\
\mathrm{H}_{\mathrm{a}}: \text { at least one Question effect } \neq 0\end{array}$ & $<0.0001$ & 29.1983 \\
\hline
\end{tabular}




\section{Conclusion}

This paper identified variations in how the systems engineering process is applied to complex projects and how project success is impacted by organization type. The organizations, included in this study, were commercial organizations working on government projects, commercial organizations working on commercial projects, and NASA. NASA was the focal point of the study. This research area is of interest because NASA must run its large-scale and complex projects on an increasingly limited budget. Therefore, effective implementation of systems engineering techniques is crucial. The results from this study will contribute to the design for the forthcoming NASA's systems engineering practitioners guide.

The overall study consisted of three phases: the 2007 MSFC flight hardware study, the 2013 government and commercial organizations study, and the 2014 NASA Agency study, which was the focus of this paper. Data for the 2014 NASA study was collected using a modified version of the data collection instrument that was originally designed for the 2013 study. Modifications to the data collection instrument, included the addition of a section that captured the influence of non-technical variables. Fifty-one NASA engineers participated in the 2014 study and were representative of all 10 NASA Centers, as well as Headquarters. The 2013 study included 129 participants.

To gather information on the impact the systems engineering processes have with the project success metrics, matrices were used and calculations were correlated. Notable observations were discovered using the matrices. For example, almost twice as many meaningful correlations were produced for the 2014 NASA study than for the 2013 
government and commercial organizations study. A matrix was also developed to identify meaningful correlations among non-technical variables and the project success metrics for the 2014 NASA study.

Next, three one-way ANOVA tables were constructed to identify similarities and differences among organizations with respect to project description variables, project success metrics, and the systems engineering processes. In terms of the project description variables, commercial organizations and NASA engineers were both found to be significantly different from government organizations, but not from each other. However, with regard to project success metrics, no significant difference was found between government and commercial organizations or between commercial organizations and NASA engineers, but commercial organizations and NASA engineers were determined to be significantly different. Finally, with respect to systems engineering processes, no significant difference was found between government and commercial organizations, but both were significantly different from NASA engineers.

Finally, 10 additional one-way ANOVA tables were constructed to identify similarities and differences among the modified data collection instrument's questions based on organization, with respect to project description variables, project success metrics, systems engineering processes, and non-technical variables. Regarding the project description variables, statistically significant differences were detected in the data for commercial-focused projects in commercial organizations, but no statistically significant differences were discovered within government-focused projects in commercial organizations or NASA. When testing for questions effects among project success metrics, statistically significant differences were detected within government- 
focused projects in commercial organizations, commercial-focused projects in commercial organizations, and in NASA projects. No statistically significant differences were detected in NASA projects among the systems engineering processes, but significant differences were detected within government-focused projects in commercial organizations and within commercial-focused projects in commercial organizations. The final ANOVA table tested for statistically significant question effects among nontechnical variables within NASA projects. This test indicated statistically significant differences among non-technical variables within NASA projects.

Based on the outcomes from the analysis of the survey data, it is apparent that additional data will be needed to more fully explore the similarities and more importantly the differences among the significant correlations. The one-way ANOVA table displaying results for the systems engineering processes section showed the organization and question interaction effects to have produced results that should be followed up on (see table 14 and figure 12).

Future research includes three studies that would serve as follow-ons to this research effort and are discussed in chapter 3. The first proposed study would involve a cluster analysis to gain a better understanding about how NASA Centers are grouping. For example, are they grouped together based on research focus or on culture? The ideas for the second study and third study proposed emerged during face-to-face interviews with NASA systems engineers (NASA, 2014). The second study proposes the design of a series of tools for systems engineers to use based on their project and knowledge base. The third study proposes a parallel study be conducted with the space launch systems using model-based systems engineering. 
One limitation of this study involves the different methods that were used to gather data in each of the three phases. In the 2007 MSFC flight hardware study, all the data was gathered through interviews and from one NASA Center location. This means that the responses to questions were coded and calculated for the correlation matrix by the experimenters, rather than the participants themselves. In the 2013 government and commercial organizations study, participants were primarily from the Midwest and Southeast areas of the country. Those participants also answered questions on a 4-point Likert scale, and answered questions based on a project that had completed all phases of its lifecycle. In the 2014 NASA study, participants were identified using targeted sampling. These participants filled out a modified data collection instrument that employed a 7-poing Likert scale, and they were allowed to answer questions based on projects that were cancelled and did not complete all phases of its lifecycle or projects that were still in progress. 


\section{Acknowledgments}

NASA has funded this research, and all research contributions are directly for NASA. In addition to NASA, a number of individuals and institutions were instrumental in this research effort.

First, thank you to the Industrial and Systems Engineering and Engineering Management department at the University of Alabama at Huntsville (UAH) for hosting me during the summer months of 2014. Thank you to the Space Launch System Weekly Meeting Group in Huntsville for helping me establish a foundation to gather data for this research effort. Also, thank you to all the engineers at NASA who allowed me to interview them and gather qualitative data.

Second, I would also like to recognize my alpha testers and beta testers who took the time to ensure the modified data collection instrument was appropriate and ready for survey deployment. Thank you to the NASA Agency as a whole. This research effort was able to gather data from all ten NASA Centers, as well as Headquarters because the Agency has such a passion for research and the advancement of systems engineering.

Third, thank you to the researchers who helped guide this research effort forward. These are the researchers involved in the 2007 MSFC flight hardware study, and the 2013 government and commercial organizations study. Specific researchers aiding in this thesis were my committee members and my R expert, Dr. Hoffmann. Finally, thank you to the research collaborators, Dr. Utley at UAH and Dr. Yang at MIT. 


\section{References}

Andary, J. F., So, M. M., \& Breindel, B. (2008). Systems Engineering Technical Authority: A Path to Mission success. INCOSE , $1-15$.

Barley, B., \& Bacskay, A. (2010). Heritage and Advanced Technology Systems Engineering LEssons Learned from NASA Deep Space Missions. American Institute of Aeronautics and Astronautics, 1 - 8.

Casella, G., \& George, E. (1992). Explaining the Gibbs Sampler. In The American Statistician (Vol. 46, pp. 167 - 174). Taylor \& Francis, LTc.

Chapline, G. e. (n.d.). Systems Engineering for Life Cycle of Complex Systems. Retrieved July 2014, from NASA: http://www.nasa.gov/centers/johnson/pdf/584735main_Wingsch4i-pgs302-318.pdf

Componation, P. J., Youngblood, A. D., Utley, D. R., \& Farrington, P. A. (2008). A Preliminary Assessment of the Relationship between Project Success, Systems Engineering and Team Organization. Engineering Management Journal , 20 (4), 40 - 46.

Couillard, J. (1995, December). The Role of Project Risk in Determining Project Management Approach. Project Management Journal .

Derro, M. E., \& Williams, C. R. (2009). Behavioral Competencies of Highly Regarded Systems Engineers at NASA. Aerospace Conference (pp. 1 - 17). Big Sky: IEEE.

Devolites, J. L., \& Hart, J. J. (2013). The Tailoring of Traditional Systems Engineering for the Morpheus Project. American Institute of Aeronautics and Astronautics , 1 - 25.

Doskey, S., Mazzuchi, T., \& Sarkani, S. (2013). A Measure of Systems Engineering Effectiveness in Government Acquisition of Complex Information Systems, A Bayesian Belief Network Approach. 7th Annual IEEE International Systems Conference (pp. 147 152). IEEE Computer Society.

Dvir, D., Raz, T., \& Shenhar, A. J. (2002, January 23). An empirical analysis of the relationship between project planning and project success. International Journal of Project Management, 89 - 95.

Elm, J. P., \& Goldenson, D. (2012). The Business Case for Systems Engineering Study: Results of the Systems Engineering Effectiveness Survey. Software Engineering Institute , $1-174$. 
Forsberg, K., \& Mooz, H. (1991). The Relationship of Systems Engineering to the Project Cycle. National Council On Systems Engineering and American Society for Engineering Management (pp. 2 - 12). Chattanooga: Center for Systems Management.

Grady, J. O. (2009). Correlation of System Complexity With System Engineer Effectiveness. INCOSE San Diego Chapter Annual Mini-Conference. San Diego: INCOSE.

Haimes, Y. Y. (2012). Systems-Based Guiding Principles for Risk Modeling, Planning, Assessment, Management, and Communication. Society for Risk Analysis , 12 (9), 1451 1467.

Hamaker, J. W. (2006). Improving the Predictive Capability of Spacecraft Cost Models by Considering Non-Technical Variables. 25. Huntsville, Alabama: ProQuest Information and Learning Company.

Hamaker, J. W., \& Componation, P. J. (2005). Improving Space Project Cost Estimating with Engineering Management Variables. Engineering Management Journal , 17 (2), 15 20.

Hamaker, J. W., \& Componation, P. J. (2011). Using our Right Brains to Improve Space Project Cost Estimating. Journal of Cost Analysis and Parametrics , 1 (2).

Hansen, J. L. (2013). Complex Commercial and Government Projects: An exploratory study of risks, success, and systems engineering processes.

Heusner, J. (2013). Product and Process Focus Within NASA Systems Engineering. Conference on Systems Engineering Research (pp. 1 - 10). Atlanta: Procedia Computer Science.

Honour, E. C. (2004, June). Understanding the value of systems engineering. In Proceedings of the INCOSE International Symposium , 1 - 16.

INCOSE. (2014). Standards Update. Retrieved November 6, 2014, from International Council on Systems Engineering: http://www.incose.org/practice/standardsupdate.aspx

Jansma, P. A. (2008). A Field Guide to the NASA Procedurla Requirements for Systems Engineering. Aerospace Conference (pp. 1 - 16). Big Sky: IEEE.

Locatelli, G., Mancini, M., \& Romano, E. (2013). Systems Engineering to improve the governance in complex project environments. International Journal of Project Management, 1 - 16.

Müller, R. (2009). Project Governance. Gower. 
Marmier, F., Gourc, D., \& Laarz, F. (2013, May 9). A risk oriented model to assess strategic decisions in new product development projects. Decision Support Systems , 74 82.

NASA. (2007). NASA Systems Engineering Handbook. NASA.

NASA. (2014). National Aeronautics and Space Administration. Retrieved November 3, 2014, from FY 2015 President's Budget Request Summary: http://www.nasa.gov/sites/default/files/files/508_2015_Budget_Estimates.pdf

NASA, S. E. (2014). Systems Engineering at NASA, Past and Present. (K. A. Schomburg, Interviewer)

Patton, M. Q. (1990). Qualitative Evaluation and Research Mehtods (Vol. 2). Newbury Park, California: Sage.

Pinto, J. K., \& Slevin, D. P. (1988). Project Success: Definitions and Measurement Techniques. Project Management Journal , 19, 67 - 71.

Rhodes, D. H., Valerdi, R., \& Roedler, G. J. (2008). Systems Engineering Leading Indicators for Assessing Program and Technical Effectiveness. Systems Engineering , 12 (1).

Sato, Y. (2005). Local Engineering and Systems Engineering: Cultural Conflict at NASA's Marshall Space Flight Center, 1960 - 1966. Technology and Culture , 46 (3), $561-583$.

Schomburg, K. A., Collopy, P. D., Componation, P. J., \& Krejci, C. C. (2015). Systems Engineering and Project Success at NASA. ISERC (pp. 1 - 9). Nashville: Institute for Industrial Engineers.

Schomburg, K. A., Componation, P. J., \& Krejci, C. C. (2014). The Role of NonTechnical Variables in NASA Research and Development Project Success. American Society for Engineering Management (pp. 1 - 7). Virginia Beach: International Annual Conference Proceedings.

Science and Engineering Systems Analysis and Integration Laboratory, Systems Definition Division. (1994). Systems Engineering Handbook - Volume 2: Tools, Techniques, and Lessons Learned. Huntsville, AL: George C. Marshall Space Flight Center.

Sheard, S. (2000). The Shangri-La of ROI. INCOSE International Symposium. Minneapolis, MN: INCOSE. 
Shenhar, A., Dvir, D., Milosevic, D., Mulenburg, J., Patanakul, P., Reilly, R., et al. (2005). Toward a NASA-Specific Project Management Framework. Engineering Management Journal , 17 (4).

Shinn, S., Wolfarth, L., \& Hahn, M. (2010). Estimating Incremental Cost and Schedule Growth for Systems Engineering and Project Management. Aerospace Conference, IEEE (pp. 1 - 14). Aerospace and Electronics Systems Society.

Smartt, C., \& Ferreira, S. (2013). Applying Systems Engineering to Survey Research. Converence on Systems Engineering Reserach (CSER '13) (pp. 1102 - 1111). Atlanta: Procedia Computer Science.

Stef van Buuren [aut, c. G.-O. (2014, July 2). Multivariate Imputation by Chained Equations. (S. v. Buuren, Producer, \& cran.r-project) Retrieved September 10, 2014, from Package 'mice': http://cran.r-project.org/web/packages/mice/mice.pdf

The White House. (2014). Retrieved May 12, 2014, from National Aeronautics and Space Administration:

http://www.whitehouse.gov/sites/default/files/omb/budget/fy2014/assets/nasa.pdf

Tishler, A., Dvir, D., Shenhar, A., \& Lipovetsky, S. (1995, June 27). Identifying Critical Success Factors in Defense Development Projects: A Multivariate Analysis. Technological Forecasting and Social Change, 151 - 171.

Van Marrewijk, A. (2004). Crisis in the transition of telecom alliance Unisource. Journal of Management Psychology, 19 (2), 235 - 251.

Van Marrewijk, A., Clegg, S. R., Pitsis, T. S., \& Veenswijk, M. (2008). Managing public-private megaprojects: paradoxes, complexity, and project design. International Journal of Project Management, 26 (8), 591 - 600.

Vipavetz, K., Murphy, D., \& Infeld, S. (2012). Model-Based Systems Engineering Pilot Program at NASA Langley. AIAA Conference and Exposition, (p. Pasadena).

Watters, J. K., \& Biernacki, P. (1989). Targeted Sampling: Options for the Study of Hidden Populations. Social Problems , 36 (4), 416 - 430.

Williams, C. R., \& Reyes, A. M. (2012). NASA's Systems Behind the System: Developing Systems Engineers. Aerospace Conference (pp. 1 - 11). Big Sky: IEEE. 


\section{CHAPTER 3. GENERAL CONCLUSTION}

\section{General Discussion}

This thesis addressed whether variations in the systems engineering processes applied to complex projects impact project success differently based on organization type. Specifically, the organizations tested were government organizations, commercial organizations, and NASA, with NASA as the focal point of the study. This research was performed because NASA's budget is becoming incrementally tighter each year. However, the projects NASA engineers work on are not becoming cheaper or easier. Therefore, NASA systems engineers must work harder to meet project deadlines and ensure project success under tighter budgets. One of the best ways to do this is to implement good systems engineering processes. In addition to studying systems engineering processes, the study also examined the effects of engineering management variables on project success for NASA engineers. Finally, differences among organizations based on project description variables, project success metrics, and systems engineering processes were studied.

An exhaustive literature review recognized Couillard's work in 1995 as the foundation for defining project success metrics and three focus areas for further review. The literature review also defined project success as any project that is able to successfully complete its lifecycle. The three focus areas of systems engineering in the literature were: NASA systems engineering and integration effectiveness, government 
and commercial organizations systems engineering effectiveness, and space project cost estimating with project management variables.

The overall study took part in three phases: a 2007 MSFC Flight Hardware study, a 2013 Government and Commercial Organizations study, and a 2014 NASA study, with the 2014 NASA study as the focal point for this thesis. For the 2014 NASA study, a modified data collection instrument was constructed from the 2013 study. Questions were modified to better address situations NASA engineers would experience, and three additional sections were added to the modified data collection instrument to gain further insight. Of the three additional sections, the section identifying the influence of nontechnical variables was discussed at length. For the 2014 NASA study, 51 NASA engineers participated in providing data. These engineers are representative of all 10 NASA Centers, as well as NASA Headquarters. The 2013 Government and Commercial Organizations study provided data from 129 participants, with 46 government organization participants and 83 commercial organization participants.

Matrices were used as a method to gather information on the similarities and differences organizations have on significant correlations between the project success metrics and NASA's 17 systems engineering processes. In both the 2007 NASA MSFC Flight Hardware study and 2007 NASA study, significant correlations existed for backend processes relating to project synthesis. Regarding the 2013 Government and Commercial organizations study and 2014 NASA study, almost twice as many significant correlations were produced for the 2014 study than the 2013 study. Matrices were also examined between the 2013 government-focused projects, 2013 commercial-focused projects, and the 2014 NASA study. Finally, significant correlations between non- 
technical variables and project success for the 2014 NASA study showed that familiarity in project details is significantly correlated to schedule, team experience is significantly correlated to budget, and level of testing is significantly correlated to overall project success from the stakeholder's view.

Three one-way ANOVA tables were constructed to identify similarities and differences among organizations in regards to project description variables, project success metrics, and the systems engineering processes. In regard to project description variables, commercial organizations and NASA engineers were both found to be significantly different from government organizations, but not from each other. However, in regard to project success metrics, no significant difference was found between government and commercial organizations or between commercial organizations and NASA engineers, but commercial organizations and NASA engineers were determined to be significantly different in respect to project success metrics. Finally, with regard to systems engineering processes, no significant difference was found between government and commercial organizations, but both were significantly different from NASA engineers.

\section{Recommendations for Future Research}

Recommendations for future research are based on results from the matrices, oneway ANOVA tables, and face-to-face interviews with NASA systems engineers.

The matrices looked at significant correlations between project success metrics and NASA's 17 systems engineering processes. Figure 3 had shown the 2007 NASA MSFC Flight Hardware study and the 2014 NASA study to have similarities in project 
synthesis, but in almost no other location. The 2014 NASA study also produced almost twice as many significant correlations as the 2013 government and commercial organizations study, as seen in figure 4. More interestingly, few correlations between the two studies shown in figure 4 overlapped. When the 2013 study was broken up into two matrices based on their organizations' focused projects (figure 5 and figure 6) and compared against the 2014 NASA study, again few correlations overlapped. Additional data is needed due to the similarities and more importantly the differences that were discovered among the matrices for where significant correlations were located based on the study examined. Finally, additional data should be gathered to continue to explore how engineering management variables impact project success.

The final portion of the data analysis displayed an additional 10 one-way ANOVA tables constructed to identify similarities and differences among the modified data collection instrument's questions based on organization. The sections of the modified data collection instrument were in regards to: project description variables, project success metrics, systems engineering processes, and non-technical variables. In regard to the project description variables, statistically significant differences were detected in commercial-focused projects in commercial organizations, but no statistically significant differences were discovered within government-focused projects in commercial organizations or NASA. When testing for questions effects in among project success metrics, statistically significant differences were detected within governmentfocused projects in commercial organizations, commercial-focused projects in commercial organizations, and in NASA projects. No statistically significant differences were detected in NASA projects among the systems engineering processes, but 
significant differences were detected within government-focused projects in commercial organizations and within commercial-focused projects in commercial organizations. The final ANOVA table tested for statistically significant question effects among nontechnical variables within NASA projects. This test did indicated statistically significant differences among non-technical variables within NASA projects.

Additional data and research is necessary based on the results from the hypotheses that were tested using the one-way ANOVA tables. Organizations were significantly different from each other in a different manor in each of the three sections tested using one-way ANOVA tables: the project descriptions variables section, project success metrics section, and systems engineering processes section. Also, in the systems engineering processes section, the organization and question interaction effects produced interesting results that should be followed up on, as well as the question effect. This was seen in table 13 and figure 13.

Based on the results from the matrices and one-way ANOVA tables, other than the need to gather supplemental data, two additional tasks are necessary for this research. The first task is to test a cluster analysis theory and see if certain NASA Centers cluster together. Centers are generally groups into one of three categories: human, research and robotics. A cluster analysis would be able to test if Centers are grouping into their Center type in regards to systems engineering based on their center description or if it is something else, for example location. Cultural differences among NASA Centers and a fear of getting too large to be successful at systems engineering has been present since the days of Wernher von Braun (Sato, 2005). The second task that needs to be conducted is text mining for the additional comments made by participants on the modified data 
collection instrument. The engineers who filled out the modified data collection instrument used the additional comments sections liberally. By applying text mining to these sections, additional information might be gleaned that originally was not captured through the use of a 7-point Likert scale only.

The following recommendations for future research were discovered through face-to-face interviews with NASA systems engineers (NASA, 2014). Two propositions will be discussed in detail: a collection of practical systems engineering tools titled, "The Bell Curve", and a parallel model based engineering study with the Space Launch System.

Systems engineers at NASA are looking for more practical tools for practitioners to use, but understand one universal tool is not realistic. Therefore, a combination of tools for engineers to use on projects can be modeled after a bell curve. The bottom of the bell curve would be for those individuals doing projects that are small and are unwilling to invest their time and effort into learning NASA's 17 systems engineering processes. Their tool would be something like a 30 page cookbook. Despite many feelings on engineers using cookbooks, it still could potentially be better for them to use a cookbook tool than no tools at all. The middle of the curve would consist of a tool called the System Integrated Model for Project Lifecycle (SIMPL), and would be used for the bulk of the projects done at NASA. SIMPL would be a computer program where at the beginning of your project, a project team member would answer what kind of project they were about to begin working on by answering some questions, most likely less than 100 questions. This would be similar to straw man requirements. An algorithm would then go through the database of all projects ever done at NASA and the five projects most 
similar to yours would populate. In doing so, the goal would be for SIMPL to help you figure out cost estimation, types of requirements you would need, etc. The program would help you create system models for you to use for doing the early conceptual work so that later on you can make modifications as necessary during the project's lifetime. Finally the top of the bell curve would cater to high-end projects. It would be more of a how to help you make an effective board structure and effectively implement the system, rather than advice on how to structure the system.

NASA is in the process of trying to embrace model-based systems engineering. For example, NASA Langley Research Center has conducted a pilot program to evaluate the benefits of using a Model-Based Systems Engineering (MBSE) approach during the early phase of the Materials International Space Station Experiment-X project. The goal was to understand the net gain of utilizing this approach on a moderate size flight project (Vipavetz, Murphy, \& Infeld, 2012). However, there is potential for additional work to be done, especially regarding the Space Launch System.

NASA is still a very document centric organization. When NASA captures requirements, they do so by capturing all the artifacts in systems engineering in a static format instead of a modeling format. NASA does do modeling for things, like to see how a vehicle will operate. However, those are design models to see how a rocket will fly through the atmosphere and handle the loads, how the rocket will handle acoustic environments or to see the different stresses, loads, and structural integrity of the vehicle. However, true modeling of the system where we have requirements and verification and all 17 systems engineering processes within the same model does not currently exist. NASA does the majority of its early processes through plain, static document capturing. 
NASA does some requirements management in a requirements database called, Cradle, where the Agency does vehicle performance modeling within software models. But, tying them all together into one true model does not currently exist in its entirety for a project. With the Space Launch System (SLS), there is a tight schedule and budget, so the Agency is unwilling to experiment with new ways of doing things.

The proposed idea is to try doing MBSE with a cube satellite on a smaller scale with a shorter lifecycle. Approved at the beginning of 2014 was for SLS to have secondary payloads, almost like cube satellites, that will fly in one of the adaptors in SLS. Once the crew capsule is released and goes on its way, 12 of these secondary payloads will be released.

Due to NASA's current setup, one cannot just go into a model and see all the different pieces of a project that are required to fit it. All the different pieces are in different models or documents. So the best way to run a study is to do a parallel activity with a big program development like SLS. The study would use the same information to develop a whole end-to-end process. A full model based system could be done without intruding on the main work of the program, and show as a parallel effort how much more efficiently MBSE is. Furthermore, as the program matures, the metrics can be looked at and analyzed. For example, how much time it took to do some portion of tracing the design implementation all the way back through the requirements versus how quickly it could be done in the whole system model.

However, a major obstacle would be persuading the SLS program to let researchers use their data and conduct a MBSE parallel case study. NASA is a government agency that must risk adverse because if a new way of trying systems 
engineering did not work, the outcome could be detrimental with the worst-case scenario being if the crew's safety were affected. It is recognized that there are many factors affecting why NASA is not progressing in systems engineering as quickly as industry. The most successful way to attempt a project like this would be for it to be done through a research institution where the researchers could show NASA how MBSE can be useful, and then lead NASA over to alternative and potentially better ways of doing systems engineering.

\section{Limitations of the Study}

The greatest potential limitations in this study were due to the participants and the data gathered. In the 2007 MSFC Flight Hardware study, all data was gathered through interviews and from one NASA Center location. Therefore, the questions coded and the correlations calculated in the matrix were created by the experimenters. In the 2013 Government and Commercial Organizations study, participants were primarily from the Midwest and Southeast areas of the country. Those participants also filled out the data collection instrument on a 4-point Likert scale and were to only answer the questions based on a project that had completed all phases of its lifecycle. In the 2014 NASA study, participants were collected through targeted sampling, filled out a modified data collection instrument on a 7-point Likert scale, and were allowed to answer questions based on projects that were cancelled and did not complete all phases of its lifecycle or based on projects still in progress and have not yet had a chance to complete all phases of its lifecycle. Due to the differences stated above in the three phases of the study, a 
potential limitation was the inconsistency in how the data was gathered from one phase to the next.

Allowing the 2014 NASA study engineers to answer questions on the modified data collection instrument based on projects cancelled or not yet completed was necessary in order to receive their participation. Because projects take so long at NASA and are often cancelled, such, as with Ares, few engineers would have been able to participate in the study if this allowance had not been made. However, due to this allowance, another inconsistency might have been created since all participants in the 2013 Government and Commercial Organizations study answered questions based on projects that had completed their life cycle.

Since the 2007 MSFC Flight Hardware study was conducted through interviews, the option of Not Applicable did not exist. However, in the 2013 and 2014 study, it did. Table 34 identifies the number of participants who chose to answer Not Applicable in the 2013 Government and Commercial Organization study and the 2014 NASA study for the Project Success Metrics section and the Systems Engineering Processes section. The highlighted rows draw your attention to the questions where the total between the 2013 and 2014 study, more than 10 applicants answered Note Applicable. One notable observation are the systems engineering processes $5-9$. All those processes had a large number of Not Applicable responses, which then translated into missings for the data analysis, with a sizeable portion of those missings coming from the 2014 NASA study participants. It is uncertain why so many Not Applicable responses came from this area of the processes, but it should be noted that those processes that are highlighted almost 
completely make up the back portion of the "Vee", which handles project synthesis. Due to the number of missings in this section, further investigation should be conducted.

Table 34. Number of Not Applicable Responses from Participants in Organizations

\begin{tabular}{|c|c|c|c|c|}
\hline \multirow{2}{*}{$\begin{array}{l}\text { Question } \\
\text { Section }\end{array}$} & \multicolumn{3}{|c|}{ Organization } & \multirow{2}{*}{ Total Responses /180 } \\
\hline & Commercial /83 & Government /46 & NASA $/ 51$ & \\
\hline PSM1 & 1 & 0 & 6 & 7 \\
\hline PSM2 & 5 & 2 & 5 & 12 \\
\hline PSM3 & 1 & 0 & 5 & 6 \\
\hline PSM4 & 2 & 2 & 6 & 10 \\
\hline PSM5 & 3 & 2 & 4 & 9 \\
\hline PSM6 & 6 & 5 & 5 & 16 \\
\hline PSM7 & 4 & 2 & 3 & 9 \\
\hline PSM8 & 9 & 0 & 3 & 12 \\
\hline PSM9 & 1 & 0 & 3 & 4 \\
\hline SE1 & 5 & 0 & 0 & 5 \\
\hline SE2 & 3 & 0 & 0 & 3 \\
\hline SE3 & 2 & 1 & 2 & 5 \\
\hline SE4 & 4 & 1 & 0 & 5 \\
\hline SE5 & 5 & 1 & 7 & 13 \\
\hline SE6 & 7 & 3 & 9 & 19 \\
\hline SE7 & 5 & 5 & 9 & 19 \\
\hline SE8 & 6 & 5 & 10 & 21 \\
\hline SE9 & 8 & 3 & 16 & 27 \\
\hline SE10 & 2 & 2 & 0 & 4 \\
\hline SE11 & 3 & 3 & 1 & 7 \\
\hline SE12 & 3 & 0 & 3 & 6 \\
\hline SE13 & 2 & 0 & 2 & 4 \\
\hline SE14 & 3 & 0 & 1 & 4 \\
\hline SE15 & 1 & 0 & 1 & 2 \\
\hline SE16 & 3 & 1 & 1 & 5 \\
\hline SE17 & 2 & 0 & 3 & 5 \\
\hline
\end{tabular}

Due to the number of Not Applicable responses, 500 iterations were run in $\mathrm{R}$ Studio to impute those missing. The correlations for the Project Success metrics and Systems Engineering processes for the 2014 NASA study were then calculated for the 
500 iterations and a mean for the 500 iterations, as well as its standard deviation were produced. A sample of the means and standard deviations from the correlations is illustrated in Table 35. Table 35 shows the correlations from the 2014 NASA study matrix that contained high standard deviations that show that the data points are spread out over a large range of values. Therefore, the standard deviations are great enough to make correlations listed in table 35 either significant, or remove them from being significant. This simulation further supports the study would benefit from additional data. 
Table 35. Correlations Between Systems Engineering Processes and Project Success Metrics with High Standard Deviations

\begin{tabular}{|c|c|c|}
\hline Question & Mean & Standard Deviation \\
\hline PSM4.SE4 & 0.343 & 0.065 \\
\hline PSM9.SE4 & 0.384 & 0.018 \\
\hline PSM2.SE5 & 0.431 & 0.0487 \\
\hline PSM4.SE5 & 0.364 & 0.051 \\
\hline PSM8.SE5 & 0.391 & 0.065 \\
\hline PSM9.SE5 & 0.411 & 0.079 \\
\hline PSM1.SE6 & 0.428 & 0.073 \\
\hline PSM2.SE6 & 0.465 & 0.081 \\
\hline PSM4.SE6 & 0.396 & 0.083 \\
\hline PSM6.SE6 & 0.350 & 0.093 \\
\hline PSM8.SE6 & 0.402 & 0.114 \\
\hline PSM9.SE6 & 0.362 & 0.123 \\
\hline PSM1.SE7 & 0.395 & 0.057 \\
\hline PSM4.SE7 & 0.327 & 0.073 \\
\hline PSM8.SE7 & 0.409 & 0.079 \\
\hline PSM9.SE7 & 0.399 & 0.074 \\
\hline PSM7.SE8 & 0.331 & 0.130 \\
\hline PSM8.SE8 & 0.292 & 0.132 \\
\hline PSM9.SE8 & 0.364 & 0.140 \\
\hline PSM3.SE10 & 0.462 & 0.072 \\
\hline PSM4.SE10 & 0.438 & 0.060 \\
\hline PSM7.SE10 & 0.398 & 0.017 \\
\hline PSM4.SE11 & 0.386 & 0.038 \\
\hline PSM8.SE11 & 0.406 & 0.017 \\
\hline PSM1.SE12 & 0.418 & 0.042 \\
\hline PSM2.SE12 & 0.4287 & 0.032 \\
\hline PSM8.SE12 & 0.390 & 0.023 \\
\hline PSM9.SE12 & 0.410 & 0.023 \\
\hline PSM1.SE13 & 0.396 & 0.043 \\
\hline
\end{tabular}




\section{References}

NASA, S. E. (2014). Systems Engineering at NASA, Past and Present. (K. A. Schomburg, Interviewer)

Sato, Y. (2005). Local Engineering and Systems Engineering: Cultural Conflict at NASA's Marshall Space Flight Center, 1960 - 1966. Technology and Culture , 46 (3), 561 - 583.

Vipavetz, K., Murphy, D., \& Infeld, S. (2012). Model-Based Systems Engineering Pilot Program at NASA Langley. AIAA Conference and Exposition, (p. Pasadena). 


\section{APPENDIX A. MODIFIED DATA COLLECTION INSTRUMENT}

The purpose of this survey is to gather information on what factor's influence a project's success at NASA.

Please focus on one, specific project when completing the survey.

The data collected in this survey will be used to help managers at NASA better utilize their resources.

Your contribution to this survey is anonymous and confidential. Information released will be in aggregate.

Please feel free to contact me. Kathryne Schomburg at Iowa State University, if you have any questions or concerns at kathryne@iastate.edu.

Thank you in advance for your contribution!

\section{1 - CD 4 = Company Description Question Block}

\section{CD1}

1. My organization is part of the:

- Public Sector

- Private sector (publicly traded)

- Other (please specify)

\section{CD1.1}

1.1 I am physically located at the:

- Ames Research Center

- Armstrong Flight Research Center

- Glenn Research Center

- Goddard Space Flight Center

- Goddard Institute of Space Studies

- Independent Verification and Validation Facility

- Jet Propulsion Laboratory

- Johnson Space Center

- Kennedy Space Center

- Langley Research Center

- Marshall Space Flight Center

- Michoud Assembly Facility

- NASA Headquarters

- NASA Shard Services Center

- Plum Brook Station

- Stennis Space Center

- Wallops Flight Facility

- White Sands Test Facility

- Other (please specify) 


\section{CD2}

2. My organization's industry or service is best described by (select the most representative category):

- Aerospace

- Agriculture

- Communications

- Defense \& Security

- Electronics \& Electrical

- Energy

- Environmental

- Health \& Welfare

- Infrastructure

- Transportation

- Other (please specify):

\section{CD3}

3. Within my physical location, Systems Engineering skills and responsibilities are:

- Contained in a single department

- Distributed throughout the organization

- Managed by a single department, but execution is done at the project level

- Not formally recognized in the organization

- Other (please specify):

\section{CD4}

4. We track SE effectiveness (select all that apply):

- At the organization level

- At the overall project level

- At the project task level

- At the individual level

- We do not track SE effectiveness

5. Please Share your organization's name (optional):

6. Additional thoughts, comments, information regarding your company description (optional)? 


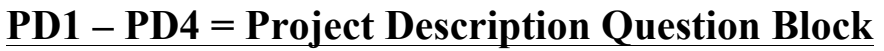

\section{PD1}

7. This project was representative of the scope of work my organization typically completes.

- Strongly Agree

- Agree

- Somewhat Agree

- Neither Agree nor Disagree

- Somewhat Disagree

- Disagree

- Strongly Disagree

- Not Applicable

\section{PD2}

8. This project had significant technical risk.

- Strongly Agree

- Agree

- Somewhat Agree

- Neither Agree nor Disagree

- Somewhat Disagree

- Disagree

- Strongly Disagree

- Not Applicable

\section{PD3}

9. This project had significant budgetary risk.

- Strongly Agree

- Agree

- Somewhat Agree

- Neither Agree nor Disagree

- Somewhat Disagree

- Disagree

- Strongly Disagree

- Not Applicable

\section{PD4}

10. This project had significant schedule risk.

- Agree

- Somewhat Agree

- Neither Agree nor Disagree

- Somewhat Disagree

- Disagree

- Strongly Disagree

- Not Applicable 


\section{PD5}

11. Which SE standard(s) was (were) used on this project (select all that apply):

- No standard was used

- Internally developed standard

- Defense Acquisition Guidebook

- ANSI/GEIA EIA-632

- EIA/IS 731.1

- IEEE 1220-2005

- ISO/IEC 15288

- ISO/IEC 15504: 2004

- ISO 10303-AP233

- CMMI

- NASA NPR 7123

- Other (please specify):

\section{PD6}

12. This project used a tailored approach based on the above SE standard(s):

- Followed the standard(s) with no tailoring

- Some tailoring of the standard(s)

- Extensive tailoring of the standard(s)

- No standard was followed - no tailoring

\section{PD7}

13. This project's primary focus is for:

- Aeronautics

- Human Exploration and Operations

- Science

- Space Technology

- Office of the Chief Technologist

- Other (please specify):

14. Additional thoughts, comments, information regarding your project description (optional)? 


\section{$\underline{\text { PSM1 - PSM9 = Project Success Metrics Question Block }}$}

\section{PSM1}

15. This project was a success when compared to the original technical requirements.

- Strongly Agree

- Agree

- Somewhat Agree

- Neither Agree nor Disagree

- Somewhat Disagree

- Disagree

- Strongly Disagree

- Not Applicable

\section{PSM2}

16. This project was a technical success when compared to other similar projects.

- Strongly Agree

- Agree

- Somewhat Agree

- Neither Agree nor Disagree

- Somewhat Disagree

- Disagree

- Strongly Disagree

- Not Applicable

\section{PSM3}

17. This project was a success when compared to the original project schedule

- Strongly Agree

- Agree

- Somewhat Agree

- Neither Agree nor Disagree

- Somewhat Disagree

- Disagree

- Strongly Disagree

- Not Applicable

\section{PSM4}

18. This project was a scheduling success when compared to other similar projects.

- Strongly Agree

- Agree

- Somewhat Agree

- Neither Agree nor Disagree

- Somewhat Disagree

- Disagree

- Strongly Disagree

- Not Applicable 


\section{PSM5}

19. This project was a success when compared to the original project budget.

- Strongly Agree

- Agree

- Somewhat Agree

- Neither Agree nor Disagree

- Somewhat Disagree

- Disagree

- Strongly Disagree

- Not Applicable

\section{PSM6}

20. This project was a budgeting success when compared to other similar projects.

- Strongly Agree

- Agree

- Somewhat Agree

- Neither Agree nor Disagree

- Somewhat Disagree

- Disagree

- Strongly Disagree

- Not Applicable

\section{PSM7}

21. The project management process used was effective.

- Strongly Agree

- Agree

- Somewhat Agree

- Neither Agree nor Disagree

- Somewhat Disagree

- Disagree

- Strongly Disagree

- Not Applicable

\section{PSM8}

22. Overall this project was viewed by our organization as a success.

- Strongly Agree

- Agree

- Somewhat Agree

- Neither Agree nor Disagree

- Somewhat Disagree

- Disagree

- Strongly Disagree

- Not Applicable 


\section{PSM9}

23. Overall this project was viewed by our stakeholders as a success.

- Strongly Agree

- Agree

- Somewhat Agree

- Neither Agree nor Disagree

- Somewhat Disagree

- Disagree

- Strongly Disagree

- Not Applicable

24. Additional thoughts, comments, information regarding your project success metrics (optional)?

\section{SE1 - SE17 = Systems Engineering Processes Question Block}

There are three sets of common technical processes in the NASA Systems Engineering Processes and Requirements: system design, product realization, and technical management. The processes in these three sets collectively make up 17 steps known as the "systems engineering engine". The 17 questions in this section are a reflection of the 17 steps in the "systems engineering engine".

\section{SE1}

25. This project identified all the stakeholders and their expectations for the system under development.

- Strongly Agree

- Agree

- Somewhat Agree

- Neither Agree nor Disagree

- Somewhat Disagree

- Disagree

- Strongly Disagree

- Not Applicable

\section{SE2}

26. The project transformed stakeholder expectations into unique, quantitative, and measurable technical requirements that can be used for defining a design solution.

- Strongly Agree

- Agree

- Somewhat Agree

- Neither Agree nor Disagree

- Somewhat Disagree

- Disagree

- Strongly Disagree

- Not Applicable 


\section{SE3}

27. This project decomposed and allocated requirements to the lowest possible level of the system.

- Strongly Agree

- Agree

- Somewhat Agree

- Neither Agree nor Disagree

- Somewhat Disagree

- Disagree

- Strongly Disagree

- Not Applicable

\section{SE4}

28. This project translated the requirements into a design solution.

- Strongly Agree

- Agree

- Somewhat Agree

- Neither Agree nor Disagree

- Somewhat Disagree

- Disagree

- Strongly Disagree

- Not Applicable

\section{SE5}

29. This project translated the design solution into the actual system.

- Strongly Agree

- Agree

- Somewhat Agree

- Neither Agree nor Disagree

- Somewhat Disagree

- Disagree

- Strongly Disagree

- Not Applicable

SE6

30. This project integrated lower level products into higher level products and ensured proper functionality of the system.

- Strongly Agree

- Agree

- Somewhat Agree

- Neither Agree nor Disagree

- Somewhat Disagree

- Disagree

- Strongly Disagree

- Not Applicable 
SE7

31. The project conducted a verification program to ensure the end product conforms to design requirements and specifications (the system was completed correctly).

- Strongly Agree

- Agree

- Somewhat Agree

- Neither Agree nor Disagree

- Somewhat Disagree

- Disagree

- Strongly Disagree

- Not Applicable

\section{SE8}

32. This project conducted a validation program to ensure the end product satisfied stakeholder expectations and would perform its intended use or function (the correct system was completed).

- Strongly Agree

- Agree

- Somewhat Agree

- Neither Agree nor Disagree

- Somewhat Disagree

- Disagree

- Strongly Disagree

- Not Applicable

\section{SE9}

33. This project transitioned a verified and validated realized system to a customer at the next level of integration or the end-user.

- Strongly Agree

- Agree

- Somewhat Agree

- Neither Agree nor Disagree

- Somewhat Disagree

- Disagree

- Strongly Disagree

- Not Applicable 


\section{SE10}

34. This project established a plan to apply and manage the technical processes within all technical and programmatic constraints.

- Strongly Agree

- Agree

- Somewhat Agree

- Neither Agree nor Disagree

- Somewhat Disagree

- Disagree

- Strongly Disagree

- Not Applicable

\section{SE11}

35. The project managed the product requirements providing traceability and changes to established requirements.

- Strongly Agree

- Agree

- Somewhat Agree

- Neither Agree nor Disagree

- Somewhat Disagree

- Disagree

- Strongly Disagree

- Not Applicable

\section{SE12}

36. This project managed interface development, maintaining definition and compliance.

- Strongly Agree

- Agree

- Somewhat Agree

- Neither Agree nor Disagree

- Somewhat Disagree

- Disagree

- Strongly Disagree

- Not Applicable

\section{SE13}

37. This project measured, assessed, and managed risk.

- Strongly Agree

- Agree

- Somewhat Agree

- Neither Agree nor Disagree

- Somewhat Disagree

- Disagree

- Strongly Disagree

- Not Applicable 


\section{SE14}

38. This project identified, controlled, and preserved (recorded) the system configuration.

- Strongly Agree

- Agree

- Somewhat Agree

- Neither Agree nor Disagree

- Somewhat Disagree

- Disagree

- Strongly Disagree

- Not Applicable

\section{SE15}

39. This project managed the identification, acquisition, access, protection, and distribution of technical data.

- Strongly Agree

- Agree

- Somewhat Agree

- Neither Agree nor Disagree

- Somewhat Disagree

- Disagree

- Strongly Disagree

- Not Applicable

\section{SE16}

40. This project monitored technical progress and provided status updates in support of the systems engineering process.

- Strongly Agree

- Agree

- Somewhat Agree

- Neither Agree nor Disagree

- Somewhat Disagree

- Disagree

- Strongly Disagree

- Not Applicable

\section{SE17}

41. This project employed established decision analysis processes regarding technical decisions, alternatives, and uncertainties impacting cost, schedule, and risk.

- Strongly Agree

- Agree

- Somewhat Agree

- Neither Agree nor Disagree

- Somewhat Disagree

- Disagree

- Strongly Disagree

- Not Applicable 
42. Additional thoughts, comments, information regarding your systems engineering processes (optional)?

\section{$\underline{\text { DTMI }=\text { Distributed Team Member Interactions Question Block }}$}

\section{DTMI1}

43. How many groups of team members at remote locations were involved in your project's day-to-day work (i.e. you cannot easily walk over to talk with them)?

\section{DTMI2}

44. For your project, what is the average percentage of your total team that typically participated in meetings from other location? $\%$

\section{DTMI3}

45. Please indicate what percentages of your team meetings were informal versus formal (i.e. brainstorming versus design reviews).

Formal team meetings Informal team meetings Total

$$
\overline{100 \%}
$$

\section{DTMI4}

46. If some of your meetings involved virtual participants, what technologies did you use (select all that apply)?

- Telephone conferencing system

- Shared desktop software (e.g. WebEx, Lync, Connect, Sametime, etc.)

- Low fidelity video conferencing (e.g. Skype, webcam)

- High fidelity video conferencing systems (e.g. point-to-point video conferencing)

- Electronic distribution of documents (e.g. email)

- Shared drawing surfaces (e.g. electronic whiteboards)

- Text-based communication software (e.g. Google chat, Facebook, cellphone)

- Other (please specify):

47. List any differences you have noticed when having virtual meetings instead of faceto-face meetings (optional): 


\section{DTMI6}

48. On average, how often do you interact with your team members who are located at the same facility as you?

- Daily

- 2-3 Times a Wee

- Once a Week

- 2-3 Times a Month

- Once a Month

- Less than Once a Month

- Annually

\section{DTMI7}

49. On average, how often do you interact with your team members who are located at a different facility than you?

- Daily

- 2-3 Times a Wee

- Once a Week

- 2-3 Times a Month

- Once a Month

- Less than Once a Month

- Annually

50. Additional thoughts, comments, information regarding your team dynamics (optional)?

\section{$\underline{\text { NTV }=\text { Non-Technical Variables Question Block }}$}

\section{NTV1}

51. I was very familiar with the details of the project during the project life cycle.

- Strongly Agree

- Agree

- Somewhat Agree

- Neither Agree nor Disagree

- Somewhat Disagree

- Disagree

- Strongly Disagree

- Not Applicable

\section{NTV2}

52. I was a part of this project from the birth of the project through to the end of the project's completion.

- Yes

- No 


\section{NTV3}

53. I was professionally invested in the project.

- Strongly Agree

- Agree

- Somewhat Agree

- Neither Agree nor Disagree

- Somewhat Disagree

- Disagree

- Strongly Disagree

- Not Applicable

\section{NTV4}

54. I was personally invested in the project.

- Strongly Agree

- Agree

- Somewhat Agree

- Neither Agree nor Disagree

- Somewhat Disagree

- Disagree

- Strongly Disagree

- Not Applicable

\section{NTV5}

55. How many other projects were you involved with while working on this project?

$$
\begin{aligned}
& -0 \\
& -1 \\
& -2 \\
& -3 \\
& -4+
\end{aligned}
$$

\section{NTV6}

56. Funding constraints positively impacted the project's success.

- Strongly Agree

- Agree

- Somewhat Agree

- Neither Agree nor Disagree

- Somewhat Disagree

- Disagree

- Strongly Disagree

- Not Applicable 


\section{NTV7}

57. Volatility of requirements positively impacted the project's success.

- Strongly Agree

- Agree

- Somewhat Agree

- Neither Agree nor Disagree

- Somewhat Disagree

- Disagree

- Strongly Disagree

- Not Applicable

\section{NTV8}

58. Team experience positively impacted the project's success.

- Strongly Agree

- Agree

- Somewhat Agree

- Neither Agree nor Disagree

- Somewhat Disagree

- Disagree

- Strongly Disagree

- Not Applicable

\section{NTV9}

59. The level of testing positively impacted the project's success.

- Strongly Agree

- Agree

- Somewhat Agree

- Neither Agree nor Disagree

- Somewhat Disagree

- Disagree

- Strongly Disagree

- Not Applicable

\section{NTV10}

60. Development duration (in month) positively impacted the project's success.

- Strongly Agree

- Agree

- Somewhat Agree

- Neither Agree nor Disagree

- Somewhat Disagree

- Disagree

- Strongly Disagree

- Not Applicable 


\section{NTV11}

61. The number of organizations involved positively impacted the project's success.

- Strongly Agree

- Agree

- Somewhat Agree

- Neither Agree nor Disagree

- Somewhat Disagree

- Disagree

- Strongly Disagree

- Not Applicable

\section{NTV12}

62. The degree of formulation study positively impacted the project's success.

- Strongly Agree

- Agree

- Somewhat Agree

- Neither Agree nor Disagree

- Somewhat Disagree

- Disagree

- Strongly Disagree

- Not Applicable

\section{NTV13}

63. The new design factor (development of new hardware for this project) positively impacted the project's success.

- Strongly Agree

- Agree

- Somewhat Agree

- Neither Agree nor Disagree

- Somewhat Disagree

- Disagree

- Strongly Disagree

- Not Applicable

64. Additional thoughts, comments, information regarding your non-technical experience (optional): 


\section{$\mathrm{CO}=$ Information on the project's communication and organization level}

\section{CO1}

65. My position the project was:

- Project Manager

- Deputy Project Manager

- Chief Engineer

- Deputy Chief Engineer

- Systems Engineer

- Deputy Systems Engineer

- Functional lead Engineer

- Design Lead Engineer

- Other (please specify):

$\mathrm{CO2}$

66. Rate this project's communication formality versus informality as compared to other similar projects:

- Very Formal

- Formal

- Slightly Formal

- Average

- Less Formal

- Informal

- Very Informal

- Not Applicable

\section{$\mathrm{CO3}$}

67. Rate the communication speed within this project as compared to other similar projects:

- Extremely Slow

- Slow

- Somewhat Slow

- Average

- Somewhat Fast

- Fast

- Extremely Fast

- Not Applicable 


\section{$\mathrm{CO} 4$}

68. Rate this project's process procedures in terms of flexibility versus standardization when compared to other similar projects:

- Very Flexible

- Flexible

- Slightly Flexible

- Average

- Less Flexible

- Standardized

- Completely Standardized

- Not Applicable

\section{CO5}

69. Rate the complexity of the design mission compared to other projects in the organization:

- Very Complex

- Complex

- Slightly Complex

- Average

- Less Complex

- Simple

- Very Simple

- Not Applicable

\section{CO6}

70. Rate the number of communication gaps seen within this project as compared to other similar projects.

- An Extreme Amount

- Quite a Bit

- Some

- Average

- Few

- Almost None

- None

- Not Applicable

\section{CO7}

71. Please list up to 3 of the 17 steps from the systems engineering engine you consider to be most important for the success of the project (optional).

Item I:

Item II:

Item III: 


\section{CO8:}

72. From your perspective, describe the formal or informal responsibility you have for the systems engineering/ life cycle process of this project. You may find it helpful to discuss the areas that you feel are outside your area of responsibility (optional).

\section{CO9:}

73. Describe the organization structure, including Approval Boards, of the project in question (i.e. small management group consisting of $\mathrm{X}$ people with matrixed employees for task accomplishment from $\mathrm{Y}$ and $\mathrm{Z}$ areas of the organization (optional).

74. Additional thoughts, comments, information regarding the organization, culture or communication influences on the SE process (optional):

\section{$\underline{\text { ISIS }=\text { Informal Subsystems Integration Strategies }}$}

The following questions below are about your experiences in facilitating the integration of subsystems. A "margin" is a buffer added to a design parameter, cost estimate, or schedule estimate as a hedge against future needs, e.g.: "Holding something in your back pocket" during negotiations between subsystems.

\section{ISSI1}

75. In this project, subsystems held back significant margins when negotiating parameter integration with other subsystems.

- Strongly Agree

- Agree

- Somewhat Agree

- Neither Agree nor Disagree

- Somewhat Disagree

- Disagree

- Strongly Disagree

- Not Applicable 


\section{ISIS2}

76. In this project, subsystems understood when other subsystems were holding back margins.

- Never

- Rarely

- Sometimes

- Often

- Frequently

- Almost Always

- Always

- Not Applicable

\section{ISIS3}

77. In this project, subsystems accounted for the margins of other subsystems when making design decisions.

- Never

- Rarely

- Sometimes

- Often

- Frequently

- Almost Always

- Always

- Not Applicable

\section{ISSI4}

78. In this project, holding back margins during subsystem integration affected the overall system integration.

- Strongly Agree

- Agree

- Somewhat Agree

- Neither Agree nor Disagree

- Somewhat Disagree

- Disagree

- Strongly Disagree

- Not Applicable

79. Additional thoughts, comments, information regarding informal subsystems integration strategies (optional): 


\section{APPENDIX B. TERM DESCRIPTIONS}

The following section describes reasoning for select questions and why they were asked. Also, some terms are defined or expanded upon.

\section{My organization is part of the:}

Reasoning: This question was necessary incase any non-NASA systems engineers or engineering managers participated in the survey.

\subsection{I am physically located at the:}

Reasoning: Knowing the participant's physical location allows us to compare how projects are experienced from one center to another. See www.nasa.gov for more information.

2. My organization's industry or service is best described by (select the most representative category):

Reasoning: This question was necessary incase any non-NASA systems engineers or engineering managers participated in the survey. Also, the original data collection instrument from the 2013 study included this question and was necessary to maintain consistency through the study.

\section{Which SE standard(s) was (were) used on this project (select all that apply):}

Reasoning: Please see http://www.incose.org/practice/standardsupdate.aspx for additional information.

\section{This project's primary focus is for:}

Reasoning: This question was asked to see if the project experiences within the Mission Directorates were $\quad$ Please serm. http://www.nasa.gov/offices/education/missions/index.html\#.U5XfmxbtBg0 for additional information. 
15. This project was a success when compared to the original technical requirements.

16. This project was a technical success when compared to other similar projects.

17. This project was a success when compared to the original project schedule

18. This project was a scheduling success when compared to other similar projects.

19. This project was a success when compared to the original project budget.

20. This project was a budgeting success when compared to other similar projects.

21. The project management process used was effective.

22. Overall this project was viewed by our organization as a success.

23. Overall this project was viewed by our stakeholders as a success.

Reasoning: Questions 15 - 23 were developed through, "The Role of Project Risk in Determining Project Management Approach" and exhibit 3 from "A Preliminary Assessment of the Relationship Between Project Success, System Engineering, and Team Organization". Please see Tech1 (X41), Tech2 (X42), Time (X44), Cost (X43), Process (X45) and Overall (X47) for additional information.

25. This project identified all the stakeholders and their expectations for the system under development.

Definition: The Stakeholder Expectations Definition Process is the initial process within the systems engineering engine that establishes the foundation from which the system is designed and the product is realized. The main purpose of this process is to identify who the stakeholders are and how they intend to use the product. This is usually accomplished through use-case scenarios, Design Reference Missions (DRMs), and ConOps. For additional information, please see page 33 of the 2007 NASA handbook. 
26. The project transformed stakeholder expectations into unique, quantitative, and measurable technical requirements that can be used for defining a design solution.

Definition: The Technical Requirements Definition Process transforms the stakeholder expectations into a definition of the problem, then into a definition of the problem, and then into a complete set of validated technical requirements expressed as "shall" statements that can be used for defining a design solution for the Product Breakdown Structure (PBS) model and related enabling products. The process of requirements definition is a recursive and iterative one that develops the stakeholders' requirements, product requirements, and lower level product/component requirements (e.g., PBS model products such as systems or subsystems and related enabling products such as external systems that provide or consume data). The requirements should enable the description of all inputs, outputs, and required relationships between inputs and outputs. The requirements documents organize and communicate requirements to the customer and other stakeholders and the technical community. This applies to the definition of all technical requirements from the program, project, and system levels down to the lowest level product/component requirements document. For additional information, please see page 40 of the 2007 NASA handbook.

\section{This project decomposed and allocated requirements to the lowest possible level of the system.}

Definition: The Logical Decomposition is the process for creating the detailed functional requirements that enable NASA programs and projects to meet the stakeholder expectations. It identifies the "what" that must be achieved by the system at each level to enable a successful project. It also utilizes functional analysis to create a system architecture and to decompose top-level (or parent) requirements and allocates them down to the lowest desired levels of the project. For additional information, please see page 49 of the handbook.

\section{This project translated the requirements into a design solution.}

Definition: The Design Solution Definition Process is used to translate the highlevel requirements derived from the stakeholder expectations and the outputs of the Logical Decomposition Process into a design solution. This is transforming the defined logical decomposition models and their associated sets of derived technical requirements into alternative solutions. Alternative solutions are analyzed through detailed trade studies that result in the selection of a preferred alternative. The preferred alternative is then fully defined into a final design solution that will satisfy the technical requirements. The design solution definition will be used to generate the end product specifications that will be used to produce the product and to conduct product verification. The process may be further refined depending on whether there are additional subsystems of the end product that need to be defined. For additional information, please see page 55 of the NASA handbook. 


\section{This project translated the design solution into the actual system.}

Definition: The Product Implementation is the first process encountered in the systems engineering engine that begins the movement from the bottom of the product hierarch up towards the Product Transition Process. This is where plans, designs, analysis, requirements development, and drawings are realized into actual products. For additional information, please see page 73 of the NASA handbook.

\section{This project integrated lower level products into higher-level products and} ensured proper functionality of the system.

Definition: Product Integration is one of the systems engineering engine product realization processes that make up the system structure. The lower level products are assembled into higher-level products and checked to make sure that the integrated product function properly. It is an element of the processes that lead realized products from a level below to realize end products at a level above, between the Product Implementation, Verification, and Validation Processes. For additional information, please see page 78 of the NASA handbook.

31. The project conducted a verification program to ensure the end product conforms to design requirements and specifications (the system was completed correctly).

Definition: The Product Verification Process is the first of the verification and validation processes conducted on a realized end product. A realized product is one provided by either the Product Implementation Process or the Product Integration Process in a form suitable for meeting applicable life-cycle phase success criteria. Realization is the act of verifying, validating, and transitioning the realized product for use at the next level up of the system structure or to the customer. This process determines if the end product was realized correctly. For additional information, please see page 83 of the NASA handbook.

32. This project conducted a validation program to ensure the end product satisfied stakeholder expectations and would perform its intended use or function (the correct system was completed).

Definition: The Validation Process is the second of the verification and validation processes conducted on a realized end product. This answers the question of if the correct system was done. It provides objective evidence that every "shall" statement was met, whereas validation is performed for the benefit of the customers and users to ensure that the system functions in the expected manner when placed in the intended environment. This confirms that realized end products at any position within the system structure conform to their set of stakeholder expectations captured in the ConOps, and ensures that any anomalies discovered during validation are appropriately resolved prior to product delivery. For additional information, please see page 98 of the NASA handbook. 


\section{This project transitioned a verified and validated realized system to a customer at the next level of integration or the end-user.}

Definition: The Product Transition Process is used to transition a verified and validated end product that has been generated by product implementation or product integration to the customer at the next level in the system structure for integration into an end product or, for the top-level end product, transitioned to the intended end used. The form of the product transitioned will be a function of the product-line life-cycle phase success criteria and the location within the system structure of the WBS model in which the end product exists. For additional information, please see page 106 of the NASA handbook.

34. This project established a plan to apply and manage the technical processes within all technical and programmatic constraints.

Definition: The Technical Planning Process, the first of eight technical management processes contained in the systems engineering engine, establishes a plan for applying and managing each of the common technical processes that will be used to drive the development of system products and associated work products. It establishes a plan for identifying and defining the technical effort required to satisfy the project objectives and life-cycle phase success criteria within the cost, schedule, and risk constraints of the project. For additional information, please see page 112 of the NASA handbook.

\section{The project managed the product requirements providing traceability and changes to established requirements.}

Definition: Requirements Management activities apply to the management of all stakeholder expectations, customer requirements, and technical product requirements down to the lowest level product component requirements (hereafter referred to as expectations and requirements). It is used to: manage the product requirements identified, baselined, and used in the definition of the work breakdown structure (WBS) model products during system design, provides bi-directional traceability back to the top WBS model requirements, and manage the changes to established requirement baselines over the life cycle of the system products. For additional information, please see page 131 of the NASA handbook.

\section{This project managed interface development, maintaining definition and compliance.}

Definition: The management and control for interfaces is crucial to successful

programs or projects. The interface management is a process to assist in controlling product development when efforts are divided among parties (e.g. Government, contractors, geographically diverse technical teams) and/or to define and maintain compliance among the products that must interoperate. For additional information, please see page 136 of the NASA handbook. 


\section{This project measured, assessed, and managed risk.}

Definition: The Technical Risk Management Process is one of the crosscutting technical management processes. Risk is defined as the combination of (1) the probability that a program or project will experience an undesired event and (2) the consequences, impact, or severity of the undesired event, were it to occur. Technical risk management is an organized, systematic risk-informed decision making discipline that proactively identifies, analyzes, plans, tracks, controls communicates, documents, and manages risk to increase the likelihood of achieving project goals. Risk Management Process focuses on project objectives, bringing to bear an analytical basis for risk management decisions and the ensuing management activities, and a framework for dealing with uncertainty. For additional information, please see page 139 of the NASA handbook.

\section{This project identified, controlled, and preserved (recorded) the system configuration.}

Definition: Configuration Management is a management discipline applied over the product's life cycle to provide visibility into and to control changes to performance and functional and physical characteristics. Configuration management ensures that the configuration of a product is known and reflected in product information, that any product change is beneficial and is effected without adverse consequences, and that changes are managed. Configuration management reduces technical risks by ensuring correct product configurations, distinguishes among product versions, ensures consistency between the product and information about the product, and avoids the embarrassment of stakeholder dissatisfaction and complaint. NASA adopts the configuration management principles as defined by ANSI/EIA 649, NASA methods of implementation as defined by NASA configuration management professionals, and as approved by NASA management. For additional information, please see page 151 of the NASA handbook.

39. This project managed the identification, acquisition, access, protection, and distribution of technical data.

Definition: The Technical Data Management Process is used to plan for, acquire, access, manage, protect, and use data of a technical nature to support, eventual retirement, and retention of appropriate technical, to include mission and science, data beyond system retirement as required by NPR 1441.1, NASA Records Retention Schedules. The key aspects are: application of policies and procedures for data identification and control, timely and economical acquisition of technical data, assurance of the adequacy of data and its protection, facilitating access to distribution of the data to the point of use, analysis of data use, evaluation of data for future value to other programs/ projects, and process access to information written in legacy software. For additional information, please see page 158 of the NASA handbook. 
40. This project monitored technical progress and provided status updates in support of the systems engineering process.

Definition: The Technical assessment is the crosscutting process used to help monitor technical progress of a program/project through Periodic Technical Reviews (PTRs). It provides status information to support assessing system design, product realization, and technical management decisions. For additional information, please see page 166 of the NASA handbook.

41. This project employed established decision analysis processes regarding technical decisions, alternatives, and uncertainties impacting cost, schedule, and risk.

Definition: Decision analysis offers individuals and organizations a methodology for making decisions; it also offers techniques for modeling decision problems mathematically and finding optimal decisions numerically. For additional information, please see page 197 of the NASA handbook.

51. I was very familiar with the details of the project during the project life cycle.

52. I was a part of this project from the birth of the project through to the end of the project's completion.

\section{I was professionally invested in the project.}

\section{I was personally invested in the project.}

55. How many other projects were you involved with while working on this project?

Reasoning: For more information on questions 51-55, please see the "Systems Engineering for Life cycle of Complex Systems" on pages $302-317$.

\section{Funding constraints positively impacted the project's success.}

Reasoning: This question is trying to learn about budget constraints, and measure the difficulties the project had in obtaining timely funding. Whether or not the project has a capped budget at the outset, or worse, a budget constrained after the project has been given authority to proceed. Project budgets normally follow a bell-shaped curveinitially low periodic funding (annually in the case of space projects) that grows in later years to a peak and then tapers off in the last years. A constrained budget is one in which these period to period budget commitments from the sponsor exhibit an irregular pattern such as initial grown followed by stagnation or even decreases before picking up again. For additional information, please see "Using our Right Brains to Improve Space Project Cost Estimating" on pages (1 - 16) and "Improving Space Project Cost Estimating with Engineering Management Variables” on pages (15 - 20). 


\section{Volatility of requirements positively impacted the project's success.}

Reasoning: This question looked at changes in what the project was originally intended to do from a mission point of view, and the degree to which the top-level requirements of the projects have been determined, documented and stabilized. A project with requirements' volatility is one in which the initial requirements were substantially changed after project start. For additional information, please see "Using our Right Brains to Improve Space Project Cost Estimating" on pages $(1-16)$ and "Improving Space Project Cost Estimating with Engineering Management Variables" on pages (15 20).

\section{Team experience positively impacted the project's success.}

Reasoning: The experience of the team is very rarely discussed, except in some lessons learned documents. When the team experiences are discussed, they are almost always in glowing terms. The familiarity of the project development team with the technologies being used in the specific design implementation of the mission gained from previous experience with similar missions. For additional information, please see "Using our Right Brains to Improve Space Project Cost Estimating" on pages (1 - 16) and "Improving Space Project Cost Estimating with Engineering Management Variables” on pages $(15-20)$.

\section{The level of testing positively impacted the project's success.}

Reasoning: The project manager decides how much testing to perform. The amount of testing performed, versus analytical verification, should be positively correlated to cost. While more testing tends to cost more, this variable rather obviously needs to be considered in relation to mission success rate. Testing should be "right sized" in order to perform as cost effectively as possible while not jeopardizing project success. For additional information, please see "Using our Right Brains to Improve Space Project Cost Estimating" on pages $(1-16)$ and "Improving Space Project Cost Estimating with Engineering Management Variables” on pages (15 - 20).

\section{Development duration (in month) positively impacted the project's success.}

Reasoning: Schedule span is the date by which the project is ready for initial operating capability in relation to the start date. Projects that are either required too quickly or are stretched out too far will presumably suffer budget inefficiencies. For additional information, please see "Using our Right Brains to Improve Space Project Cost Estimating" on pages (1 - 16) and "Improving Space Project Cost Estimating with Engineering Management Variables” on pages (15 - 20). 


\section{The number of organizations involved positively impacted the project's success.}

Reasoning: We tabulated the number of distinct government laboratory, contractor, research institute and university organizations for each project and simply counted them. We did not count organizations, which only worked on the spacecraft bus. Sometimes one organization worked on different aspects of the science part of the project. The number of government sponsors such as NASA, DOD, NOAA, etc.), the number of prime contractors involved and the number of science organizations involved. More organizations would hypothetically complicate the project and drive cost and schedule. For additional information, please see "Using our Right Brains to Improve Space Project Cost Estimating" on pages $(1-16)$ and "Improving Space Project Cost Estimating with Engineering Management Variables” on pages (15 - 20).

\section{The degree of formulation study positively impacted the project's success.}

Reasoning: Counted Phase A and B efforts and calculated the percent spent there as a function of the Phase $C / D$ cost. The amount of resources expended prior to the beginning of full-scale development on advancing the understanding of the complexities of the project development undertaking. The hypothesis here was that projects that have spent more on formulation study would exhibit lower ultimate cost. For additional information, please see "Using our Right Brains to Improve Space Project Cost Estimating" on pages $(1-16)$ and "Improving Space Project Cost Estimating with Engineering Management Variables” on pages (15 - 20).

\section{The new design factor (development of new hardware for this project) positively impacted the project's success.}

Reasoning: The project manager makes a conscious decision on the extent to which he or she will use off-the-shelf hardware versus develop new hardware. For additional information, please see "Using our Right Brains to Improve Space Project Cost Estimating” on pages $(1-16)$. 


\section{APPENDIX C. NASA CENTER DESCRIPTIONS}

\begin{tabular}{|c|c|c|}
\hline Center/ Facility & Location & Center/ Facility Description \\
\hline $\begin{array}{c}\text { Ames Research } \\
\text { Center }\end{array}$ & $\begin{array}{l}\text { Silicon Valley, } \\
\text { California }\end{array}$ & $\begin{array}{l}\text { - } \text { Research and Development } \\
\text { - Specializes in research geared towards } \\
\text { creating new knowledge and new } \\
\text { technologies that span the spectrum of } \\
\text { NASA interests. } \\
\text { - Focuses: Entry systems, Supercomputing, } \\
\text { NextGen air transportation, Airborne } \\
\text { Science, Low-Cost Missions, Biology \& } \\
\text { Astrobiology, Exoplanets, Autonomy \& } \\
\text { Robotics, Lunar Science, Human Factors, } \\
\text { Wind Tunnels. }\end{array}$ \\
\hline $\begin{array}{c}\text { Armstrong } \\
\text { Flight Research } \\
\text { Center }\end{array}$ & $\begin{array}{l}\text { Edwards, } \\
\text { California }\end{array}$ & $\begin{array}{l}\text { - NASA's primary center for atmospheric } \\
\text { flight research and operations } \\
\text { - Lead center for flight research, and } \\
\text { innovates in aeronautics and space } \\
\text { technology. }\end{array}$ \\
\hline $\begin{array}{c}\text { Glenn Research } \\
\text { Center }\end{array}$ & Cleveland, Ohio & $\begin{array}{l}\text { - } \text { Research Center } \\
\text { Develops and transfers critical } \\
\text { technologies that address national priorities } \\
\text { through research, technologies that address } \\
\text { national priorities through research, } \\
\text { technology development, and systems } \\
\text { development for safe and reliable } \\
\text { aeronautics, aerospace, and space } \\
\text { applications. }\end{array}$ \\
\hline $\begin{array}{l}\text { Goddard Space } \\
\text { Flight Center }\end{array}$ & $\begin{array}{l}\text { Greenbelt, } \\
\text { Maryland }\end{array}$ & $\begin{array}{l}\text { - Robotics Center } \\
\text { - Its mission is to expand knowledge on the } \\
\text { Earth and its environment, the solar } \\
\text { system, and the universe through } \\
\text { observations from space. } \\
\text { - Focuses: Earth Science, Astrophysics, } \\
\text { Heliophysics, Planetary Science }\end{array}$ \\
\hline
\end{tabular}




\begin{tabular}{|c|c|c|}
\hline Center/ Facility & Location & Center/Facility Description \\
\hline $\begin{array}{l}\text { Jet Propulsion } \\
\text { Laboratory }\end{array}$ & $\begin{array}{l}\text { Pasadena, } \\
\text { California }\end{array}$ & $\begin{array}{l}\text { - Robotics Center } \\
\text { Managed by the California Institute of } \\
\text { Technology, is NASA's lead center for } \\
\text { robotic exploration of the Solar System. }\end{array}$ \\
\hline $\begin{array}{c}\text { Johnson Space } \\
\text { Center }\end{array}$ & Houston, Texas & $\begin{array}{l}\text { - Hub of human spaceflight activity for } 50+ \\
\text { - } \text { years } \\
\text { - Mome to ISS mission operations } \\
\text { - Leads NASA's effort in Human Space } \\
\text { Exploration e.g., the Space Shuttle and } \\
\text { International Space Station programs. }\end{array}$ \\
\hline $\begin{array}{c}\text { Kennedy Space } \\
\text { Center }\end{array}$ & $\begin{array}{c}\text { Cape Canaveral, } \\
\text { Florida }\end{array}$ & $\begin{array}{l}\text { - Launching } \\
\text { - Home to NASA's Launch Service Program } \\
\text { - Launches satellites and robotic missions } \\
\text { NASA's lead center for preparing and } \\
\text { launching missions around the Earth and } \\
\text { beyond. }\end{array}$ \\
\hline $\begin{array}{c}\text { Langley } \\
\text { Research } \\
\text { Center }\end{array}$ & $\begin{array}{l}\text { Hampton, } \\
\text { Virginia }\end{array}$ & $\begin{array}{l}\text { - Research Center } \\
\text { - Conducts aviation and space research for } \\
\text { aerospace, atmospheric sciences, and } \\
\text { technology commercialization. }\end{array}$ \\
\hline $\begin{array}{l}\text { Marshall Space } \\
\text { Flight Center }\end{array}$ & $\begin{array}{l}\text { Huntsville, } \\
\text { Alabama }\end{array}$ & $\begin{array}{l}\text { - } \text { Field Center } \\
\text { - } \text { Propulsion and space transportation } \\
\text { - } \text { Engineering } \\
\text { - Science } \\
\text { - Space systems } \\
\text { - } \text { Project and program management } \\
\text { - Leader in access to space and the use of } \\
\text { space for research and development to } \\
\text { benefit humanity. }\end{array}$ \\
\hline
\end{tabular}




\begin{tabular}{|c|c|c|}
\hline Center/ Facility & Location & Center/Facility Description \\
\hline $\begin{array}{l}\text { Stennis Space } \\
\text { Center }\end{array}$ & $\begin{array}{l}\text { Bay St. Louis, } \\
\text { Mississippi }\end{array}$ & $\begin{array}{l}\text { - Rocket engine test complex } \\
\text { - NASA's program manager for rocket } \\
\text { propulsion testing } \\
\text { Responsible for NASA's rocket propulsion } \\
\text { testing and for partnering with industry to } \\
\text { develop and implement remote sensing } \\
\text { technology. }\end{array}$ \\
\hline $\begin{array}{c}\text { NASA } \\
\text { Headquarters }\end{array}$ & $\begin{array}{l}\text { Washington, } \\
\text { D.C. }\end{array}$ & $\begin{array}{l}\text { - Provides overall guidance and direction to } \\
\text { the agency, under the leadership of the } \\
\text { Administrator (Charles F. Bolden) }\end{array}$ \\
\hline $\begin{array}{c}\text { Goddard } \\
\text { Institute of } \\
\text { Space Studies }\end{array}$ & $\begin{array}{c}\text { New York City, } \\
\text { New York }\end{array}$ & $\begin{array}{l}\text { - Located at Columbia University } \\
\text { Managed by GSFC, focuses on research tat } \\
\text { emphasize a broad study of global climate } \\
\text { change. }\end{array}$ \\
\hline $\begin{array}{l}\text { IV and V } \\
\text { Facility }\end{array}$ & $\begin{array}{c}\text { Fairmont, West } \\
\text { Virginia }\end{array}$ & $\begin{array}{l}\text { - Managed by GSFC, performs software IV } \\
\& \mathrm{~V} \text { for mission critical software and } \\
\text { conducts research in software assurance } \\
\text { technology. }\end{array}$ \\
\hline $\begin{array}{l}\text { Michoud } \\
\text { Assembly } \\
\text { Facility }\end{array}$ & $\begin{array}{l}\text { New Orleans, } \\
\text { Louisiana }\end{array}$ & $\begin{array}{l}\text { - Manufacture and assembly of critical } \\
\text { hardware components for exploration } \\
\text { vehicles under development at MSFC and } \\
\text { other NASA centers }\end{array}$ \\
\hline $\begin{array}{l}\text { NASA Shared } \\
\text { Services Center }\end{array}$ & Mississippi & $\begin{array}{l}\text { - Performs selected business activities for all } \\
\text { NASA Centers in financial management, } \\
\text { human resources, information technology, } \\
\text { procurement and business support services } \\
\text { - Located on grounds of Stennis Space } \\
\text { Center }\end{array}$ \\
\hline
\end{tabular}




\begin{tabular}{|c|c|c|}
\hline Location & Center/Facility & Center/ Facility Description \\
\hline $\begin{array}{c}\text { Plum Brook } \\
\text { Station }\end{array}$ & Cleveland, Ohio & $\begin{array}{l}\text { - } \text { Located at Glenn Research Center } \\
\text { - Space power facility } \\
\text { - Spacecraft propulsion research facility } \\
\text { - } \text { Cryogenic propellant tank facility } \\
\text { - Cryogenic components laboratory } \\
\text { - Hypersonic tunnel facility }\end{array}$ \\
\hline $\begin{array}{c}\text { Wallops Flight } \\
\text { Facility }\end{array}$ & $\begin{array}{l}\text { Wallops Island, } \\
\text { Virginia }\end{array}$ & $\begin{array}{l}\text { - Management and implementation of } \\
\text { suborbital research programs } \\
\text { Managed by GSFC, is NASA's site for } \\
\text { suborbital and small orbital flight projects, } \\
\text { Earth Science research and technology } \\
\text { development, and also operates a launch } \\
\text { range. }\end{array}$ \\
\hline $\begin{array}{l}\text { White Sands } \\
\text { Test Facility }\end{array}$ & $\begin{array}{c}\text { Las Cruces, New } \\
\text { Mexico }\end{array}$ & $\begin{array}{l}\text { - Conducts simulated mission duty cycle } \\
\text { testing to develop numerous full-scale } \\
\text { propulsion systems } \\
\text { - Managed by JSC, provides the expertise } \\
\text { and infrastructure to safely test and } \\
\text { evaluate spacecraft materials, components, } \\
\text { and rocket propulsion systems. }\end{array}$ \\
\hline
\end{tabular}

Sources: (Jansma, 2008); www.nasa.gov 


\section{ACKNOWLEDGMENTS}

NASA has funded this research, and all research contributions are directly for NASA. In addition to NASA, a number of individuals and institutions were instrumental in this research effort.

First, thank you to the Industrial and Systems Engineering and Engineering Management department at the University of Alabama at Huntsville (UAH) for hosting me during the summer months of 2014. Thank you to the Space Launch System Weekly Meeting Group in Huntsville for helping me establish a foundation to gather data for this research effort. Also, thank you to all the engineers at NASA who allowed me to interview them and gather qualitative data.

Second, I would also like to recognize my alpha testers and beta testers who took the time to ensure the modified data collection instrument was appropriate and ready for survey deployment. Thank you to the NASA Agency as a whole. This research effort was able to gather data from all ten NASA Centers, as well as Headquarters because the Agency has such a passion for research and the advancement of systems engineering.

Third, thank you to the researchers who helped guide this research effort forward. These are the researchers involved in the 2007 MSFC flight hardware study, and the 2013 government and commercial organizations study. Specific researchers aiding in this thesis were my committee members and my R expert, Dr. Hoffmann. Finally, thank you to the research collaborators, Dr. Utley at UAH and Dr. Yang at MIT. 